LUCIANA DOS SANTOS ARNAUT

\title{
Estudo radiográfico das afecções do sistema esquelético em aves
}

São Paulo 


\section{LUCIANA DOS SANTOS ARNAUT}

\section{Estudo radiográfico das afecções do sistema esquelético em aves}

Dissertação apresentada ao Programa de Pós-
Graduação em Clínica Cirúrgica Veterinária
da Faculdade de Medicina Veterinária e
Zootecnia da Universidade de São Paulo, para
obtenção do título de Mestre em Medicina
Veterinária

Departamento:

Cirurgia

Área de concentração:

Clínica Cirúrgica Veterinária

Orientador:

Prof. Dr. Franklin de Almeida Sterman

\section{São Paulo}


Autorizo a reprodução parcial ou total desta obra, para fins acadêmicos, desde que citada a fonte.

DADOS INTERNACIONAIS DE CATALOGAÇÃO-NA-PUBLICAÇÃO

(Biblioteca Virginie Buff D’Ápice da Faculdade de Medicina Veterinária e Zootecnia da Universidade de São Paulo)

T.1767

FMVZ
Arnaut, Luciana dos Santos

Estudo radiográfico das afecções do sistema esquelético em aves / Luciana dos Santos Arnaut. - São Paulo: L. S. Arnaut, 2006.

$121 \mathrm{f}$ : : il.

Dissertação (mestrado) - Universidade de São Paulo. Faculdade de Medicina Veterinária e Zootecnia. Departamento de Cirurgia, 2006.

Programa de Pós-graduação: Clínica Cirúrgica Veterinária.

Área de concentração: Clínica Cirúrgica Veterinária.

Orientador: Prof. Dr. Franklin de Almeida Sterman.

1. Estudo radiográfico. 2. Doenças esqueléticas. 3. Aves. I. Título. 


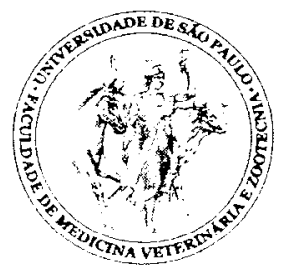

UNIVERSIDADE DE SÃO PAULO

Faculdade de Medicina Veterinaria e Zootecnia

Assistência Acadêmica

Comissão Bioética

\section{CERTIFICADO}

Certificamos que o Projeto intitulado "Fstudo radiográfico de afecções ósseas em aves", protocolo n $753 / 2005$, utilizando exames radiográficos pertencentes ao arquivo da disciplina de Diagnóstico por Imagem, sob a responsabilidade do Prof. Dr. Franklin de Almeida Sterman, está de acordo com os principios éticos de experimentação animal da Comissão de Bioética da Faculdade de Medicina Veterinária e Zootecnia da Universidade de São Paulo e foi aprovado "ad referendun".

(We certify that the Research "Radiographic study of bone affections in birds", protocol number 753/2005, under the responsibility of Prof. Dr. Franklin de Almeida Sterman, agree with Ethical Principles in Animal Research adopted by Bioethic Commission of the Faculty of Veterinary Medicine and Zootechny of University of São Paulo and was approved "ad referendun", meeting).

São Paulo, 20 de setembro de 2005

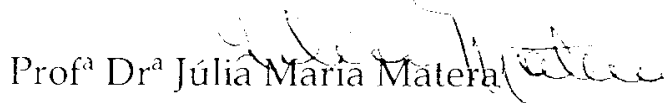

Presidente da Comissão de Bioética

FMVZ/USP 


\section{FOLHA DE AVALIAÇÃO}

Autor: ARNAUT, Luciana dos Santos

Título: Estudo radiográfico das afecções do sistema esquelético em aves

Dissertação apresentada ao Programa de Pós-

Graduação em Clínica Cirúrgica Veterinária da Faculdade de Medicina Veterinária e Zootecnia da Universidade de São Paulo, para obtenção do título de Mestre em Medicina Veterinária

Data:

Banca Examinadora

Prof. Dr.

Instituição:

Assinatura: Julgamento:

Prof. Dr. Instituição:

Assinatura: Julgamento:

Prof. Dr. Instituição:

Assinatura: Julgamento: 
Dedico este trabalho

a minha avó materna, Liberata (in memorian), aos meus pais, Diamantino e Delmina, irmãos, Marcelo e Adriana, e ao meu noivo, Rodrigo.

O apoio e o incentivo que sempre me proporcionaram, foram fundamentais para a concretização do meu sonho. 


\section{AGRADECIMENTOS}

Primeiramente, agradeço a Deus, por me proporcionar momentos de intensa felicidade e realização, como a conclusão deste trabalho.

Ao Prof. Dr. Franklin de Almeida Sterman, como médico veterinário, professor, orientador e estimulador. Minha eterna gratidão por confiar em mim.

A Profa. Dra. Ana Carolina Brandão de Campos Fonseca Pinto, pelo incentivo desde o início, por estar sempre disposta a me ajudar e por muito contribuir para a minha formação profissional.

A Sandra Maria de Oliveira, Antônio Fernandes Filho, Benedicto Wlademir De Martin e Roberto Pimenta de Pádua Foz Filho, pela elaboração das cartas de referência.

A amiga Silvana Maria Unruh, pelo auxílio na interpretação dos exames radiográficos e por muito ter me ensinado durante este convívio.

Ao Prof. Dr. Stefano Carlo Filippo Hagen, pela tradução dos textos em alemão.

A Rodrigo Dias Arnaut, pelo "tratamento" das imagens digitais.

A Luciane Maria Kanayama Faria, pela agradável companhia durante as inúmeras noites de trabalho no Laboratório de Densitometria Óptica.

Aos colegas de pós-graduação Caterina Muramoto, Cláudia Matsunaga Martín, Iara Levino dos Santos, Luciana Fortunato Burgese, Marcia Lembo e Maria Cristina Ferrarini Nunes Soares Hage, pela agradável companhia e ensinamentos trocados.

A Alda Maria Backx Noronha Madeira, por permitir-me livre acesso ao Ambulatório de Aves - Departamento de Patologia da Faculdade de Medicina Veterinária e Zootecnia da Universidade de São Paulo. 
A Marta Brito Guimarães, pela paciência e dedicação durante a minha estadia no Ambulatório de Aves.

A Cinthia Guedes de Almeida, Juliana Anaya Sinhorini e Vanessa Vertematti Duarte, pela nova amizade enlaçada.

A médica Flavia Puppi, que nos momentos mais difíceis dessa caminhada, me estendeu sua mão.

A Jimmy Adans, pelo desenvolvimento das análises estatísticas.

Ao Prof. Dr. Antonio Augusto Coppi Maciel Ribeiro, pelo auxílio na descrição da nomenclatura aviária.

A Elza Maria Rosa Bernardo Faquim, pela revisão ágil e precisa das diretrizes para apresentação de dissertações e teses na FMVZ-USP.

A Solange Alves Santana, pela revisão gramatical.

A Elena Aparecida Tanganini, pela revisão das referências.

A André Luiz Cavalcante, pela revisão do abstract.

Ao Conselho Nacional de Desenvolvimento Científico e Tecnológico (CNPq), pelo apoio financeiro.

A Belarmino Ney Pereira, secretário do Programa de Pós-Graduação em Clínica Cirúrgica Veterinária da FMVZ-USP, pela orientação quanto à parte burocrática. 


\section{RESUMO}

ARNAUT, L. S. Estudo radiográfico das afecções do sistema esquelético em aves. [Radiographic study of skeletal system diseases in birds]. 2006. 121 f. Dissertação (Mestrado em Medicina Veterinária) - Faculdade de Medicina Veterinária e Zootecnia, Universidade de São Paulo, São Paulo, 2006.

Este estudo retrospectivo revisa os achados radiográficos simples em 201 aves, de espécies e idades variadas, com alterações esqueléticas. Os dados foram obtidos do Serviço de Radiologia do Hospital Veterinário da Faculdade de Medicina Veterinária e Zootecnia da Universidade de São Paulo, durante o período de janeiro de 2000 a dezembro de 2004. A distribuição das alterações e das localizações esqueléticas, assim como as suas respectivas espécies e idades, foram estudadas. O sexo não foi considerado neste estudo. Os psitacídeos alcançaram a porcentagem mais elevada $(64,68 \%)$ entre as diversas ordens, seguidos pelos passeres $(16,42 \%)$. Neste período de cinco anos, as afecções traumáticas, abrangendo fraturas, luxações e amputações ósseas, foram as mais comuns, perfazendo 46,77\% do total de aves (n =94), seguidas por 48 aves $(23,88 \%)$ com doença ósseo-metabólica e 34 (16,92\%) com hiperostose poliostótica. Entre as afecções inflamatório-infecciosas, osteomielite foi mais freqüente do que artrite $(9,95 \%$ e $3,48 \%$, respectivamente). A articulação intertársica foi a única articulação afetada com mudanças artríticas. Osteófitos periarticulares foram identificados em todas as aves com doença articular degenerativa (7,46\%). Por fim, algumas aves também exibiram alterações radiográficas de diagnóstico incerto. Assim sendo, observaram-se $6,47 \%$ de aves com osteopenia localizada em um ou mais ossos e 4,48\% com diversas deformidades ósseas, tais como alterações angulares dos ossos longos e da coluna vertebral, e anquilose óssea das vértebras caudais. Quatro casos $(1,99 \%)$ com alterações ósseas agressivas foram encontrados, mas nenhuma neoplasia óssea foi diagnosticada. Neoplasias ósseas são, freqüentemente, difíceis de serem distingüidas de osteomielite, e, ainda que o exame radiográfico revele as alterações, biopsia e cultura são necessárias para auxiliar na diferenciação.

Palavras-chave: Estudo radiográfico. Doenças esqueléticas. Aves. 


\begin{abstract}
ARNAUT, L. S. Radiographic study of skeletal system diseases in birds. [Estudo radiográfico das afecções do sistema esquelético em aves]. 2006. 121 f. Dissertação (Mestrado em Medicina Veterinária) - Faculdade de Medicina Veterinária e Zootecnia, Universidade de São Paulo, São Paulo, 2006.
\end{abstract}

This retrospective study reviews the plain radiographic findings in 201 birds of different species and ages, with skeletal alterations. The data were obtained from the Radiology Service of the Veterinary Teaching Hospital, School Veterinary Medicine of University of Sao Paulo, from January 2000 to December 2004. The distribution of the skeletal alterations and localization, as well as their respective species and ages, were studied. The gender was not considered in this study. Psittacines performed the highest percentage $(64.68 \%)$ among the diverse avian orders, followed by passerines (16.42\%). In this 5-year period, traumatic disorders, including fractures, luxations and amputations, were the most common alterations, adding $46.77 \%$ of total birds (94 birds), followed by 48 birds (23.88\%) with metabolic bone disease and $34(16.92 \%)$ with polyostotic hyperostosis. Osteomyelitis was more common than arthritis (9.95\% and 3.48\%, respectively). The tibiotarsal joint was the only affected joint with arthritic changes. Periarticular osteophytes were seen in all the birds with degenerative joint disease (7.46\%). Finally, some birds had also shown very vague radiographic alterations, not expressing a diagnostic clearly. Thus being, the radiographic findings had shown the presence of decreased opacity localized in one or more bones (6.47\%) and several skeletal deformities (4.48\%), such as angular alterations of the long bones and the spine, and bony ankylosis of the tail. Four cases $(1.99 \%)$ with aggressive lesions were found but no case of bone neoplasia was identified. It may often be difficult to differentiate bone infection from bone neoplasia. Although survey radiographs have demonstrated the abnormalities, a biopsy and culture should be taken to assist in differentiation.

Key words: Radiographic study. Skeletal diseases. Birds. 


\section{LISTA DE QUADROS}

Quadro 1 - $\quad$ Sítios de hiperostose poliostótica identificados em 34 aves. HOVET-FMVZUSP, 2000-2004 71 


\section{LISTA DE FIGURAS}

Figura 1 - Exemplo de contenção física. A ave é primeiramente posicionada e segura com fita adesiva sobre uma superfície intermediária radiolucente. Posteriormente, esta superfície intermediária é posicionada sobre o chassi.

Figura 2- Exemplo de contenção física e posicionamento radiográfico para as projeções laterolateral (A) e ventrodorsal (B).

Figura $3-$ Exemplo de contenção manual para o posicionamento radiográfico da asa em projeção caudocranial. Vista por cima (A) e vista lateral (B). 118

Figura 4 - $\quad$ Ilustração do efeito de magnificação da imagem registrada, aumentando-se a distância entre o paciente e o chassi.

Figura $5-\quad$ Sistema esquelético de um papagaio (Amazona $\mathrm{sp).}$

Figura $6-$ Anatomia macroscópica do úmero de uma ave aquática. Córtex delgado (a) e cavidade medular (b) com uma rede de espículas ósseas.

Figura 7 - $\quad$ Projeção ventrodorsal, de uma coruja, de espécie e idade indeterminadas. Presença de fratura exposta de segmento proximal do úmero esquerdo (seta). 85

Figura $8-$ Projeção ventrodorsal, de um periquito-verde (Brotogeris viridissimus), de idade indeterminada. Observar a presença de fraturas na escápula (círculo), rádio e ulna esquerdos. 85

Figura 9- Projeção mediolateral, do membro pélvico direito de um papagaioverdadeiro (Amazona aestiva), de nove anos de idade. Articulação intertársica luxada (seta). 86 
Figura 10 - Projeção ventrodorsal, de um papagaio-verdadeiro (Amazona aestiva), de um mês de idade. Notar a luxação coxofemoral direita (círculo) com concomitante aumento de volume de tecidos moles em região adjacente. ... 86

Figura 11 - Projeção laterolateral, do crânio de uma cacatua-branca (Cacatua alba), de 10 anos de idade. Amputação do bico superior (seta). Causa: briga com outra ave. 86

Figura 12 - Projeção ventrodorsal, de um papagaio-verdadeiro (Amazona aestiva), de 35 dias de idade. Observar a acentuada osteopenia generalizada, adelgaçamento do osso cortical e fraturas patológicas localizadas nos tibiotarsos (setas). Observação: a alimentação desse paciente consistia apenas de fubá e milharina, misturados com água. 87

Figura 13 - $\quad$ Projeções laterolateral (A) e ventrodorsal (B), de um canário (de espécie indeterminada), de três anos de idade. Presença de acentuada esclerose medular homogênea generalizada e cavidade celomática caudal distendida e homogênea. 87

Figura 14- Projeção mediolateral do membro pélvico direito de um papagaio (de espécie indeterminada), de três meses de idade. Reação do periósteo (setas) e aumento de volume de tecidos moles no segmento distal do tibiotarso. Causa: compressão local por objeto linear. 88

Figura 15 - Projeção laterolateral do crânio de um papagaio-verdadeiro (Amazona aestiva), de oito anos de idade. Osteólise de premaxila cranial (seta sólida) e opacificação de seios infraorbitários (seta vazia). Causa: sinusite crônica causada por Streptococcus sp. 88

Figura 16 - Projeção mediolateral, da articulação intertársica direita de uma pombagoura (Goura cristata), de 10 anos de idade. Observar a presença de múltiplas alterações ósseas como osteólise e esclerose subcondrais, mineralização de tecidos moles e aumento de volume de tecidos moles. ..... 88 
Figura 17 - $\quad$ Projeção laterolateral, de um papagaio-verdadeiro-do-sul (Amazona aestiva xanthopteryx), de oito anos de idade. Notar a presença de osteófitos ventrais localizados nas epífises das vértebras torácicas caudais (setas).

Figura 18 - Projeção ventrodorsal, de um tucano (de espécie indeterminada), de dois anos de idade. Notar a osteopenia localizada no membro pélvico esquerdo. Causa: impotência funcional em razão da presença de luxação coxofemoral e fratura de tibiotarso. 89

Figura 19 - Projeção ventrodorsal, de um ganso (de espécie indeterminada), de um mês de idade. Observar a curvatura anormal do segmento vertebral toracolombar (escoliose). 90

Figura 20 - $\quad$ Projeção mediolateral, da asa direita de um Agapornis sp, de seis anos de idade. Observar a presença de uma extensa reação osteolítica acometendo o segmento distal do úmero.

Figura 21 - $\quad$ Projeção ventrodorsal, de um Agapornis sp, de um ano de idade. Observar a presença de uma extensa reação proliferativa acometendo segmento vertebral cervical, úmeros e costelas. 


\section{LISTA DE TABELAS}

Tabela 1 - Distribuição numérica (N) e percentual (\%) de 201 aves, segundo a taxonomia. HOVET-FMVZ-USP, 2000-2004 62

Tabela 2 - Distribuição numérica (N) e percentual (\%) de 201 aves analisadas, segundo as ordens. HOVET-FMVZ-USP, 2000-2004

Tabela 3 - Distribuição numérica (N) e percentual (\%) de 201 aves analisadas, segundo os resultados apresentados. HOVET-FMVZ-USP, 2000-2004 63

Tabela $4-$ Distribuição numérica (N) e percentual (\%) de 94 aves com afecções traumáticas, segundo as espécies. HOVET-FMVZ-USP, 2000-2004 64

Tabela $5-$ Distribuição numérica $(\mathrm{N})$ e percentual (\%) de 94 aves com afecções traumáticas, segundo as ordens. HOVET-FMVZ-USP, 2000-2004. 65

Tabela $6-$ Distribuição numérica (N) e percentual (\%) de 94 aves com afecções traumáticas, segundo as idades. HOVET-FMVZ-USP, 2000-2004 65

Tabela 7 - Distribuição numérica $(\mathrm{N})$ e percentual (\%) de 94 aves com afecções traumáticas, segundo o tipo de trauma. HOVET-FMVZ-USP, 2000-2004_.65

Tabela 8 - Distribuição numérica $(\mathrm{N})$ e percentual (\%) de 86 fraturas, segundo as localizações. HOVET-FMVZ-USP, 2000-2004 66

Tabela 9 - $\quad$ Distribuição numérica $(\mathrm{N})$ e percentual (\%) de 86 fraturas, segundo as localizações. HOVET-FMVZ-USP, 2000-2004 66

Tabela 10 - Distribuição numérica $(\mathrm{N})$ e percentual (\%) de 26 luxações, segundo as localizações. HOVET-FMVZ-USP, 2000-2004 67 
Tabela 11 - Distribuição numérica $(\mathrm{N})$ e percentual (\%) de 13 amputações ósseas, segundo as localizações. HOVET-FMVZ-USP, 2000-2004 67

Tabela 12 - Distribuição numérica $(\mathrm{N})$ e percentual (\%) de 48 aves com doença ósseometabólica, segundo as espécies. HOVET-FMVZ-USP, 2000-2004 68

Tabela 13 - Distribuição numérica $(\mathrm{N})$ e percentual (\%) de 48 aves com doença ósseometabólica, segundo as idades. HOVET-FMVZ-USP, 2000-2004. 68

Tabela 14 - Distribuição numérica $(\mathrm{N})$ e percentual (\%) de 48 aves com doença ósseometabólica, segundo as alterações radiográficas. HOVET-FMVZ-USP, 2000-2004 69

Tabela $15-$ Distribuição numérica (N) e percentual (\%) de 71 fraturas patológicas, segundo as localizações. HOVET-FMVZ-USP, 2000-2004 69

Tabela 16 - Distribuição numérica $(\mathrm{N})$ e percentual (\%) de 34 aves com hiperostose poliostótica, segundo as espécies. HOVET-FMVZ-USP, 2000-2004 70

Tabela 17 - Distribuição numérica $(\mathrm{N})$ e percentual (\%) de 34 aves com hiperostose poliostótica, segundo as idades. HOVET-FMVZ-USP, 2000-2004. 70

Tabela 18 - Distribuição numérica (N) e percentual (\%) de 34 aves com hiperostose poliostótica, segundo as localizações. HOVET-FMVZ-USP, 2000-2004 _... 72

Tabela 19 - Distribuição numérica (N) e percentual (\%) de 20 aves com osteomielite, segundo as espécies. HOVET-FMVZ-USP, 2000-2004 73

Tabela 20 - Distribuição numérica (N) e percentual (\%) de 20 aves com osteomielite, segundo as idades. HOVET-FMVZ-USP, 2000-2004 73

Tabela 21 - Distribuição numérica (N) e percentual (\%) de 20 aves com osteomielite, segundo as localizações. HOVET-FMVZ-USP, 2000-2004 74 
Tabela 22 - Distribuição numérica (N) e percentual (\%) de 20 aves com osteomielite, segundo as alterações radiográficas. HOVET-FMVZ-USP, 2000-2004_..... 74

Tabela 23 - Distribuição numérica (N) e percentual (\%) de sete aves com artrite, segundo as espécies. HOVET-FMVZ-USP, 2000-2004 75

Tabela 24 - Distribuição numérica $(\mathrm{N})$ e percentual (\%) de sete aves com artrite, segundo as idades. HOVET-FMVZ-USP, 2000-2004 75

Tabela 25 - Distribuição numérica (N) e percentual (\%) de sete aves com artrite, segundo as alterações radiográficas. HOVET-FMVZ-USP, 2000-2004 _..... 75

Tabela 26- Distribuição numérica (N) e percentual (\%) de 15 aves com afecções degenerativas, segundo as espécies. HOVET-FMVZ-USP, 2000-2004 _..... 76

Tabela 27 - Distribuição numérica $(\mathrm{N})$ e percentual (\%) de 15 aves com afecções degenerativas, segundo as idades. HOVET-FMVZ-USP, 2000-2004 _....... 76

Tabela 28 - Distribuição numérica $(\mathrm{N})$ e percentual (\%) de 15 aves com afecções degenerativas, segundo as localizações. HOVET-FMVZ-USP, 2000-200477

Tabela 29 - Distribuição numérica $(\mathrm{N})$ e percentual (\%) de 15 aves com afecções degenerativas, segundo as alterações radiográficas. HOVET-FMVZ-USP, 2000-2004 77

Tabela 30 - Distribuição numérica (N) e percentual (\%) de 13 aves com osteopenia localizada, segundo as espécies. HOVET-FMVZ-USP, 2000-2004 79

Tabela 31 - Distribuição numérica (N) e percentual (\%) de 13 aves com osteopenia localizada, segundo as idades. HOVET-FMVZ-USP, 2000-2004 79

Tabela 32 - Distribuição numérica (N) e percentual (\%) de 13 aves com osteopenia localizada, segundo as localizações. HOVET-FMVZ-USP, 2000-2004 _..... 80 
Tabela 33 - Distribuição numérica $(\mathrm{N})$ e percentual $(\%)$ de nove aves com deformidades ósseas, segundo as espécies. HOVET-FMVZ-USP, 2000-2004

Tabela 34 - Distribuição numérica (N) e percentual (\%) de nove aves com deformidades ósseas, segundo as idades. HOVET-FMVZ-USP, 2000-2004 81

Tabela 35 - $\quad$ Distribuição numérica $(\mathrm{N})$ e percentual (\%) de nove aves com deformidades ósseas, segundo as localizações. HOVET-FMVZ-USP, 2000-2004. 81

Tabela 36 - Distribuição numérica (N) e percentual (\%) de nove aves com deformidades ósseas, segundo as alterações radiográficas. HOVET-FMVZ-USP, 20002004 82 


\section{LISTA DE ABREVIATURAS E SIGLAS}

cm centímetro

FMVZ Faculdade de Medicina Veterinária e Zootecnia

HOVET Hospital Veterinário

$\mathbf{k V} \quad$ quilovolts

sf $\quad$ substantivo feminino

USP Universidade de São Paulo 


\section{LISTA DE SÍMBOLOS}

$\begin{array}{ll}\text { N ou n } & \text { distribuição numérica } \\ \text { p-valor } & \begin{array}{l}\text { resultados da significância estatística pelo teste de Igualdade de Duas } \\ \text { Proporções }\end{array} \\ \mathbf{\%} & \text { distribuição percentual } \\ \leq & \text { menor ou igual a } \\ & \end{array}$ 


\section{SUMÁRIO}

1 INTRODUÇÃO

2 REVISÃO DA LITERATURA

2.1 OSSIFICAÇÃO

2.2 EXAME RADIOGRÁFICO

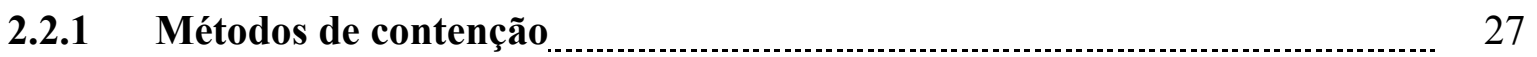

2.2.2 Posicionamentos radiográficos $\ldots$

2.2.3 Fatores de exposição $\ldots$

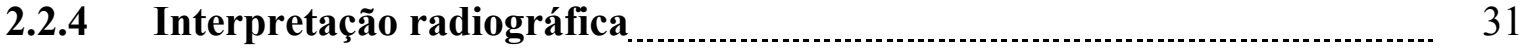

$2.3 \quad$ ANATOMIA 32

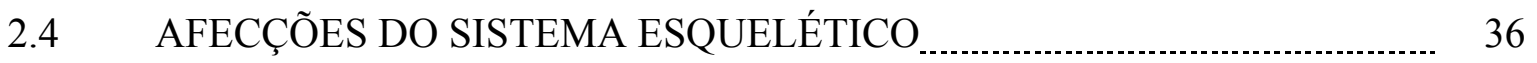

2.4.1 Traumáticas

2.4.1.1 Fraturas

2.4.1.2 Luxações $\ldots$

2.4.2 Doença ósseo-metabólica (DOM) … 42

2.4.3 Osteopenia localizada $\ldots$

2.4.4 Hiperostose poliostótica

2.4.5 Inflamatório-infecciosas

2.4.5.1 Artrite $\ldots$

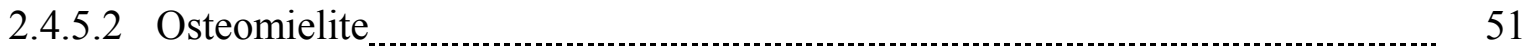

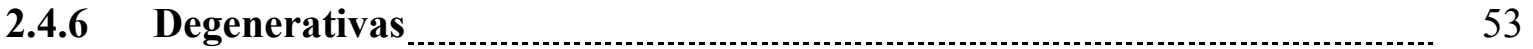

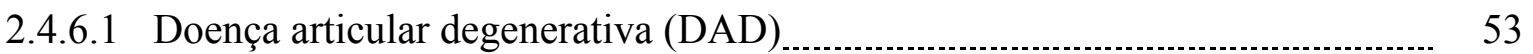

2.4.6.2 Espondilose vertebral

2.4.7 Deformidades ósseas

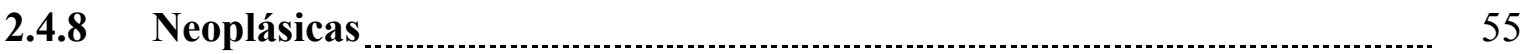

$3 \quad$ MATERIAL E MÉTODOS 
3.1 EXAME RADIOGRÁFICO

3.1.1 Equipamentos radiográficos $\ldots$

3.1.2 Métodos de contenção $\ldots$

3.1.3 Posicionamentos radiográficos $\ldots$

3.1.4 Técnicas radiográficas $\ldots$

3.2 ANÁLISE DAS RADIOGRAFIAS _ 59

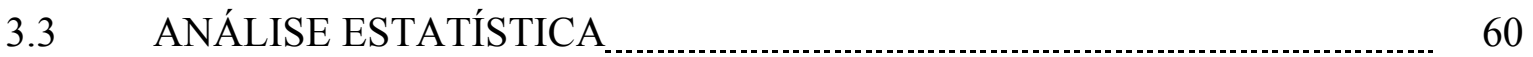

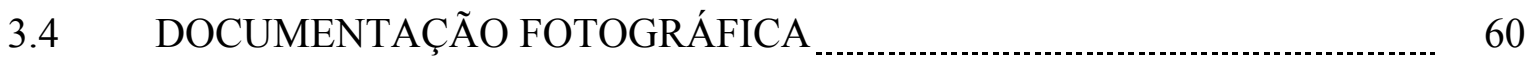

$4 \quad$ RESULTADOS $\ldots \ldots \ldots$

$5 \quad$ DISCUSSÃO

6 CONCLUSÕES

REFERENCIAS

ANEXOS 


\section{$1 \quad$ INTRODUÇÃO}

A crescente popularidade das aves, como animais de estimação, tem criado maiores exigências quanto à obtenção de informações especializadas a respeito desses animais. Das inúmeras afecções que podem acometer as aves, as que acometem o sistema esquelético estão entre as mais freqüentes observadas na clínica. Diante disso, o exame radiográfico provou ser um método de diagnóstico por imagem essencial aplicado a essas afecções, sendo importante tanto na identificação quanto no diagnóstico diferencial entre as alterações que caracterizam uma doença óssea.

O exame radiográfico possibilita ao profissional evidenciar informações que, em conjunto com o exame clínico, são fundamentais para a definição do diagnóstico.

Neste estudo foram analisados exames radiográficos de aves, encaminhadas ao Serviço de Diagnóstico por Imagem do Hospital Veterinário da Faculdade de Medicina Veterinária e Zootecnia da Universidade de São Paulo, no período de janeiro de 2000 a dezembro de 2004, com os seguintes objetivos:

- apresentar a ocorrência das principais afecções que acometem o sistema esquelético de aves;

- estabelecer a distribuição de freqüência segundo as espécies, idades, localizações e alterações radiográficas observadas nas diferentes afecções;

- comparar os resultados obtidos com as informações adquiridas na literatura. 
A classe das aves é formada por um grande e diversificado grupo de espécies (BENEZ, 2004). O total de aves para todo o mundo é estimado em 9.700 espécies (O’MALLEY, 2005; SIBLEY; MONROE', 1990 apud SICK, 2001, p. 17). Deste total, aproximadamente um terço, o equivalente a 3.200 espécies, encontram-se na América do Sul (SIBLEY; MONROE ${ }^{1}, 1990$ apud SICK, 2001, p. 17). A avifauna brasileira reúne 1.796 espécies (CBRO, 2006).

Dividem-se as aves em duas subclasses, Archaeornithes e Neornithes. A primeira está representada por aves fósseis. Neornithes, por sua vez, está subdividida em quatro superordens: duas representadas apenas por aves fósseis, Impennes, representada pelos pingüins e Neognathae, que abrange todas as demais aves vivas e algumas aves fósseis. Os Neognathae estão divididos em mais de 25 ordens. O número exato, entretanto, varia com o sistema de classificação que for adotado $\left(\right.$ STORER $^{2}, 1960$ apud KING, 1986, p. 1678; THOMSON 33,1964 apud KING, 1986, p. 1678).

A maioria das aves de estimação pertence às ordens Psittaciformes e Passeriformes (FORBES; LAWTON, 1996; PETRAK; GILMORE, 1969; WALLACH; BOEVER, 1983).

Os psitacídeos são aves que pertencem à família Psittacidae e estão representados pelas araras, periquitos e papagaios. São conhecidos como aves de "bico redondo" (SICK, 2001) e têm se tornado muito populares por sua inteligência e capacidade de imitar e ser treinado (FORBES; LAWTON, 1996). Das 358 espécies existentes no mundo (GILL, 1995), 83 são brasileiras (CBRO, 2006), sendo o Brasil considerado o país mais rico do mundo em psitacídeos (SICK, 2001). Alguns representantes comumente encontrados em cativeiro são: periquito-australiano (Melopsittacus undulatus), agapornis (Agapornis roseicollis e Agapornis personata), calopsita (Nymphicus hollandicus), papagaio-verdadeiro (Amazona aestiva),

1 SIBLEY, C. G.; MONROE, B. L. Distribution and taxonomy of birds of the world. New Haven: Yale Univ. Press, 1990.

2 STORER, R. W. The classification of birds. In: MARSHALL, A. J. (Ed.). Biology and comparative physiology of birds. New York: Academic Press, 1960.

3 THOMSON, A. L. Classification; orders. In: THOMSON, A. L. (Ed.). A new dictionary of birds. London and New York: Nelson, 1964. 
periquitos (Brotogeris sp), maritacas (Aratinga sp), arara-canindé (Ara ararauna) e araravermelha (Ara chloroptera) (CARCIOFI, 1996).

Contra 358 espécies de psitacídeos (GILL, 1995), a ordem dos Passeriformes ou passeres, constitui um grupo bastante numeroso e diversificado, compreendendo 5.739 espécies, o que representa mais do que a metade do total de aves do mundo (SIBLEY; MONROE ${ }^{4}, 1993$ apud SICK, 2001, p. 519). Bentevi, canário, sabiá, pardal, curió, pássaropreto, corrupião, rouxinol, tico-tico e joão-de-barro, são alguns exemplares constituintes da ordem (SICK, 2001).

Adaptado basicamente ao vôo, o esqueleto das aves exibe duas características principais: leveza e resistência (FEDUCCIA, 1986).

A leveza é obtida graças ao processo de pneumatização dos ossos por extensões dos sacos aéreos (EVANS, 1996; FEDUCCIA, 1986; NICKEL et al., 1977). Os sacos aéreos, extensões do sistema brônquico, ocupam principalmente a cavidade celomática, junto com as vísceras torácicas e abdominais. Divertículos desses sacos aéreos estendem-se, através de forames pneumáticos, pelas cavidades medulares dos ossos adjacentes (DYCE et al., 1997). O úmero é o principal osso pneumático, todavia, graus variados de pneumatização também existem no crânio, coluna vertebral, costelas, esterno, coracóide, cíngulo pélvico, fêmur (KRAUTWALD-JUNGHANNS, 1996) e clavícula (MCKIBBEN; HARRISON, 1986). O grau de pneumatização está diretamente relacionado com a eficiência de vôo das aves, sendo mais avançado naquelas com maior capacidade de vôo (DYCE et al., 1997).

Já a resistência, é alcançada pela fusão e, muitas vezes, supressão dos ossos. A fusão é perceptível nos ossos do crânio e do cíngulo pélvico. Os ossos distais da asa e do membro pélvico exibem fusão e supressão associadas (FEDUCCIA, 1986). Além disso, a presença de um elevado conteúdo mineral (DYCE et al., 1997; KOCH, 1973; MARTIN; RITCHIE, 1994; NICKEL et al., 1977), torna os ossos mais "duros", aumentando assim, a resistência dos mesmos (NICKEL et al., 1977).

\footnotetext{
4 SIBLEY, C. G.; MONROE, B. L. A supplement to distribution and taxonomy of birds of the world. New
} Haven: Yale University Press, 1993. 


\subsection{OSSIFICAÇÃO}

A maioria dos ossos das aves, assim como nos mamíferos, desenvolve-se a partir de um modelo cartilaginoso por meio do processo de ossificação endocondral. A cartilagem é completamente transformada em osso, à exceção de uma camada fina localizada na superfície articular (KING; MCLELLAND, 1984). Autores descrevem, de forma pormenorizada, a sucessão de eventos notada tanto no processo de ossificação endocondral (KING; MCLELLAND, 1984; TULLY JUNIOR, 2002) como no de ossificação intramembranosa (TULLY JUNIOR, 2002).

O sistema esquelético das aves exibe características marcadamente diferentes se comparado com o dos mamíferos (FOWLER ${ }^{5}, 1980$ apud MARTIN; RITCHIE, 1994, p. 1142; MCMILLAN, 1994), a considerar:

- desenvolvimento, geralmente ausente, de centros secundários de ossificação nas epífises ósseas (KING; MCLELLAND, 1984; KRAUTWALD-JUNGHANNS, 1996), à exceção da extremidade proximal do tibiotarso (KING; MCLELLAND, 1984). Alguns autores se referem aos ossos do tarso, cuja diferenciação está presente apenas nas aves jovens, como centros secundários de ossificação (KOSTKA et al., 1988; KRAUTWALD-JUNGHANNS, 1996);

- osso cortical delgado (DYCE et al., 1997; KRAUTWALD-JUNGHANNS, 1996; LAVIN, 1994; MCKIBBEN; HARRISON, 1986; MCMILLAN, 1994; RUPLEY, 1999; SMITH; SMITH, 1997; SMITH et al., 1990; WALSH, 1986; WILLIAMS, 2002);

- osso trabecular de padrão delicado (KRAUTWALD-JUNGHANNS, 1996; RUPLEY, 1999);

- linha de cartilagem epifisária indistinta (KRAUTWALD-JUNGHANNS, 1996);

- possuem, como os ossos longos dos mamíferos, osso esponjoso e osso compacto, com periósteo e endósteo (MCKIBBEN; HARRISON, 1986);

- ossos leves, compactos e fortes (DYCE et al., 1997).

FOWLER, M. E. Ossification of long bones in raptors. In: COOPER, J. E.; GREENWOOD, A. Recent advances in the study of raptor diseases. Proceedings of the International Symposium on Diseases of Birds of Prey. London, 1980. p. 75-82. 


\subsection{EXAME RADIOGRÁFICO}

As modalidades de imagem disponíveis em aves são: radiologia, ultra-sonografia, fluoroscopia, tomografia computadorizada (MCMILLAN, 1994; RUPLEY, 1999), ressonância magnética (RUPLEY, 1999) e cintilografia nuclear (MCMILLAN, 1994). O exame radiográfico é a modalidade de imagem de maior aplicabilidade (LAFEBER, 1968; MCMILLAN, 1994; RUPLEY, 1999). Simples e não-invasivo (CRACKNELL, 2004a; SMITH; SMITH, 1997), além de ser relativamente barato (CRACKNELL, 2004a), pode ser utilizado para:

- diagnóstico de afecções tanto do sistema esquelético como da cavidade celomática (SILVERMAN, 1987);

- monitoração de tratamentos (CRACKNELL, 2004a; LAFEBER, 1968; SMITH; SMITH, 1997);

- seleção dos melhores procedimentos para a redução e imobilização de afecções ósseas traumáticas (PIERMATTEI; FLO, 1999);

- avaliação pós-operatória de afecções ósseas traumáticas (REDIG, 1986);

- avaliação de aves recém chegadas a bandos (CRACKNELL, 2004a);

- avaliação de triagem em centros de reabilitação (CRACKNELL, 2004a);

- exames forenses ou patológicos (CRACKNELL, 2004a).

Em se tratando de aves, o tamanho das espécies (ALTMAN, 1973) e a capacidade limitada de se contar com exames laboratoriais têm dificultado o estabelecimento de diagnósticos definitivos. Diante disso, o exame radiográfico vem assumindo especial importância no processo conclusivo do diagnóstico (ALTMAN, 1973; KRAUTWALDJUNGHANNS, 1996; LAFEBER, 1968). Além disso, as aves geralmente são apresentadas ao clínico com enfermidades em estágio avançado de desenvolvimento, requerendo, portanto, um diagnóstico rápido e preciso (KRAUTWALD-JUNGHANNS, 1996; KRAUTWALDJUNGHANNS; HENDRICH-SCHUSTER, 1996). O exame radiográfico é uma técnica diagnóstica não-invasiva e de rápida interpretação (LAVIN, 1994). 
Referindo-se aos exames laboratoriais, de acordo com Krautwald-Junghanns (1996), a remoção de sangue, em quantidades suficientes, é limitada nas aves que pesam menos de 40 gramas.

O exame radiográfico é contra-indicado para pacientes em estado crítico de saúde (RUPLEY, 1999; SILVERMAN, 1987; WALSH, 1986), pois a manipulação excessiva causada pela contenção e posicionamento radiográficos, aumenta o estresse e, conseqüentemente, o risco de morte (SILVERMAN, 1987; SMITH; SMITH, 1997). Segundo Walsh (1986), o exame radiográfico é uma importante ferramenta diagnóstica, mesmo em pacientes de risco.

A relutância dos profissionais quanto à prática do exame radiográfico em aves, segundo Walsh (1986), diz respeito principalmente à falta de familiaridade com os métodos de contenção, técnica radiográfica, anatomia básica e interpretação da radiografia.

\subsubsection{Métodos de contenção}

Artefato de movimento pode tornar-se um problema na contenção inadequada da ave (PAUL-MURPHY et al., 1990).

A contenção manual é indicada para aves tranqüilas (WALSH, 1986; WILLIAMS, 2002) e de rapina (WALSH, 1986). A desvantagem deste método é o aumento da exposição à radiação do pessoal envolvido (LAVIN, 1994; WALSH, 1986).

A contenção física é alcançada à custa de ferramentas, como lâminas de acrílico, cordas, sacos de areia, fitas adesivas (LAVIN, 1994), blocos de espuma, luvas de chumbo e faixas de velcro (MCMILLAN 61982 apud MCMILLAN, 1994, p. 248).

O paciente deve ser posicionado diretamente em cima do chassi radiográfico (LAVIN, 1994; SMITH; SMITH, 1997; WILLIAMS, 2002). Entretanto, quando se pretende realizar várias exposições de uma mesma projeção radiográfica, é recomendado que ele seja posicionado primeiramente sobre uma lâmina de acrílico, que posteriormente é posicionada

6 MCMILLAN, M. C. Avian radiology. In: PETRAK, M. L. (Ed.). Diseases of cage and aviary birds. 2. ed. Philadelphia: Lea \& Febiger, 1982. p. 329-360. 
sobre o chassi (LAVIN, 1994; SILVERMAN, 1987), permitindo, desse modo, que o técnico troque o filme repetidas vezes sem ter que reposicionar o paciente sobre um novo chassi (SILVERMAN, 1987) (Anexo A, Figura 1).

Seja na projeção laterolateral ou ventrodorsal, fitas adesivas geralmente são aplicadas na região de carpometacarpos, tarsometatarsos e região cervical cranial (SMITH; SMITH, 1997). Cavidade celomática e cauda são fixadas somente se necessárias (LAVIN, 1994). Fitas adesivas aplicadas na região cervical e cavidade celomática não devem ficar apertadas a ponto de limitar o movimento respiratório (LAVIN, 1994; SMITH; SMITH, 1997).

Ferramentas alternativas de contenção física incluem enrolar o paciente em um papel toalha (LAFEBER, 1968), plástico ou radiografia, ou colocá-lo dentro de uma malha tubular ou tubo (SMITH; SMITH, 1997). Além disso, pode-se tirar a radiografia com a ave de pé, por meio da emissão horizontal de raios-X (ALTMAN, 1973; LAFEBER, 1968; RUPLEY, 1999; SMITH; SMITH, 1997), particularmente para pacientes em estado crítico de saúde (RUPLEY, 1999). A desvantagem, entretanto, refere-se ao posicionamento inadequado, com sobreposição das estruturas ósseas dos membros na cavidade celomática, resultando em radiografias não diagnósticas (SMITH; SMITH, 1997).

A utilização de métodos de contenção manual e física é contra-indicada em aves excitadas, pela possibilidade de ocasionar injúrias às mesmas. Assim, o emprego de sedativos injetáveis e anestésicos inalatórios tem se tornado mais seguro para a realização dos exames radiográficos (LAVIN, 1994). Aliada a essa vantagem, o emprego de contenção química nas aves é indicado para:

- facilitar a contenção (WALSH, 1986);

- radiografar grandes espécies excitadas, como as aves de rapina (WILLIAMS, 2002);

- evitar o risco de injúrias adicionais em aves traumatizadas (COLES, 1996);

- aumentar a segurança do paciente e da equipe técnica (WILLIAMS, 2002);

- alcançar o posicionamento radiográfico adequado (LAVIN, 1994; WILLIAMS, 2002), juntamente com outros métodos de contenção (LAVIN, 1994);

- evitar artefato de movimento (KRAUTWALD-JUNGHANNS, 1996; WILLIAMS, 2002);

- obter filmes de alta qualidade diagnóstica (SMITH; SMITH, 1997; WALSH, 1986; WILLIAMS, 2002); 
- diminuir a necessidade de repetidas exposições radiográficas (SMITH; SMITH, 1997);

- evitar a exposição radiográfica desnecessária à equipe técnica (COLES, 1996);

- radiografar cíngulo torácico (RICH, 1996) e crânio (KRAUTWALD-JUNGHANNS, 1996; PAUL-MURPHY et al., 1990).

\subsubsection{Posicionamentos radiográficos}

O posicionamento incorreto do paciente é a razão mais comum para radiografias não diagnósticas ou mal diagnosticadas (WILLIAMS, 2002).

Radiografias de corpo inteiro são rotineiramente realizadas (RUPLEY, 1999; SILVERMAN, 1987; WILLIAMS, 2002), permitindo em uma única radiografia, a avaliação conjunta da cavidade celomática e do sistema esquelético (SILVERMAN, 1987). Duas projeções radiográficas perpendiculares entre si são necessárias para uma interpretação radiográfica precisa (KRAUTWALD-JUNGHANNS; HENDRICH-SCHUSTER, 1996; RUPLEY, 1999; WILLIAMS, 2002), incluindo: projeções laterolateral e ventrodorsal. Projeções radiográficas adicionais são efetuadas conforme a suspeita clínica (CRACKNELL, 2004a).

A projeção laterolateral é alcançada com o paciente posicionado convencionalmente em decúbito lateral direito. As asas são estendidas dorsalmente e os membros pélvicos caudoventralmente (BEREGI et al., 1999; CRACKNELL, 2004a), evitando-se, com isso, a sobreposição das estruturas ósseas na cavidade celomática (SILVERMAN, 1987). O posicionamento estará correto se as articulações dos ombros e as articulações coxofemorais estiverem sobrepostas (BEREGI et al., 1999). A projeção laterolateral, bem como as demais, relatadas a seguir, estão ilustradas no anexo B, figuras 2 e 3 .

Para a projeção ventrodorsal, o paciente deve ser posicionado em decúbito dorsal sobre o chassi. Cabeça, asas e membros pélvicos são estendidos na direção cranial, lateral e caudal, respectivamente. A sobreposição do esterno com a coluna vertebral confirmará um posicionamento radiográfico correto (LAVIN, 1994). 
A projeção mediolateral da asa é obtida radiografando-se a ave em decúbito lateral ou dorsal (KRAUTWALD-JUNGHANNS, 1996), através do posicionamento radiográfico para a cavidade celomática (SILVERMAN, 1987). Para a projeção caudocranial, a ave é contida manualmente de cabeça para baixo, de modo que o corpo fique perpendicular à mesa. A ponta da asa é estendida e posicionada sobre o chassi. Para permitir que a asa fique em contato com o chassi, é necessário manter o corpo da ave afastado da borda do chassi (LAVIN, 1994).

\subsubsection{Fatores de exposição}

Para a execução dos exames radiográficos em aves, utilizam-se equipamentos de raios-X convencionais, os mesmos utilizados em animais domésticos (LAVIN, 1994).

Em vista do tamanho das aves, geralmente pequeno, e da freqüência respiratória alta, artefato de movimento pode ser evitado através da utilização de tempos curtos de exposição radiográfica (CRACKNELL, 2004a; WILLIAMS, 2002). Uma miliamperagem alta (TICER, 1987), écrans fosforescentes de terra rara, com emissão de luz verde, e filme de raios-X de alta velocidade (KRAUTWALD-JUNGHANNS, 1996; KRAUTWALD-JUNGHANNS; HENDRICH-SCHUSTER, 1996) requerem menos exposição radiográfica e, portanto, têm sido propostos para a obtenção de radiografias de alta qualidade diagnóstica. Para a escolha da voltagem, a ave deve ser mensurada em sua região mais larga (ALTMAN, 1973), lembrando que o uso de lâminas de plexiglas requer a adição de dois a quatro $\mathrm{kV}$ ao valor original (LAVIN, 1994). O ponto de foco efetivo do tubo de raios-X deve permanecer tão pequeno quanto possível, a fim de aumentar o detalhe da imagem radiográfica (TICER, 1987).

Os chassis são posicionados diretamente em cima da mesa radiográfica (ALTMAN, 1973; SMITH; SMITH, 1997). Uma grade antidifusora, posicionada entre o paciente e o filme de raios-X, geralmente não é necessária (ALTMAN, 1973; KRAUTWALD-JUNGHANNS, 1996; KRAUTWALD-JUNGHANNS; HENDRICH-SCHUSTER, 1996; LAVIN, 1994; WILLIAMS, 2002), exceto em espécies grandes (KRAUTWALD-JUNGHANNS, 1996; KRAUTWALD-JUNGHANNS; HENDRICH-SCHUSTER, 1996), cuja espessura ultrapasse nove $\mathrm{cm}$ (TICER, 1987). 


\subsubsection{Interpretação radiográfica}

Para uma interpretação radiográfica precisa, é/são fundamental/ais:

- radiografias de elevada qualidade diagnóstica (RUPLEY, 1999);

- conhecimento da anatomia (ALTMAN, 1973; KRAUTWALD-JUNGHANNS, 1996; KRAUTWALD-JUNGHANNS; HENDRICH-SCHUSTER，1996; SILVERMAN, 1987; SMITH; SMITH, 1997; SMITH et al., 1990; WILLIAMS, 2002);

- radiografar também o membro contralateral, no caso da avaliação do esqueleto apendicular (KRAUTWALD-JUNGHANNS; HENDRICH-SCHUSTER, 1996);

- comparar a imagem radiográfica da espécie em questão com radiografias normais de outros pacientes de mesma espécie (KRAUTWALD-JUNGHANNS; HENDRICHSCHUSTER, 1996);

- radiografias de magnificação (WILLIAMS, 2002).

Em virtude do pequeno tamanho da maioria das aves de gaiola, radiografias de magnificação são requeridas, além do estudo radiográfico convencional, para otimizar a interpretação radiográfica de pequenas estruturas esqueléticas. São alcançadas aumentando-se a distância entre o paciente e o chassi. Ferramentas espessas e radiotransparentes, como blocos de espuma, podem ser utilizadas para esta finalidade (WILLIAMS, 2002). Um exemplo da aplicação de radiografias de magnificação é no crânio, região anatomicamente complexa nas aves (PAUL-MURPHY et al., 1990). O anexo C, figura 4, ilustra este efeito de magnificação.

Outra alternativa para a otimização da imagem registrada é a utilização de lentes de aumento (MCMILLAN, 1994; WILLIAMS, 2002). As vantagens dessa ferramenta sobre a técnica de magnificação abrangem a redução do número de exposições radiográficas e a manutenção do detalhe radiográfico dos contornos dos ossos (WILLIAMS, 2002).

O esqueleto deve ser cuidadosamente examinado, pesquisando-se a presença de fraturas, reação do periósteo, esclerose, osteólise, adelgaçamento de corticais, deformidades angulares e alargamento ou diminuição da interlinha radiográfica (KOSTKA et al., 1988). 


\subsection{ANATOMIA}

O sistema esquelético das aves (Anexo D, Figura 5) está dividido, segundo Baumel e Witmer (1993), em:

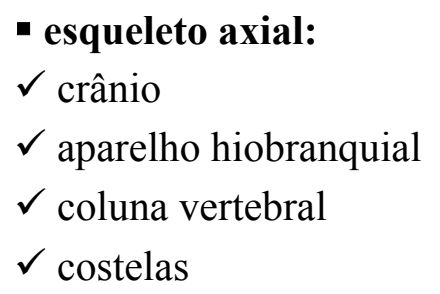

- esqueleto axial:

$\checkmark$ crânio

$\checkmark$ coluna vertebral

$\checkmark$ costelas

\section{- esqueleto apendicular:}

$\checkmark$ esterno

$\checkmark$ cíngulo torácico

$\checkmark$ membros torácicos

$\checkmark$ cíngulo pélvico

$\checkmark$ membros pélvicos

Existem diferenças anatômicas entre o sistema esquelético de aves e mamíferos que são relevantes à interpretação radiográfica, e serão brevemente relatadas. A descrição da nomenclatura anatômica está de acordo com a Nomina Anatômica Aviária (BAUMEL; WITMER, 1993) e a Nomenclatura Anatômica Veterinária (SCHALLER, 1999).

O crânio é cinético (EVANS, 1996; FEDUCCIA, 1986; KING; MCLELLAND, 1984; MCLELLAND, 1991; PAUL-MURPHY et al., 1990). O maxilar é móvel em relação à abóbada craniana, movimentando-se para cima e para baixo por meio da articulação nasofrontal (FEDUCCIA, 1986). Esta mobilidade é atingida graças à articulação conjunta do arco zigomático, palatino, pterigóide e quadrado. Tais ossos são melhor visibilizados na superfície ventral do crânio (EVANS, 1996).

As superfícies orbitárias são grandes (FEDUCCIA, 1986; SMITH et al., 1990). A esclera possui um anel ósseo formado por uma série de ossículos que se sobrepõem um ao outro (EVANS, 1996; FEDUCCIA, 1986; PAUL-MURPHY et al., 1990).

Mandíbulas, bem como maxilas, são desprovidas de dentes (DYCE et al., 1997; SMITH; SMITH, 1992; STORER et al., 1998).

Os componentes ósseos da língua são tão extensos em algumas espécies, como em papagaios do gênero Amazona, que cautela é requerida durante a interpretação radiográfica 
para evitar que sejam confundidos com corpo-estranho lingual (MCKIBBEN; HARRISON, 1986).

O número de vértebras cervicais varia de oito a 25 , conforme o comprimento do pescoço (DYCE et al., 1997; EVANS, 1996; KING; MCLELLAND, 1984; KOCH, 1973; MCKIBBEN; HARRISON, 1986; MCLELLAND, 1991; MCMILLAN, 1994; NICKEL et al., 1977). Com exceção do atlas, cuja forma é anelar, as superfícies articulares dos corpos vertebrais são em forma de sela (FEDUCCIA, 1986). A superfície articular cranial é côncava na vista ventral e convexa na lateral. A superfície articular caudal assume curvaturas inversas (KING; MCLELLAND, 1984; NICKEL et al., 1977).

O número de vértebras torácicas varia de três a 10 (DYCE et al., 1997; EVANS, 1996; FEDUCCIA, 1986; KING; MCLELLAND, 1984; KOCH, 1973; MCMILLAN, 1994; NICKEL et al., 1977; O’MALLEY, 2005). Duas a cinco vértebras torácicas fundem-se para formar o notário (DYCE et al., 1997; FEDUCCIA, 1986; KING; MCLELLAND, 1984; KOCH, 1973; NICKEL et al., 1977).

O sinsacro é formado pela fusão de uma ou mais vértebras torácicas caudais, todas as vértebras lombares, todas as vértebras sacrais e uma ou mais vértebras coccígeas craniais (DYCE et al., 1997; EVANS, 1996; KING; MCLELLAND, 1984; MCKIBBEN; HARRISON, 1986; NICKEL et al., 1977; O’MALLEY, 2005; OROSZ, 1997b; SMITH; SMITH, 1992; SMITH et al., 1990; WILLIAMS, 2002). O sinsacro, também, funde-se aos ílios (CRACKNELL, 2004b; DYCE et al., 1997; FEDUCCIA, 1986; KING; MCLELLAND, 1984; MCMILLAN, 1994; NICKEL et al., 1977; OROSZ, 1997b; SMITH et al., 1990).

Caudal ao sinsacro, quatro a nove vértebras caudais livres têm sido identificadas (DYCE et al., 1997; EVANS, 1996; FEDUCCIA，1986; KING; MCLELLAND, 1984; MCKIBBEN; HARRISON, 1986; MCLELLAND, 1991; MCMILLAN, 1994; NICKEL et al., 1977; OROSZ, 1997b). Por fim, a fusão de quatro a 10 vértebras caudais forma o pigóstilo (FEDUCCIA, 1986; KING; MCLELLAND, 1984; MCLELLAND, 1991).

Costelas torácicas consistem de segmentos dorsal e ventral, articulando-se com a vértebra torácica e o esterno, respectivamente (EVANS, 1996; KING; MCLELLAND, 1984; MCMILLAN, 1994; SMITH; SMITH, 1992). O segmento ventral é equivalente à cartilagem 
costal dos mamíferos (DYCE et al., 1997; KING; MCLELLAND, 1984; MCLELLAND, 1991; MCMILLAN, 1994; OROSZ, 1997b; SMITH et al., 1990).

O esterno é um grande osso não segmentado, formando parte considerável da parede corpórea ventral (DYCE et al., 1997). Está modificado ventralmente em forma de uma quilha. Com o objetivo de oferecer fixação aos grandes músculos do vôo, o grau de desenvolvimento da quilha está diretamente relacionado à capacidade de vôo da ave, sendo particularmente mais desenvolvida nas grandes aves voadoras (KING; MCLELLAND, 1984). Aves ratitas, do latim ratis (balsa), possuem uma quilha plana, lembrando uma balsa. De modo contrário, aves carinatas, do latim carina, referindo-se à calha de uma embarcação, dispõem de uma quilha altamente proeminente (FEDUCCIA, 1986).

Formado por três pares de ossos (FEDUCCIA, 1986; GILL, 1995; STORER et al., 1998), o cíngulo torácico faz a ligação entre o tronco e as asas (DYCE et al., 1997; NICKEL et al., 1977). As clavículas são bastante desenvolvidas (EVANS, 1996; SMITH et al., 1990). São ossos delgados (FEDUCCIA, 1986; MCKIBBEN; HARRISON, 1986), e suas extremidades distais fundem-se para formar a fúrcula, conhecida popularmente por "osso da sorte” (EVANS, 1996; MCMILLAN, 1994; SMITH; SMITH, 1992). A escápula estende-se caudalmente, paralela à coluna vertebral (FEDUCCIA, 1986). Ela pode ser tão comprida a ponto de alcançar os ílios (KING; MCLELLAND, 1984). O coracóide é o osso mais robusto (DYCE et al., 1997; EVANS, 1996; FEDUCCIA, 1986; KING; MCLELLAND, 1984; NICKEL et al., 1977; STORER et al., 1998). As extremidades proximais dos três ossos encontram-se para formar o canal triósseo (EVANS, 1996; FEDUCCIA, 1986).

$\mathrm{O}$ úmero articula-se proximalmente em uma fossa glenóide rasa, formada pela escápula e coracóide (EVANS, 1996). No antebraço, a ulna é curvada (EVANS, 1996; NICKEL et al., 1977) e mais espessa que o rádio (CRACKNELL, 2004b; DYCE et al., 1997; FEDUCCIA, 1986; MCKIBBEN; HARRISON, 1986; O’MALLEY, 2005; SMITH; SMITH, 1992, 1997; SMITH et al., 1990). O olécrano é pouco desenvolvido (EVANS, 1996; NICKEL et al., 1977). A articulação do carpo está representada apenas por dois ossos distintos, o carporradial e o ulnar do carpo (EVANS, 1996; KING; MCLELLAND, 1984; MCKIBBEN; HARRISON, 1986; MCMILLAN, 1994; NICKEL et al., 1977; SMITH; SMITH, 1992, 1997; SMITH et al., 1990). Tais elementos ósseos representam a fusão da fileira proximal dos ossos do carpo (EVANS, 1996; KING; MCLELLAND, 1984; SMITH; SMITH, 1992; SMITH et 
al., 1990). Os ossos cárpicos da fileira distal fundem-se uns nos outros e com as extremidades proximais dos metacárpicos, constituindo o carpometacarpo (BAUMEL; WITMER, 1993; MCMILLAN, 1994; SMITH et al., 1990). Três ossos metacárpicos estão presentes. Os metacárpicos II e III são longos e se unem em suas extremidades distais (FEDUCCIA, 1986). Dígitos I e III possuem uma falange cada, e o dígito II duas falanges (BAUMEL; WITMER, 1993; EVANS, 1996).

O cíngulo pélvico é equivalente aos ossos coxais direito e esquerdo, cada um formado por um grau variável de fusão óssea entre ílio, ísquio e púbis (NICKEL et al., 1977). Ele é côncavo na região ventral (DYCE et al., 1997), inexistindo articulação entre os ossos coxais na linha média (KING; MCLELLAND, 1984).

Tibiotarso e fíbula constituem os ossos da perna (KOCH, 1973; NICKEL et al., 1977). É denominado tibiotarso em razão da fusão de sua extremidade distal com a fileira proximal dos ossos do tarso (NICKEL et al., 1977). A fíbula é pouco desenvolvida nas aves (EVANS, 1996). A cabeça da fíbula articula-se com o côndilo lateral do fêmur (EVANS, 1996; MCKIBBEN; HARRISON, 1986).

Os társicos tibial e fibular, da fileira proximal, fundem-se entre si e com a tíbia, formando os côndilos da extremidade distal do tibiotarso (BAUMEL; WITMER, 1993). A distinção entre esses dois ossos proximais, entretanto, pode ser perceptível por até alguns meses após o nascimento (KING; MCLELLAND, 1984). O társico distal, único osso da fileira distal, funde-se com os metatársicos II, III e IV, estes, por sua vez, fundidos entre si, formando a extremidade proximal do tarsometatarso (BAUMEL; WITMER, 1993). Logo, a união entre tibiotarso e tarsometatarso, forma a articulação intertársica (DYCE et al., 1997; KING; MCLELLAND, 1984). O metatársico I é um osso pequeno e separado, articulando-se proximalmente com a extremidade mediodistal do tarsometatarso (SMITH et al., 1990). Por isso, deve-se ter atenção para não confundir o metatársico I com uma falange (SMITH; SMITH, 1997).

O número de dígitos dos membros pélvicos varia de dois a quatro (EVANS, 1996; MCKIBBEN; HARRISON, 1986). A maioria das espécies aviárias possui dígitos I, II, III e IV, contendo duas, três, quatro e cinco falanges, respectivamente (EVANS, 1996; KING; MCLELLAND, 1984; SMITH; SMITH, 1997; SMITH et al., 1990). 


\subsection{AFECÇÕES DO SISTEMA ESQUELÉTICO}

As afecções do sistema esquelético são muito freqüentes nas aves de estimação (QUESENBERRY, 1997; RUPLEY, 1999). Podem ser de origem traumática, metabólica, degenerativa, infecciosa, neoplásica (WILLIAMS, 2002) ou congênita (ALTMAN, 1969; RICH, 1991). Elas diferem das afecções encontradas nos cães e gatos, apenas pelas diferenças anatômicas e resposta do osso às injúrias (WILLIAMS, 2002).

Sintomas resultantes de anormalidades no sistema esquelético incluem: aumento de volume de tecidos moles ao longo dos ossos e/ou nas articulações, crepitação e enfisema subcutâneos à palpação, deformidades de membros pélvicos, ferimentos cutâneos, fraturas, assimetria na postura de repouso da(s) asa(s), claudicação (RUPLEY, 1999), flexão de membro pélvico, inabilidade para andar e/ou voar e inflamação das articulações, caracterizada por dor e calor locais à palpação (ALTMAN, 1969).

\subsubsection{Traumáticas}

As afecções traumáticas são as injúrias musculoesqueléticas mais freqüentemente encontradas em aves (QUESENBERRY, 1997; ROUSH, 1984). Traumas no sistema musculoesquelético comumente resultam em fraturas e luxações, além de injúrias a músculos, tendões, nervos e ao tegumento (pele e penas) (ROUSH, 1984). As causas são várias, sendo as principais: colisões com veículos em movimento e objetos estacionários, membros presos na gaiola, mordeduras de animais, autotraumatismo, relutância à contenção e gaiolas inseguras (BENNETT, 1997; MARTIN; RITCHIE, 1994; MCMILLAN, 1994; RICH, 1996; RUPLEY, 1999; SIMPSON, 1996).

\subsubsection{Fraturas}

As fraturas são as anormalidades musculoesqueléticas mais comuns (EVANS, 1986), sendo as de ossos longos das asas e dos membros pélvicos as maiores causas de atendimento às aves (MCCARTNEY, 1994). 
Kostka et al. (1988), analisaram, por meio de radiografias, 1.700 aves atendidas no Instituto de Doenças Aviárias da Universidade de Gießen, no Estado de Hessen, na Alemanha. Das 154 aves com alterações musculoesqueléticas, 114 (74,03\%) possuíam fraturas de origem traumática.

Kostka e Krautwald-Junghanns (1991), relatam que as fraturas representam 62\% das afecções do sistema esquelético em aves atendidas na Policlínica Veterinária da Universidade de Gießen.

McCartney (1994), avaliando problemas ortopédicos em 327 pombas atendidas em um Hospital Veterinário da Inglaterra, concluiu que as fraturas representam $70,3 \%$ dos atendimentos.

Devido à grande diversidade de ambientes não naturais onde as aves vivem, é fácil entender porque muitas aves são apresentadas com fraturas do sistema esquelético (REDIG ${ }^{7}$, 1994 apud RICH, 1996, p. 533).

O crânio é freqüentemente traumatizado (PAUL-MURPHY et al., 1990), todavia, fraturas têm sido infreqüentemente relatadas (MCMILLAN, 1994). Algumas razões se devem à sua complexidade anatômica, ao pequeno tamanho do paciente e à necessidade de se tirar várias projeções radiográficas (PAUL-MURPHY et al., 1990). Além disso, o adelgaçamento de corticais somado à pneumatização do crânio, também representam importantes desafios para a identificação radiográfica de fraturas (WILLIAMS, 2002). Para otimizar a avaliação radiográfica do crânio em aves, projeções radiográficas oblíqüas e de magnificação são requeridas em adição às projeções ventrodorsais e laterolaterais (PAUL-MURPHY et al., 1990). Psitacídeos (Ara ararauna) com fraturas de arco jugal, pterigóide, quadrado e ceratobranquial (PAUL-MURPHY et al., 1990), e rapinantes (Buteo jamaicensis) com fraturas de anel escleral e osso lacrimal (LINDLEY et al., 1988) têm sido relatados.

Fraturas de bico são muito comuns (MARTIN; RITCHIE, 1994), particularmente nas espécies dotadas de bico grande e longo, como os tucanos, papagaios, patos e aves pernaltas (COLES, 1985). Injúrias do quadrado e arco jugal, freqüentemente, estão associadas (MARTIN; RITCHIE, 1994). Além de traumas, outras causas que levam à instabilidade do bico são infecções, neoplasias e anormalidades congênitas (GREENWELL et al., 1990).

REDIG, P. Orthopedics. Seminars in Avian and Exotic Pet Medicine, v. 3, n. 2, p. 49-108, 1994. 
Fraturas ou luxações da coluna vertebral são incomuns (WILLIAMS, 2002). Quando presentes, geralmente representam injúrias devastadoras em razão da transecção da medula espinhal. Os segmentos vertebrais comumente fraturados são notário e sinsacro (MACCOY, 1996).

O diagnóstico de fraturas localizadas na coluna vertebral normalmente exige atenção e conhecimento anatômico redobrados pelo examinador (KOSTKA; KRAUTWALDJUNGHANNS, 1991). O segmento vertebral cervical apresenta uma curvatura sigmóide normal (KOCH, 1973; MCMILLAN, 1994), porque os tecidos moles do pescoço, traquéia e esôfago, são menores em extensão do que o segmento vertebral em questão (KOCH, 1973). Portanto, fraturas de coluna cervical podem ser equivocadamente diagnosticadas (MCMILLAN, 1994).

Afecções traumáticas afetando o cíngulo torácico estão presentes geralmente como resultado de colisões com objetos sólidos (BENNETT, 1997; REDIG, 1986), ocasionando freqüentemente fraturas de coracóide (REDIG, 1986). Fraturas de escápula e/ou clavícula podem estar associadas (MACCOY, 1996).

Em razão da sobreposição dos ossos do cíngulo torácico entre si, especificamente coracóide e escápula quando realizada a projeção ventrodorsal (KOSTKA; KRAUTWALDJUNGHANNS, 1991), e desses com estruturas adjacentes, o diagnóstico radiográfico de fraturas no coracóide, escápula e clavícula torna-se difícil. Projeções oblíqüas, portanto, são requeridas (KRAUTWALD-JUNGHANNS, 1996).

Fraturas de coracóide representam aproximadamente 10\% das injúrias ortopédicas em aves silvestres, apresentadas para tratamento no Santuário de Healesville, em Melbourne, Austrália (HOLZ, 2003).

Em um levantamento com 6.212 esqueletos de aves selvagens, Passeriformes, 3,41\% $(\mathrm{n}=212)$ apresentavam fraturas de clavícula $\left(\right.$ TIEMEIER $^{8}, 1941$ apud COLES, 1985, p. 146).

Fraturas de membros torácicos são menos freqüentes do que fraturas de membros pélvicos, e normalmente envolvem o úmero, rádio e ulna (BLASS, 1987). Em um estudo com pombos, entretanto, fraturas de membros torácicos foram duas vezes e meia mais comuns do que fraturas de membros pélvicos (MCCARTNEY, 1994). Fraturas umerais são comuns (MACCOY, 1996), principalmente nos segmentos médio e distal, correspondentes às áreas de

8 TIEMEIER, O. W. Repaired bone injuries in birds. The Auk, v. 58, n. 3, p. 350-359, 1941. 
escassa quantidade de tecidos moles (COLES, 1985). No antebraço, a maioria das fraturas envolve apenas o rádio ou a ulna (REDIG, 1986). Segundo Coles (1985), a porcentagem de casos envolvendo fraturas isoladas dos ossos do antebraço, encontra-se ao redor de $50 \%$. Martin e Ritchie (1994), entretanto, relatam que injúrias traumáticas freqüentemente causam fraturas de ambos os ossos. Em uma amostragem com 14 fraturas de antebraço, oito (57\%) envolviam tanto o rádio quanto a ulna (MCCARTNEY, 1994). Fraturas de carpos (COLES, 1985; MACCOY, 1996; RICH, 1996), metacarpos (COLES, 1985; MACCOY, 1996) e falanges (COLES, 1985), também têm sido relatadas.

Os ossos do cíngulo pélvico raramente são fraturados. Na presença de fraturas, todavia, os segmentos ósseos normalmente não se encontram deslocados graças à musculatura pélvica que os mantêm no lugar (HARCOURT-BROWN, 1996).

Fraturas de membros pélvicos são menos freqüentes do que fraturas de membros torácicos (BENETT, 1997; MCCARTNEY, 1994). O fêmur está protegido por uma grande musculatura. Fraturas nessa região, portanto, não são freqüentes (ALTMAN, 1969; BLASS, 1987; MACCOY, 1992). Quando presentes, os músculos normalmente proporcionam um adequado alinhamento dos fragmentos ósseos (MACCOY, 1992). Fraturas da cabeça femoral têm sido relatadas em associação com luxação coxofemoral. O tibiotarso é o osso mais freqüentemente fraturado (HARCOURT-BROWN, 1996), principalmente nos periquitosaustralianos (Melopsittacus undulatus) (ALTMAN, 1969; ROSSKOPF JUNIOR; WOERPEL, 1991). Passeriformes e aves aquáticas pernaltas, comumente são apresentadas com fraturas de tarsometatarso (MACCOY, 1992, 1996). Muitas dessas fraturas são observadas em aves anilhadas que prendem as suas anilhas nos aramados da gaiola. A fratura é provocada no momento em que a ave tenta se desprender do aramado (HARCOURT-BROWN, 1996). Um estudo retrospectivo de aves vítimas de fraturas, mostrou o envolvimento do tarsometatarso em 71\% dos casos (ALTMAN, 1969). Fraturas de falanges não ocorrem com freqüência, ou, por outro lado, não são comumente identificadas (MACCOY, 1992, 1996), salvo quando estão em fase de consolidação (BLASS, 1987).

O exame radiográfico é um método diagnóstico indispensável na avaliação das fraturas (SMITH; SMITH, 1997). As indicações mais freqüentes para o seu emprego são: confirmar um diagnóstico clínico, classificar a fratura, selecionar o melhor método de fixação, determinar a idade da fratura, demonstrar outras fraturas imperceptíveis ao exame clínico e 
avaliar o grau de reparo (KEALY; MCALLISTER, 2000). As fraturas devem ser avaliadas radiograficamente quanto à localização, radiopacidade óssea, reação do periósteo e envolvimento de tecidos moles (MCMILLAN, 1994). A classificação é similar à dos mamíferos (SMITH; SMITH, 1997; WILLIAMS, 2002) e tem sido descrita por Kealy e McAllister (2000).

Em aves traumatizadas, radiografias do sistema esquelético, bem como da cavidade celomática, são necessárias para avaliar outras alterações ósseas ou de tecidos moles passíveis de ocorrer durante o trauma (COLES, 1996; MARTIN; RITCHIE, 1994).

\subsubsection{Luxações}

Luxações são infreqüentes em aves (ALTMAN, 1969; BLASS, 1987; MARTIN; RITCHIE, 1994; MCMILLAN, 1994). Estando presentes, normalmente envolvem os dígitos, as articulações coxofemorais ou as articulações fêmorotibiotársicas (MCMILLAN, 1994). Segundo Altman (1969), a baixa prevalência pode ser justificada pela pneumatização dos ossos somada à presença de articulações bastante desenvolvidas, tocante aos ligamentos, ocasionando fraturas ao invés de luxações.

McCartney (1994), avaliando as injúrias ortopédicas encontradas nas asas de 75 pombos, atendidos em um Hospital Veterinário, na cidade de Birmingham, Inglaterra, encontrou três luxações de ombro e uma de cotovelo, perfazendo um total de 5,3\% dos atendimentos.

Vítimas de acidentes automobilísticos, 35 aves da ordem Passeriformes foram examinadas radiograficamente durante 26 meses. Um total de 30 injúrias esqueléticas foi observado em 17 aves (48,5\%), incluindo 29 fraturas de ossos longos (96,5\%) e apenas uma luxação vertebral (3,5\%) (ORLOWSKI; SIEMBIEDA, 2005).

As luxações são freqüentemente decorrentes de episódios traumáticos (ALTMAN, 1969; BLASS, 1987; MCMILLAN, 1994), e podem, ocasionalmente, estar presentes em associação com fraturas (ALTMAN, 1969). Luxações secundárias à doença articular degenerativa, decorrentes de frouxidão articular (WILLIAMS, 2002), e luxações congênitas, encontradas nos periquitos-australianos (Melopsittacus undulatus) (BLASS, 1987), também têm sido relatadas. 
Uma arara-canindé (Ara ararauna), macho, de dois anos de idade, foi apresentada com incapacidade aguda de oclusão de bico. O estudo radiográfico revelou luxação de osso quadrado em combinação com fraturas de arco jugal e de osso pterigóide (PAUL-MURPHY et al., 1990).

Luxações vertebrais normalmente estão localizadas nas unidades móveis da coluna vertebral (KOSTKA; KRAUTWALD-JUNGHANNS, 1991), tais como o segmento cervical (RUPLEY, 1999) e entre a última ou penúltima vértebra torácica e o sinsacro (HARCOURTBROWN, 1996; KOSTKA; KRAUTWALD-JUNGHANNS, 1991; KRAUTWALDJUNGHANNS, 1996; RUPLEY, 1999; WILLIAMS, 2002). Em algumas espécies de aves, como as araras, o sinsacro é incompletamente fundido às asas dos ílios, portanto, traumas na região podem resultar em deslocamentos (HARCOURT-BROWN, 1996).

A articulação do ombro é bem suportada por músculos, ligamentos e tendões (COLES, 1985). Luxações são raras (BLASS, 1987; ROUSH, 1984). Segundo Redig (1986), o ombro é freqüentemente deslocado como resultado de colisões com objetos estacionários. Relatos têm sido apresentados em aves de rapina e freqüentemente ocorrem em associação com fratura por avulsão do tubérculo ventral do úmero proximal (MARTIN; RITCHIE, 1994).

A presença de uma delicada cápsula articular comum ao úmero, rádio e ulna, além da escassa quantidade de tecidos moles adjacentes, propiciam a freqüente ocorrência de luxações do cotovelo (COLES, 1985). De ocorrência improvável em aves de estimação, segundo Redig (1986), têm sido comumente encontradas em rapinantes, com deslocamento caudal ou dorsocaudal da ulna (MARTIN; RITCHIE, 1994).

Luxação coxofemoral é infreqüente (BLASS, 1987; MACCOY, 1996; OROSZ, 1997b). Alguns autores justificam isso em razão da presença de algumas características anatômicas que ajudam a reforçar a inserção da cabeça femoral no acetábulo (MACCOY ${ }^{9}$, 1989 apud BENNETT, 1997, p. 760; OROSZ, 1997b), incluindo: uma projeção óssea, denominada antitrocânter, localizada caudodorsalmente ao acetábulo, que se articula com o

9 MACCOY, D. M. Excision arthroplasty for management of coxofemoral luxations in pet birds. Journal of the American Veterinary Medical Association, v. 194, n. 1, p. 95-97, 1989. 
colo e o trocânter do fêmur (BAUMEL; WITMER, 1993), um acetábulo profundo (OROSZ, 1997b) e, por fim, a presença dos ligamentos pubofemoral, iliofemoral e redondo (MACCOY $^{10}, 1989$ apud BENNETT, 1997, p. 760). A cabeça femoral, quando deslocada, geralmente se orienta craniodorsalmente em relação ao acetábulo (MACCOY, 1996; MARTIN; RITCHIE, 1994; OROSZ, 1997b). Luxação ventral ou cranioventral também pode ser evidenciada (MACCOY, 1996).

Traumas severos são capazes de deslocar a articulação do joelho (HARCOURTBROWN, 1996). Já Roush (1984), refere que forças excessivas aplicadas nessa região, têm sido capazes de produzir fraturas de fêmur e de tibiotarso com maior freqüência do que luxações.

Articulação intertársica é ocasionalmente luxada como resultado de alteração do desenvolvimento ósseo normal, envolvendo tibiotarso e tarsometatarso. Em aves adultas, esta articulação pode ser freqüentemente injuriada por traumas severos (HARCOURT-BROWN, 1996).

Falanges também são suscetíveis à luxação (HARCOURT-BROWN, 1996).

\subsubsection{Doença ósseo-metabólica (DOM)}

Desequilíbrios de cálcio, fósforo e vitamina $\mathrm{D}_{3}$ são freqüentes em aves e podem resultar em DOM (RUPLEY, 1999). Para Mcmillan (1994), as alterações ósseas decorrentes de DOM são predominantes em relação às alterações decorrentes de processos traumáticos ou infecciosos.

DOM desenvolve-se como resultado de uma deficiência prolongada de cálcio ou vitamina $\mathrm{D}$, ou de um desequilíbrio na relação cálcio:fósforo na dieta. A nomenclatura é muito variada e inclui, por exemplo, osteoporose, osteomalacia, raquitismo, osteogênese imperfeita, paralisia de gaiola, hiperparatireoidismo nutricional secundário, atrofia óssea e osteoporose juvenil (FOWLER, 1986).

10 MACCOY, D. M. Excision arthroplasty for management of coxofemoral luxations in pet birds. Journal of the American Veterinary Medical Association, v. 194, n. 1, p. 95-97, 1989. 
Desequilíbrios de nutrientes minerais e vitamínicos atingem preferencialmente aves recém-nascidas e jovens (KOSTKA: KRAUTWALD-JUNGHANNS, 1991), comumente como resultado do oferecimento de dietas desbalanceadas. Dietas a base de sementes, fornecidas às espécies granívoras, são pobres em cálcio e ricas em fósforo e gorduras (RUPLEY, 1999). O alto teor de gorduras reduz a absorção de cálcio como resultado da formação de sabões de cálcio (HOCHLEITHNER ${ }^{11}$, 1989 apud GOODMAN, 1996, p. 472). Todas as sementes apresentam uma relação cálcio:fósforo inadequada, variando de 1:6,25 (girassol) a 1:40 (painço) (CARCIOFI, 1996). A relação desejável varia de 1:1 a 2:1 (RANDELL, 1981; ROUDYBUSH, 1996; RUPLEY, 1999; SMITH; ROUDYBUSH, 1997). Do mesmo modo, dietas a base de carne, fornecidas às espécies carnívoras, também são pobres em cálcio e ricas em fósforo $\left(\mathrm{OLSEN}^{12}, 1990\right.$ apud MACWHIRTER, 1994, p. 858; RUPLEY, 1999), com uma relação cálcio:fósforo em torno de 1:20 (OLSEN ${ }^{12}, 1990$ apud MACWHIRTER, 1994, p. 858). Aves adultas, com um manejo nutricional inadequado, também podem desenvolver alterações ósseas de origem metabólica (KOSTKA: KRAUTWALD-JUNGHANNS, 1991).

DOM foi detectada em um papagaio (Amazona viridigenalis), fêmea, de quatro anos de idade. Além dos achados físicos, radiográficos e laboratoriais, que foram consistentes com o diagnóstico, a dieta, há quatro anos, consistia apenas de amendoim e milho, ambos apresentando uma relação cálcio:fósforo bem acima do nível desejado (RANDELL, 1981).

Os achados de necropsia de três psitacídeos com hiperparatireoidismo nutricional secundário reveleram a presença de sementes de girassol no ventrículo. Eclectus roratus, Calyptorhynchus funereus e Aratinga pertinax, eram todos alimentados com uma dieta a base de sementes, que consistia de amendoim e aveia, além de girassol (WALLACH; FLIEG, 1967).

De acordo com Carciofi (1996), os desbalanços nutricionais são causados em razão do oferecimento ad libitum dos alimentos, propiciando o desenvolvimento de preferências

\footnotetext{
11 HOCHLEITHNER, M. Convulsions in African grey parrots. In: ANNUAL CONFERENCE OF THE ASSOCIATION OF AVIAN VETERINARIANS, 1989, Lake Worth. Proceedings... Lake Worth: Association of Avian Veterinarians, 1989. p. 78-81.

12 OLSEN, J. Caring for birds of prey. Occasional Publication of the Applied Ecology Research Group, p. 27-29, 1990.
} 
individuais. Segundo o autor, a aceitação dos alimentos é, muitas vezes, difícil, necessitando paciência e insistência por parte do proprietário.

A deficiência de cálcio, em particular, é a anormalidade nutricional mais comum (FORBES, 1998; RANDELL, 1981; ROUDYBUSH, 1996). Quando a utilização e excreção de cálcio exceder a absorção do cálcio dietético por um período prolongado, hiperparatireoidismo nutricional secundário se desenvolverá (WALLACH; FLIEG, 1969). As glândulas paratireóides, como nos mamíferos, secretam paratormônio $(\mathrm{PTH})$ em resposta à hipocalcemia. O paratormônio estimula a atividade dos osteoclastos, que por sua vez reabsorvem cálcio dos ossos, e interfere na reabsorção tubular de fósforo, aumentando, com isso, a sua excreção renal. Isso efetivamente aumentará a concentração de cálcio no sangue (KING; MCLELLAND, 1984). Diversos trabalhos, no entanto, têm demonstrado que os osteoclastos não possuem receptores para o PTH e que os osteoblastos, que possuem esses receptores, controlam o início da reabsorção (DOIGE; WEISBRODE, 1998). Vitamina $\mathrm{D}_{3} \mathrm{e}$ calcitonina também são requeridas para o adequado metabolismo do cálcio, conforme explicado detalhadamente por Roudybush (1996).

Hiperparatireoidismo primário, decorrente de neoplasias das glândulas paratireóides, e hiperparatireoidismo renal secundário, não têm sido relatados em aves (LOTHROP JUNIOR, 1996). Decorrente de nefropatias crônicas, o hiperparatireoidismo renal secundário é possível de acontecer (RUPLEY, 1999). Entretanto, pouco se sabe a respeito, e acredita-se que isso se deve à razão do paciente com nefropatia morrer antes do aparecimento de sintomas de hiperplasia glandular, e da omissão de informações dos patologistas durante a necropsia (BLACKMORE, 1969).

O exame radiográfico pode diagnosticar a DOM antes do desenvolvimento de sintomas severos (RANDELL, 1981). As alterações radiográficas abrangem: diminuição generalizada da radiopacidade óssea (KRAUTWALD-JUNGHANNS, 1996; WILLIAMS, 2002), adelgaçamento de corticais ósseos (RUPLEY, 1999; WILLIAMS, 2002), deformidades angulares de ossos longos ou, mais raramente, de costelas e coluna vertebral, e/ou fraturas patológicas das metáfises (KRAUTWALD-JUNGHANNS, 1996). Os principais ossos longos passíveis de sofrerem deformidades angulares são rádios, ulnas e tibiotarsos (KOSTKA: KRAUTWALD-JUNGHANNS, 1991). Para Mcmillan (1994), fraturas decorrentes de DOM são mais comuns do que as decorrentes de traumas. 
Casos avançados de hiperparatireoidismo nutricional secundário, associados a uma deficiência de vitamina $\mathrm{D}$, manifestam-se radiograficamente por um alargamento dos discos epifisários e das extremidades articulares (BIESTER; SCHWARTE ${ }^{13}, 1965$ apud WALLACH; FLIEG, 1969, p. 1048).

É de grande importância a contenção cuidadosa de pacientes com suspeita de DOM. Ossos desmineralizados tornam-se mais fragilizados e predisponentes às fraturas (FOWLER, 1986; ROUDYBUSH, 1996; RUPLEY, 1999).

O diagnóstico de DOM é feito através da combinação dos achados radiográficos com informações obtidas por meio da anamnese, incluindo uma avaliação da dieta oferecida, do exame físico e de outros exames complementares, tais como a determinação das concentrações séricas de cálcio e fosfatase alcalina (RUPLEY, 1999). Aves com DOM podem apresentar alterações angulares dos ossos longos, deformidades de bico, convulsões tetânicas e fraturas patológicas. Por causa da dor, manifestações clínicas iniciais incluem relutância em locomover-se e apatia (CARCIOFI, 1996). Fêmeas em postura podem apresentar ovos com casca fina ou mole, atonia de útero e retenção de ovos no oviduto (HARRISON, 1986).

\subsubsection{Osteopenia localizada}

Osteopenia pode estar associada também com desuso mecânico, conforme relatado por Freeman et al. (1999). Uma calopsita (Nymphicus hollandicus), macho, de sete anos de idade, foi apresentada com história de uma semana de desuso do membro pélvico direito. Ao exame radiográfico, osteopenia e atrofia muscular do membro pélvico direito, além de uma massa em topografia de silhuetas renais, foram evidenciadas. Diagnóstico de adenocarcinoma renal com compressão do nervo isquiático direito foi realizado.

13 BIESTER, H. E.; SCHWARTE, L. H. Diseases of poultry. 5. ed. Ames: Iowa State University Press, 1965. p. 49, 159-163, 194. 


\subsubsection{Hiperostose poliostótica}

Uma peculiaridade do sistema esquelético das aves é a formação de osso medular em fêmeas antes da época de postura (DYCE et al., 1997). As fêmeas normalmente acumulam cálcio no osso medular, cerca de 10 dias antes da oviposição, para a formação da casca do ovo (OROSZ, 1997a). Este processo fisiológico, denominado hiperostose poliostótica ou osteomieloesclerose (SMITH; SMITH, 1997), é estimulado por ações simultâneas de estrógenos e andrógenos e coincide com a maturação de folículos ovarianos (MAZZUCO, 2005; SIMKISS ${ }^{14}, 1967$ apud THORP, 1994, p. 220-221).

Localizado na cavidade medular (MAZZUCO, 2005), o osso medular é formado por inúmeras espículas ósseas interconectadas (KING; MCLELLAND, 1984), segundo ilustradas no anexo E, figura 6. Exerce uma função de suporte (MILLER ${ }^{15}, 1977$ apud THORP, 1994, p. 220), aumentando a resistência do osso (MCLELLAND, 1991), mas atua também como uma fonte de cálcio lábil (MILLER ${ }^{15}, 1977$ apud THORP, 1994, p. 220), fornecendo 40\% do cálcio exigido para a formação da casca do ovo (MEULLER ${ }^{16}$ et al., 1964 apud THORP, 1994, p. 220). Aves são capazes de ovipor um ovo por dia (LOTHROP JUNIOR, 1996; OROSZ, 1997a), em particular a galinha-doméstica (Gallus gallus domesticus) e a codornadoméstica (Coturnix coturnix japonica) (LOTHROP JUNIOR, 1996), requerendo, portanto, grande quantidade de cálcio (OROSZ, 1997a).

A hiperostose poliostótica reflete uma condição normal quando associada à postura de ovos (RUPLEY, 1999; SILVERMAN, 1987; SMITH; SMITH, 1997; WALSH, 1986). Todavia, é considerada uma anormalidade quando ocorre em casos de hiperestrogenismo (SMITH; SMITH, 1997). Deste modo, tem sido relatada em associação com cistos ou tumores ovarianos, tumores de oviduto, e, ainda, em casos de sertolinomas nos machos (RUPLEY, 1999).

14 SIMKISS, K. Calcium in reproductive physiology. London: Chapman \& Hall, 1967.

15 MILLER, S. C. Osteoclast cell-surface changes during the egg-laying cycle in japanese quail. Journal of Cell Biology, v. 75, p. 104-118, 1977.

16 MEULLER, W. J.; SCHRAER, R.; SCHRAER, H. Calcium metabolism and skeletal dynamics of laying pullets. Journal of Nutrition, v. 84, p. 20-26, 1964. 
Stauber et al. (1990), relatam a ocorrência de um carcinoma de oviduto em uma calopsita (Nymphicus hollandicus), fêmea, de 10 anos de idade, com hiperostose poliostótica nos ossos longos dos membros torácicos e pélvicos.

Autores referem-se ao hiperestrogenismo como causador da hiperostose poliostótica (KRAUTWALD-JUNGHANNS， 1996; MCMILLAN，1994; SCHLUMBERGER，1959). Outros, entretanto, não sustentam essa hipótese, após terem mensurado as concentrações de hormônios estrogênicos e androgênicos de 35 aves com hiperostose poliostótica (BAUMGARTNER et al., 1995).

O primeiro relato de hiperostose poliostótica foi feito em 1934 por Kyes e Potter (SCHLUMBERGER, 1959). No presente relato, a medula óssea de 850 pombos, incluindo 449 machos e 401 fêmeas, foi exposta e analisada mensalmente durante dois anos. Diferentes graus de ossificação medular foram observados em 186 fêmeas, variando diretamente com o tamanho dos folículos ovarianos. Macho algum mostrou ossificação medular.

O periquito-australiano (Melopsittacus undulatus) é a espécie mais freqüentemente acometida (BAUMGARTNER et al., 1995; COLES, 1985; KOSTKA; KRAUTWALDJUNGHANNS, 1991; KOSTKA et al., 1988; KRAUTWALD-JUNGHANNS, 1996), contudo, a condição de hiperostose poliostótica pode, também, ser vista ocasionalmente em outras espécies (BAUMGARTNER et al., 1995; COLES, 1985).

Acomete principalmente os ossos longos dos membros (EVANS, 1986; KOSTKA; KRAUTWALD-JUNGHANNS，1991; KRAUTWALD-JUNGHANNS，1996; LUMEIJ ${ }^{17}$, 1987 apud GOODMAN, 1996, p. 472; LUMEIJ, 1994; MCLELLAND, 1991; RUPLEY, 1999; SMITH; SMITH, 1997). A maioria (LUMEIJ ${ }^{17}$, 1987 apud GOODMAN, 1996, p. 472; SCHLUMBERGER, 1959) ou, até mesmo, todo o sistema esquelético (KRAUTWALDJUNGHANNS, 1996), pode estar envolvido.

A hiperostose poliostótica é usualmente um achado acidental (COLES, 1985; RUPLEY, 1999), não resultando em sintomas clínicos como queda alar, claudicação ou

17 LUMEIJ, J. A contribution to clinical investigative methods for birds, with special reference to the racing pigeon, Columba livia domestica. Dissertation - School of Veterinary Medicine, State University Utrecht. 1987. 
fraturas (RUPLEY, 1999). Em galinhas-domésticas, a presença do osso medular aumenta o peso do esqueleto em aproximadamente 20\% (MCLELLAND, 1991). Hérnias abdominais, aliadas à hiperostose poliostótica, ocorrem freqüentemente nas fêmeas de psitacídeos, especialmente no periquito-australiano, como resultado de hiperestrogenismo (SMITH; SMITH, 1997).

As alterações radiográficas podem adquirir uma aparência bizarra (SILVERMAN, 1987), uma vez que o osso medular é capaz de obliterar completamente a cavidade medular dos ossos longos (LUMEIJ ${ }^{18}, 1987$ apud GOODMAN, 1996, p. 472; LUMEIJ, 1994). Radiograficamente, nota-se um aumento da radiopacidade medular dos ossos longos, particularmente do rádio, ulna, fêmur e tibiotarso (QUESENBERRY, 1997), de aspecto homogêneo ou heterogêneo (MCMILLAN, 1994; RUPLEY, 1999).

O correto diagnóstico da hiperostose poliostótica tem sua maior importância na diferenciação para com outras afecções que apresentam alterações radiográficas semelhantes (DYCE et al., 1997). Assim, osteopetrose, neoplasia metastática, osteopatia hipertrófica, doença óssea metabólica (LATIMER, 1994) e doença óssea infecciosa (QUESENBERRY, 1997), devem ser consideradas no diagnóstico diferencial.

\subsubsection{Inflamatório-infecciosas}

As principais vias de infecção que predispõem ao desenvolvimento de artrite séptica e osteomielite em aves são: inoculação direta (por exemplo, fraturas expostas, feridas penetrantes, infecção iatrogênica), extensão por contigüidade a partir de um foco infeccioso (por exemplo, aerossaculite e pododermatite), e disseminação hematogênica (MCMILLAN, 1994).

18 LUMEIJ, J. A contribution to clinical investigative methods for birds, with special reference to the racing pigeon, Columba livia domestica. Dissertation - School of Veterinary Medicine, State University Utrecht. 1987. 


\subsubsection{Artrite}

De ocorrência ocasional em aves, artrites normalmente resultam de traumas (SMITH; SMITH, 1997). Outras causas, além dos traumas, são doenças infecciosas e distúrbios metabólicos (ALTMAN, 1969). As alterações geralmente são unilaterais (ALTMAN, 1969) e quanto à faixa etária, em especial as artrites do tipo supurativas, atingem predominantemente aves entre seis e 12 meses de idade (JANOVSKI, 1966).

O processo de infecção instalado em aves com pododermatite séptica, especialmente se não tratado, pode se propagar aos ossos e articulações adjacentes. Portanto, diante de casos crônicos de pododermatite, as aves devem ser radiografadas, objetivando avaliar o grau de envolvimento ósseo e/ou articular local (SMITH; SMITH, 1997; WALSH, 1986). Injúrias ortopédicas localizadas nos membros pélvicos, com capacidade para afetar a sustentação do peso corporal, podem predispor ao desenvolvimento da pododermatite (MARTIN; RITCHIE, 1994).

Osteomielites induzidas por bactérias podem estender-se por meio do osso cortical para a articulação (DOIGE; WEISBRODE, 1998; MCMILLAN, 1994).

Associada à ausência da enzima uricase em aves (DOIGE; WEISBRODE, 1998), a artrite induzida por cristais ocorre na gota, onde cristais de urato se depositam nas articulações como resultado do aumento da concentração de ácido úrico no sangue (LOTHROP et al., 1986). É comumente observada nas articulações intertársicas, tarsometatarsofalangeanas e interfalangeanas dos membros pélvicos de periquitos-australianos (Melopsittacus undulatus) (LOTHROP et al., 1986; RICH, 1991). Canários, além de periquitos-australianos, também são afetados (ALTMAN, 1969).

Segundo o agente etiológico, as artrites infecciosas podem ser causadas por diferentes microrganismos, a saber: Aspergillus sp, Escherichia coli, Mycobacterium sp, Mycoplasma sp, Proteus sp, Pseudomonas sp, Salmonella sp, Staphylococcus sp, Streptococcus sp (GYLSTORFF; GRIMM, 1987), Erysipelothrix rhusiopathiae, Actinobacillus sp e Pasteurella multocida (GERLACH, 1994). Artrites assépticas são raras, 
mas têm sido descritas por Mcmillan ${ }^{19}$ (1982 apud KOSTKA et al., 1988, p. 38) em decorrência de episódios traumáticos.

Artrite séptica é comumente observada nas articulações intertársicas (MCMILLAN, 1994; QUESENBERRY, 1997; WALSH, 1986), especialmente quando é secundária à pododermatite (MCMILLAN, 1994). De acordo com Altman (1969) e Kostka et al. (1988), as articulações tarsometatarsofalangeanas são os sítios principais das alterações ósseas, resultantes da disseminação do processo de infecção de aves com pododermatite. Artrite séptica associada a bactérias do gênero Salmonella, tem sido freqüentemente relatada em aves pertencentes à ordem Columbiformes, família Columbidae (KOSTKA; KRAUTWALDJUNGHANNS, 1991; KOSTKA et al., 1988; QUESENBERRY, 1997), na articulação do cotovelo (KOSTKA et al., 1988; QUESENBERRY, 1997).

O exame radiográfico é essencial na avaliação das artrites. Citologia e cultura do líqüido sinovial, bem como biopsia da membrana sinovial, também são procedimentos úteis para a obtenção de um diagnóstico definitivo (QUESENBERRY, 1997). Durante a fase aguda, é provável existir pouca evidência radiográfica de artrite. Efusão articular pode ser a única alteração radiográfica perceptível (MCMILLAN, 1994). Com a progressão da infecção, as alterações radiográficas que se adicionam são: diminuição da interlinha articular (KRAUTWALD-JUNGHANNS, 1996; MCMILLAN, 1994; RUPLEY, 1999), como resposta da cartilagem articular lesada, osteólise e reação do periósteo nas regiões epifisária e metafisária (MCMILLAN, 1994), esclerose subcondral e aumento de volume de tecidos moles (KRAUTWALD-JUNGHANNS, 1996; RUPLEY, 1999). Ocasionalmente, luxação da articulação afetada pode também ser evidenciada (MCMILLAN, 1994).

A evidência de osteólise, de extensão pronunciada, localizada nas superfícies articulares, pode indicar uma artrite séptica (KOSTKA; KRAUTWALD-JUNGHANNS, 1991; RUPLEY, 1999).

A necropsia de um passere (Estrilda subflava subflava), macho, de seis meses de idade, exposto a um ambiente de elevada contaminação fecal, exibiu graus variados de destruição cartilagínea e óssea, localizados nas articulações interdigitais dos membros

19 MCMILLAN, M. C. Avian radiology. In: PETRAK, M. L. (Ed.). Diseases of cage and aviary birds. Philadelphia: Lea \& Febiger, 1982. p. 329-360. 
pélvicos. A bactéria Escherichia coli foi isolada de diversas partes do corpo. O mecanismo patogênico, entretanto, não foi determinado (JANOVSKI, 1966).

\subsubsection{Osteomielite}

Visto que extensões dos sacos aéreos invadem a cavidade medular de alguns ossos, torna-se possível uma osteomielite resultar da extensão de uma aerossaculite, ou, de modo inverso, uma aerossaculite resultar da extensão de uma osteomielite (MCKIBBEN; HARRISON, 1986; MCMILLAN, 1994; SMITH; SMITH, 1992).

Diversos microrganismos têm sido associados com osteomielite em aves, incluindo Staphylococcus sp (GERLACH, 1994; GYLSTORFF; GRIMM, 1987), Escherichia coli, Proteus vulgaris, Pseudomonas aeruginosa, Mycobacterium sp, além de fungos do gênero Aspergillus (GYLSTORFF; GRIMM, 1987).

A osteomielite pode atingir diversos ossos do sistema esquelético, sendo mais freqüente nas extremidades dos membros (MCMILLAN, 1994). Osteomielite dos ossos do crânio normalmente é o resultado da extensão de infecções crônicas localizadas no trato respiratório superior, como rinite e sinusite (KRAUTWALD-JUNGHANNS, 1996; MCMILLAN, 1994), bem como de lesões periorbitais (MCMILLAN, 1994). Ao exame radiográfico é observado um aumento de radiopacidade localizado nas cavidades nasais e seios infraorbitários e, também, em estágio avançado, reação osteolítica nos ossos adjacentes (KRAUTWALD-JUNGHANNS, 1996). Osteomielite vertebral é rara (MCMILLAN, 1994). Estafilococose, infecção causada por Staphylococcus sp, pode acometer o segmento vertebral torácico, e seqüelas incluem deformação vertebral, estreitamento de forame intervertebral e compressão da medula espinhal (GERLACH, 1986). Cifose vertebral e compressão medular adjacente foram observadas no exame pós-morte de pintos de corte, como resultado de uma osteomielite localizada entre $\mathrm{C}_{12}$ e $\mathrm{T}_{1}$, associada à presença de Aspergillus fumigatus (VEEN et al., 1999).

Apesar dos escassos estudos existentes sobre o comportamento do osso às afecções ósseas infecciosas e neoplásicas, a utilização do critério entre "lesões ósseas não-agressivas" e "lesões ósseas agressivas", caracterizando, de modo geral, processos benignos e malignos, 
respectivamente, tem sido certeiro em aves durante a avaliação radiográfica (EVANS, 1986), pelo menos na experiência do próprio autor.

Osteólise é a alteração radiográfica sobressalente em casos de infecção óssea. Reação do periósteo é pouco extensiva durante a fase aguda. Em casos de osteomielite fúngica ou tuberculose (Mycobacterium sp), entretanto, esclerose medular, como resultado da formação de granulomas, e exuberante reação do periósteo, podem ser percebidas na radiografia (MCMILLAN, 1994). Alterações secundárias da doença incluem: disseminação hematogênica a outros ossos (DOIGE; WEISBRODE, 1998), fraturas patológicas (DOIGE; WEISBRODE, 1998; WALSH, 1986; WILLIAMS, 2002) e seqüestros ósseos (DOIGE; WEISBRODE, 1998; MCMILLAN, 1994; NEWTON; ZEITLIN, 1977).

Uma ou múltiplas áreas puntiformes de osteólise, circundadas por halo de esclerose, são, também, sugestivas de infecções ósseas causadas por Mycobacterium sp (RUPLEY, 1999). Ossos longos, especialmente fêmur e tibiotarso, são os mais acometidos por infecções micobacterianas. Alterações radiográficas associadas incluem aumento de radiopacidade nodular (granulomas), em sobreposição aos campos pulmonares, silhuetas cardíaca e hepática, e sistema digestório, além de aumento de volume das silhuetas hepática, esplênica e renal (KRAUTWALD-JUNGHANNS, 1996).

Seqüestros ósseos são relativamente mais freqüentes em aves do que nos mamíferos (EVANS, 1986). A formação de seqüestração é evidente na fase crônica da doença (DOIGE; WEISBRODE, 1998; KEALY; MCALLISTER, 2000; MCMILLAN, 1994; NEWTON; ZEITLIN, 1977; TOAL, 1986), e ocorre quando, nos locais de uma fratura composta, fragmentos ósseos são contaminados e isolados de seu suprimento sangüíneo (DOIGE; WEISBRODE, 1998). O exame radiográfico mostra uma esquírola óssea, geralmente mais radiopaca que o normal, em razão do colapso do osso trabecular, e com um envoltório radiotransparente (KEALY; MCALLISTER, 2000).

Segundo Kostka e Krautwald-Junghanns (1991), o chamado "triângulo de Codman" pode ser observado nas afecções inflamatório-infecciosas. Ao contrário dos mamíferos, os autores relatam que a sua presença frequentemente condiz com osteomielite. A alteração radiográfica é caracterizada por um triângulo formado pelo levantamento do periósteo, com deposição óssea lisa entre o periósteo levantado e o osso cortical adjacente (BERRY et al., 2002). 
Os achados radiográficos iniciais podem ser inconclusivos. O aparecimento das primeiras alterações radiográficas pode levar de sete a 10 dias, após o início da infecção. Um segundo estudo radiográfico, portanto, deve ser obtido em casos duvidosos (TOAL, 1986). Procedimentos diagnósticos complementares incluem: anamnese, exame físico, hemograma, análise bioquímica, urinálise, cultura sangüínea, citologia e cultura da região acometida (BUBENIK, 2005).

\subsubsection{Degenerativas}

\subsubsection{Doença articular degenerativa (DAD)}

A artropatia degenerativa das articulações sinoviais caracteriza-se pela degeneração da cartilagem articular. A progressão da doença freqüentemente está associada à formação de fissuras na cartilagem articular, exposição do osso subcondral, formação de osteófitos periarticulares e modelamento osteocondral. Acomete uma ou mais articulações, de animais imaturos ou adultos (DOIGE; WEISBRODE, 1998).

DAD é uma condição rara encontrada em aves (ALTMAN ${ }^{20}, 1982$ apud PENCE, 1996a, p. 459). Associada à idade, artropatia dita primária, é comum em animais mais velhos, como psitacídeos (ALTMAN ${ }^{20}, 1982$ apud PENCE, 1996a, p. 459; SMITH; SMITH, 1997) e aves de bico macio, em inglês, "softbills" (ALTMAN²0, 1982 apud PENCE, 1996a, p. 459).

Várias condições de estresses aplicadas à articulação têm sido implicadas na evolução da DAD secundária (KEALY; MCALLISTER, 2000), incluindo: fraturas com envolvimento da superfície articular, luxações e subluxações (WILLIAMS, 2002), bem como infecção bacteriana, desnutrição e neoplasia (DEGERNES, 1994). Em aves com luxação coxofemoral, alterações degenerativas têm sido observadas no membro contralateral, em razão da sustentação anormal de peso (MACCOY, 1996).

As alterações ósseas podem representar achados incidentais ou serem previamente suspeitadas como resultado do aparecimento de sintomas clínicos (DOIGE; WEISBRODE,

20 ALTMAN, R. B. Disorders of the skeletal system. In: PETRAK, M . L. (Ed.). Diseases of cage and aviary birds. 2. ed. Philadelphia: Lea \& Febiger, 1982. p. 386. 
1998). As alterações radiográficas iniciais incluem efusão articular e diminuição da interlinha radiográfica. A progressão da DAD está freqüentemente associada à esclerose do osso subcondral e osteófitos periarticulares (MCMILLAN, 1994). A condição geralmente culmina com a anquilose das superfícies articulares (GYLSTORFF; GRIMM, 1987).

A presença de osteófitos periarticulares na DAD denota instabilidade articular e constitui uma das alterações radiográficas mais evidentes da doença (JOHNSTON, 2001; WILLIAMS, 2002). Nas espécies pequenas, osteófitos periarticulares e efusão articular podem passar despercebidas em razão do tamanho reduzido da articulação (WILLIAMS, 2002).

\subsubsection{Espondilose vertebral}

A formação de osteófitos ventrais nas epífises vertebrais é muito comum nas aves idosas, como periquitos e papagaios, usualmente como um achado incidental (ARNALL; KEYMER $^{21}$, 1975 apud PENCE, 1996a, p. 459-460).

Doige e Weisbrode (1998) relatam o aparecimento de espondiloses vertebrais em caninos, bovinos, suínos e eqüinos, como resultado da degeneração dos discos intervertebrais e instabilidade da articulação intervertebral decorrente. Nas aves, acredita-se que tal condição esteja relacionada à artrite vertebral (ARNALL; KEYMER ${ }^{21}, 1975$ apud PENCE, 1996a, p. 459).

\subsubsection{Deformidades ósseas}

Deformidade, do latim deformitate, sf., é uma irregularidade, desproporção ou anormalidade de conformação; defeito; má-formação (FERREIRA, 2004). Diversas causas têm sido associadas às deformidades do sistema esquelético, incluindo traumas, deficiências nutricionais, anomalias congênitas, substrato de material inapropriado e mau posicionamento embrionário (RUPLEY, 1999).

21 ARNALL, L.; KEYMER, I. F. Bird diseases. Neptune City, New Jersey: T. F. H. Publications, 1975. p. 218. 
Exemplos de deformidades ósseas são: polidactilismo, sindactilismo, asas extras, ausentes, pequenas ou anquilosadas, articulações anquilosadas, e desvios de eixo da coluna vertebral. Curvaturas anormais da coluna vertebral, incluindo cifose, lordose e escoliose, são de origem congênita, traumática ou nutricional (BENEZ, 2004). Espinha bífida, uma anomalia de desenvolvimento, foi observada em psitacídeos e galinhas-domésticas (JOINER ${ }^{22}, 1990$ apud PENCE, 1996b, p. 467; LUTZ; LEPY²3, 1958 apud PENCE, 1996b, p. 467). Ela é caracterizada por um fechamento incompleto do arco vertebral, com protrusão ou não das meninges (KEALY; MCALLISTER, 2000). Deformidades dos membros pélvicos estão entre as mais comumente encontradas (ALTMAN, 1969; RUPLEY, 1999).

Relatam-se múltiplas deformidades ósseas congênitas em uma coruja-do-mato (Strix aluco), de 45 a 50 dias de idade (BARREIRO et al., 2003). Achados de exames físico, radiográfico e de necropsia, revelaram: ausência de várias falanges em ambas as asas, deslocamento bilateral do rádio em relação ao carporradial, ausência do carpoulnar direito, carpometacarpo bilateral reduzido, e tarsometatarso esquerdo parcialmente fundido e torcido.

\subsubsection{Neoplásicas}

Neoplasias ósseas primárias não são freqüentes nas espécies aviárias (KOSTKA; KRAUTWALD-JUNGHANNS， 1991; KRAUTWALD-JUNGHANNS; HENDRICHSCHUSTER, 1996; MCMILLAN, 1994; RUPLEY, 1999). São particularmente comuns nos periquitos e, na sua maioria, são malignas como os osteossarcomas (KOSTKA; KRAUTWALD-JUNGHANNS, 1991). A maior parte das neoplasias ósseas ocorre secundariamente a neoplasias de tecidos moles, como fibrossarcomas (MCMILLAN, 1994). O desenvolvimento de metástases é raro (KOSTKA; KRAUTWALD-JUNGHANNS, 1991; MCMILLAN, 1994).

Neoplasias específicas do sistema esquelético que têm sido relatadas em aves incluem: condroma, condrossarcoma, osteoma, osteossarcoma e sarcoma de células sinoviais (REAVILL, 2004). Osteossarcoma é a neoplasia óssea mais freqüentemente relatada nos

22 Informação fornecida por Joiner, em 1990. [S. 1.].

23 LUTZ, H.; LEPY, M. Action du gaz carbonique sur le blastoderme non incube d'Oiseau. Bulletin de la Societe Zoologique de France, v. 83, p. 76-81, 1958. 
psitacídeos (HORST et al., 1996). De acordo com Rosskopf Junior e Woerpel (1991), os periquitos-australianos (Melopsittacus undulatus) apresentam uma incidência particularmente alta a diversos tipos de neoplasias.

Crânio e ossos longos estão entre as localizações mais freqüentes de neoplasias do sistema musculoesquelético (AUSTIN ${ }^{24}, 1988$ apud RICH, 1991, p. 1143). Quanto à localização nos ossos longos, neoplasias primárias são mais prevalentes nas regiões epifisárias (BAUCK, 1996; CAMPBELL, 1986), como osteossarcomas e condrossarcomas. Fibrossarcomas, como neoplasias secundárias, também têm sido encontradas próximas da articulação (BAUCK, 1996).

Frost (1961), examinou 1.000 periquitos-australianos (Melopsittacus undulatus) entre um ano e 10 meses no Hospital Veterinário de Beaumont em Londres. De um total de 199 aves com neoplasias, um osteossarcoma e um osteoma foram encontrados nos ossos longos dos membros torácicos.

Entre 196 tumores, Petrak e Gilmore (1969) listaram três osteossarcomas. As aves acometidas foram dois periquitos-australianos (Melopsittacus undulatus), um com quatro anos de idade e o outro com sete, e um canário com um ano de idade. Os locais envolvidos foram costela, rádio e ponta da asa.

Um osteossarcoma, originando-se da mandíbula esquerda, foi diagnosticado em um Tordo-americano (Turdus Migratorius), macho e adulto. O exame radiográfico revelou a presença de uma leve reação proliferativa local. À necropsia, metástases não foram evidenciadas (HARTUP; STEINBERG, 1996).

Deprimida e com incapacidade para voar, uma coruja (Strix varia), de vida livre, adulta e do sexo masculino, foi apresentada ao Hospital Veterinário da Universidade de Tennessee, nos Estados Unidos da América. Ao exame físico, uma massa de consistência sólida foi identificada na extremidade proximal do rádio esquerdo. As alterações radiográficas revelaram a presença de áreas tanto de destruição óssea como de neoformação. Um osteoma

24 AUSTIN, L. Selected noninfections conditions in handreared psittacines. In: Avian Pediatric Seminar Proceedings. Union City, California, 1988. p. 71-79. 
foi histologicamente identificado, sem quaisquer evidências de metástases (HAHN et al., 1998).

Uma arapapá (Cochlearis cochlearius panamensis), de dois anos e seis meses de idade, com claudicação de membro pélvico esquerdo, foi examinada em um parque zoológico de Nova Iorque. Aos raios-X, foram notadas uma lesão mista na extremidade proximal do tibiotarso e inúmeras formações nodulares de radiopacidade água sobrepondo-se à cavidade celomática. Nos demais ossos longos, uma radiopacidade medular heterogênea predominava. O exame radiográfico mais a biopsia e os achados de necropsia revelaram a presença de diversos nódulos metastáticos de osteossarcoma localizados em todos os ossos longos e em múltiplos tecidos moles da cavidade celomática (LIU et al., 1982).

O primeiro relato de sarcoma de células sinoviais em aves foi descrito recentemente na articulação do cotovelo de uma Cacatua galerita, de 13 anos de idade (HORST et al., 1996). Com a evolução da neoplasia, um grande potencial metastático foi desenvolvido, com comprometimento tanto de tecidos moles, tais como laringe, fígado e baço, como de outros ossos.

O estudo radiográfico é uma ferramenta valiosa no diagnóstico das neoplasias ósseas (BAUCK, 1996; BEREGI et al., 1999). As alterações radiográficas são caracterizadas por uma discreta à extensa área de osteólise, fraturas patológicas e aumento de volume de tecidos moles (KOSTKA et al., 1988). Pouca ou nenhuma reação do periósteo é vista (KOSTKA et al., 1988; RUPLEY, 1999). Neoplasias ósseas com acentuada reação do periósteo, entretanto, podem também estar presentes (MCMILLAN, 1994).

Lesões ósseas infecciosas e neoplásicas tipicamente possuem a mesma aparência radiográfica, sendo, portanto, de difícil distinção por meio dos achados radiográficos (MCMILLAN, 1994; SMITH; SMITH, 1997; WALSH, 1986). Neoplasias ósseas, além de infreqüentes, normalmente não atravessam o espaço articular (WALSH, 1986). Além das informações obtidas através do exame físico, exames laboratoriais e exame radiográfico (SCHMIDT, 1997), biopsia e cultura devem ser realizadas a fim de estabelecer um diagnóstico preciso (SCHMIDT, 1997; SMITH; SMITH, 1997; WALSH, 1986). As limitações da biopsia, segundo Coles (1996), incluem a experiência do profissional para a execução da técnica e o tamanho da ave. 
Foram utilizados exames radiográficos de aves portadoras de alterações esqueléticas, de espécies e idades variadas, que, após avaliação clínica realizada no Serviço de Ambulatório de Aves do HOVET-FMVZ-USP, Campus de São Paulo, foram encaminhadas ao Serviço de Diagnóstico por Imagem do referido Hospital, no período compreendido entre janeiro de 2000 a dezembro de 2004. A variável sexo não foi considerada nesse estudo (veja discussão).

Os exames foram obtidos através de levantamento realizado nos arquivos da Disciplina de Diagnóstico por Imagem (VCI-513), do Departamento de Cirurgia da Faculdade de Medicina Veterinária e Zootecnia da Universidade de São Paulo.

O estudo foi aprovado pela Comissão de Bioética da FMVZ-USP, protocolo $\mathrm{n}^{\circ}$ 753/2005, em 20/09/2005.

\subsection{EXAME RADIOGRÁFICO}

\subsubsection{Equipamentos radiográficos}

Os exames radiográficos foram realizados em aparelhos de radiodiagnóstico convencionais, marca CGR, de $600 \mathrm{mAs}$ e $130 \mathrm{kV}$, modelo Chenonceaux, e marca RAY TEC, de $500 \mathrm{~mA}$ e $125 \mathrm{kV}$, modelo RT - 500/125, equipados com mesa radiográfica com grade e sistema "Potter-Bucky" recipromático tipo "Par Speed" e ampola de raios-X de ânodo giratório.

Os chassis metálicos utilizados, nas dimensões requeridas de acordo com o tamanho do animal, portavam telas intensificadoras ${ }^{1}$ e filmes radiográficos ${ }^{2}$. Eles foram posicionados diretamente sobre a mesa radiográfica, não requerendo o uso de grade antidifusora.

Os filmes radiográficos foram revelados e fixados em Processadora Automática ${ }^{3}$, após identificação luminosa apropriada.

Todos os exames radiográficos foram realizados respeitando-se as normas de proteção radiológica.

\footnotetext{
Kodak Lanex Regular Screens, Eastman Kodak Company.

T-MAT G/RA e MXG/Plus, Kodak Brasileira Com. Ind. Ltda.

RP X-OMAT Processor, Eastman Kodak Company.
} 


\subsubsection{Métodos de contenção}

Os dois principais métodos de contenção utilizados foram manual, com o auxílio dos proprietários, e física, com o auxílio de alguns artefatos, tais como luvas plumbíferas, fitas adesivas e sacos de areia. A contenção química, por meio de sedativos e/ou anestésicos, raramente foi utilizada.

\subsubsection{Posicionamentos radiográficos}

Os animais foram posicionados diretamente sobre o chassi metálico. Os posicionamentos radiográficos utilizados foram dependentes da região a ser radiografada. De modo geral, foram realizadas radiografias de corpo inteiro, variando de decúbito lateral direito ou esquerdo, no caso das projeções laterolaterais, e em decúbito dorsal, no caso da projeção ventrodorsal.

\subsubsection{Técnicas radiográficas}

As técnicas radiográficas utilizadas basearam-se no método que relaciona a quilovoltagem e a miliamperagem-segundo com a espessura da região a ser radiografada.

\subsection{ANÁLISE DAS RADIOGRAFIAS}

Os exames radiográficos foram individualmente analisados, descrevendo-se todas as alterações radiográficas encontradas nas diversas afecções do sistema esquelético. As informações clínicas contidas nos prontuários desses animais, assim como as alterações radiográficas observadas na cavidade celomática, também foram analisadas. 


\subsection{ANÁLISE ESTATÍSTICA}

Os resultados obtidos foram expressos mediante a distribuição numérica e percentual e apresentados sob a forma de tabelas e quadros.

Em situações consideradas pertinentes, utilizou-se o Teste de Igualdade de Duas Proporções, ao nível de $5 \%$ de significância $(\mathrm{p}<0,05)$, com a finalidade de comparar se a proporção de respostas entre duas determinadas variáveis e/ou seus níveis é estatisticamente significante. Existindo tendência à significância $(0,05<\mathrm{p}<0,10)$, os valores de $\mathrm{p}$ foram considerados significantes.

\subsection{DOCUMENTAÇÃO FOTOGRÁFICA}

Algumas radiografias foram selecionadas para a documentação fotográfica, com o objetivo de ilustrar a ampla variedade de alterações radiográficas encontradas no sistema esquelético de aves. 


\section{RESULTADOS}

Foram analisados exames radiográficos de 201 aves nacionais e exóticas. A análise das alterações radiográficas, muitas delas observadas conjuntamente, permitiu o diagnóstico das seguintes afecções ósseas e/ou articulares:

- traumáticas;

- doença ósseo-metabólica;

- hiperostose poliostótica;

- inflamatório-infecciosas;

- degenerativas.

As alterações radiográficas, além de limitadas, podem ser comuns a várias afecções. Assim, quatro categorias adicionais de resultados foram elaboradas:

- osteopenia localizada;

- deformidades ósseas;

- alterações ósseas agressivas;

- alterações inespecíficas.

A distribuição dos 201 animais, segundo as ordens e alterações radiográficas observadas, está demonstrada nas tabelas 1 a 3 . 
Tabela 1 - Distribuição numérica (N) e percentual (\%) de 201 aves, segundo a taxonomia. HOVET-FMVZ-USP, 2000-2004

\begin{tabular}{|c|c|c|c|c|c|}
\hline Ordem & Família & Nome científico & Nome comum & $\mathbf{N}$ & $\%$ \\
\hline \multirow{2}{*}{ ANSERIFORMES } & \multirow{2}{*}{ Anatidae } & Anser cygnoides & Ganso chinês & 1 & 0,50 \\
\hline & & (não consta) & Ganso & 3 & 1,49 \\
\hline \multirow{3}{*}{ COLUMBIFORMES } & \multirow{3}{*}{ Columbidae } & Columba livia domestica & Pombo-doméstico & 8 & 3,98 \\
\hline & & Columbina talpacoti & Rolinha & 3 & 1,49 \\
\hline & & Goura cristata & Pomba-goura & 1 & 0,50 \\
\hline FALCONIFORMES & Falconidae & Polyborus plancus & Caracará & 1 & 0,50 \\
\hline \multirow{4}{*}{ GALLIFORMES } & \multirow{4}{*}{ Phasianidae } & Gallus gallus domesticus & Galinha-doméstica & 5 & 2,49 \\
\hline & & Numida meleagris & Galinha-da-índia & 1 & 0,50 \\
\hline & & Pavo cristatus & Pavão-ombros-negros & 1 & 0,50 \\
\hline & & Phasianus colchicus & Faisão & 1 & 0,50 \\
\hline \multirow{13}{*}{ GRUIFORMES } & Cariamidae & Cariama cristata & Siriema & 1 & 0,50 \\
\hline & Gruidae & Balearica pavonina & Grou coroado & 2 & 1,00 \\
\hline & \multirow{3}{*}{ Emberizidae } & Saltator similis & Pixarro & 1 & 0,50 \\
\hline & & Sicalis flaveola & Canário-da-terra & 2 & 1,00 \\
\hline & & (não consta) & Sanhaço & 1 & 0,50 \\
\hline & Estrildidae & Taeniopygia guttata & Diamante-mandarim & 2 & 1,00 \\
\hline & \multirow{2}{*}{ Fringillidae } & \multirow{2}{*}{ Serinus canarius } & Canário-belga & 2 & 1,00 \\
\hline & & & Canário-do-reino & 4 & 1,99 \\
\hline & \multirow{2}{*}{ Icteridae } & Gnorimopsar chopi & Pássaro-preto & 3 & 1,49 \\
\hline & & Icterus jamacaii & Corrupião & 1 & 0,50 \\
\hline & Sturnidae & (não consta) & Mainá & 3 & 1,49 \\
\hline & Tyrannidae & (não consta) & Bentevi & 2 & 1,00 \\
\hline & (não consta) & (não consta) & Canário & 12 & 5,97 \\
\hline PHOENICOPTERIFORMES & Phoenicopteridae & Phoenicopterus ruber & Flamingo-comum & 1 & 0,50 \\
\hline \multirow{2}{*}{ PICIFORMES } & \multirow{2}{*}{ Ramphastidae } & Ramphastos toco & Tucanuçu & 4 & 1,99 \\
\hline & & (não consta) & Tucano & 2 & 1,00 \\
\hline \multirow{25}{*}{ PSITTACIFORMES } & \multirow{3}{*}{ Cacatuidae } & Cacatua alba & Cacatua-branca & 1 & 0,50 \\
\hline & & Cacatua galerita & Cacatua-de-crista-amarela & 1 & 0,50 \\
\hline & & Nymphicus hollandicus & Calopsita & 6 & 2,99 \\
\hline & Loriidae & Trichoglossus haematodus & Lóris arco-íris & 1 & 0,50 \\
\hline & \multirow{21}{*}{ Psittacidae } & Agapornis sp & Agapornis & 7 & 3,48 \\
\hline & & Amazona aestiva & Papagaio-verdadeiro & 45 & 22,39 \\
\hline & & Amazona aestiva xanthopteryx & Papagaio-verdadeiro-do-sul & 3 & 1,49 \\
\hline & & Amazona amazonica & Papagaio-do-mangue & 6 & 2,99 \\
\hline & & Amazona rhodocorytha & Chauá & 1 & 0,50 \\
\hline & & Anodorhynchus sp & Arara-azul & 1 & 0,50 \\
\hline & & Ara ararauna & Arara-canindé & 6 & 2,99 \\
\hline & & Ara chloroptera & Arara-vermelha & 1 & 0,50 \\
\hline & & Aratinga aurea & Jandaia-coquinho & 1 & 0,50 \\
\hline & & Aratinga leucophthalmus & Periquitão-maracanã & 3 & 1,49 \\
\hline & & Brotogeris $\mathrm{sp}$ & Periquito-brotogeris & 1 & 0,50 \\
\hline & & Brotogeris tirica & Periquito-rico & 1 & 0,50 \\
\hline & & Brotogeris viridissimus & Periquito-verde & 4 & 1,99 \\
\hline & & Melopsittacus undulatus & Periquito-australiano & 16 & 7,96 \\
\hline & & Pionus maximiliani & Maritaca & 2 & 1,00 \\
\hline & & Platycercus elegans & Rosela-elegante & 1 & 0,50 \\
\hline & & Psittacula alexandri & Moustache & 1 & 0,50 \\
\hline & & Psittacula krameri & Periquito-de-colar & 1 & 0,50 \\
\hline & & Psittacus erithacus & Papagaio-africano & 1 & 0,50 \\
\hline & & (não consta) & Papagaio & 18 & 8,96 \\
\hline & & (não consta) & Periquito & 1 & 0,50 \\
\hline STRIGIFORMES & (não consta) & (não consta) & Coruja & 3 & 1,49 \\
\hline Total & & & & 201 & 100,00 \\
\hline
\end{tabular}


Tabela 2 - Distribuição numérica $(\mathrm{N})$ e percentual (\%) de 201 aves analisadas, segundo as ordens. HOVET-FMVZ-USP, 2000-2004

\begin{tabular}{llcc}
\hline Ordem & $\mathbf{N}$ & $\mathbf{\%}$ \\
\hline 1 & PSITTACIFORMES & 130 & 64,68 \\
2 & PASSERIFORMES & 33 & 16,42 \\
3 & COLUMBIFORMES & 12 & 5,97 \\
4 & GALLIFORMES & 8 & 3,98 \\
5 & PICIFORMES & 6 & 2,99 \\
6 & ANSERIFORMES & 4 & 1,99 \\
7 & GRUIFORMES & 3 & 1,49 \\
8 & STRIGIFORMES & 3 & 1,49 \\
9 & FALCONIFORMES & 1 & 0,50 \\
10 & PHOENICOPTERIFORMES & 1 & 0,50 \\
\hline Total & 201 & 100,00 \\
\hline
\end{tabular}

Tabela 3 - Distribuição numérica $(\mathrm{N})$ e percentual (\%) de 201 aves analisadas, segundo os resultados apresentados. HOVET-FMVZ-USP, 2000-2004

\begin{tabular}{llcc}
\hline Resultado & $\mathbf{N}$ & $\mathbf{\%}$ \\
\hline 1 & Traumáticas & 94 & 46,77 \\
2 & Doença ósseo-metabólica & 48 & 23,88 \\
3 & Hiperostose poliostótica & 34 & 16,92 \\
4 & Inflamatório-infecciosas & 27 & 13,43 \\
5 & Degenerativas & 15 & 7,46 \\
6 & Osteopenia localizada & 13 & 6,47 \\
7 & Deformidades ósseas & 9 & 4,48 \\
8 & Alterações ósseas agressivas & 4 & 1,99 \\
9 & Alterações inespecíficas & 2 & 1,00 \\
\hline Total & 201 & 100,00 \\
\hline
\end{tabular}




\subsection{AFECÇÕES TRAUMÁTICAS}

A distribuição dos 94 animais com afecções traumáticas, segundo as espécies, idades, localizações e alterações radiográficas, está demonstrada nas tabelas 4 a 11 .

Tabela 4 - Distribuição numérica (N) e percentual (\%) de 94 aves com afecções traumáticas, segundo as espécies. HOVET-FMVZ-USP, 2000-2004

\begin{tabular}{|c|c|c|c|}
\hline Ordem & Nome comum & $\mathbf{N}$ & $\%$ \\
\hline ANSERIFORMES & Ganso & 1 & 1,06 \\
\hline \multirow{2}{*}{ COLUMBIFORMES } & Pombo-doméstico & 6 & 6,38 \\
\hline & Rolinha & 1 & 1,06 \\
\hline FALCONIFORMES & Caracará & 1 & 1,06 \\
\hline \multirow{2}{*}{ GRUIFORMES } & Grou coroado & 2 & 2,13 \\
\hline & Siriema & 1 & 1,06 \\
\hline \multirow{6}{*}{ PASSERIFORMES } & Bentevi & 1 & 1,06 \\
\hline & Canário & 1 & 1,06 \\
\hline & Canário-da-terra & 2 & 2,13 \\
\hline & Canário-do-reino & 3 & 3,19 \\
\hline & Corrupião & 1 & 1,06 \\
\hline & Pássaro-preto & 3 & 3,19 \\
\hline PHOENICOPTERIFORMES & Flamingo-comum & 1 & 1,06 \\
\hline \multirow{2}{*}{ PICIFORMES } & Tucano & 2 & 2,13 \\
\hline & Tucanuçu & 3 & 3,19 \\
\hline \multirow{15}{*}{ PSITTACIFORMES } & Agapornis & 2 & 2,13 \\
\hline & Arara-azul & 1 & 1,06 \\
\hline & Arara-canindé & 6 & 6,38 \\
\hline & Cacatua-branca & 1 & 1,06 \\
\hline & Calopsita & 3 & 3,19 \\
\hline & Jandaia-coquinho & 1 & 1,06 \\
\hline & Lóris arco-íris & 1 & 1,06 \\
\hline & Maritaca & 2 & 2,13 \\
\hline & Papagaio & 11 & 11,70 \\
\hline & Papagaio-do-mangue & 3 & 3,19 \\
\hline & Papagaio-verdadeiro & 26 & 27,66 \\
\hline & Periquitão-maracanã & 2 & 2,13 \\
\hline & Periquito-australiano & 1 & 1,06 \\
\hline & Periquito-brotogeris & 1 & 1,06 \\
\hline & Periquito-verde & 3 & 3,19 \\
\hline STRIGIFORMES & Coruja & 1 & 1,06 \\
\hline Total & & 94 & 100,00 \\
\hline
\end{tabular}


Tabela 5 - Distribuição numérica (N) e percentual (\%) de 94 aves com afecções traumáticas, segundo as ordens. HOVETFMVZ-USP, 2000-2004

\begin{tabular}{lcc}
\hline Ordem & N & \% \\
\hline PSITTACIFORMES & 64 & 68,09 \\
PASSERIFORMES & 11 & 11,70 \\
COLUMBIFORMES & 7 & 7,45 \\
PICIFORMES & 5 & 5,32 \\
GRUIFORMES & 3 & 3,19 \\
ANSERIFORMES & 1 & 1,06 \\
FALCONIFORMES & 1 & 1,06 \\
PHOENICOPTERIFORMES & 1 & 1,06 \\
STRIGIFORMES & 1 & 1,06 \\
\hline Total & 94 & 100,00 \\
\hline
\end{tabular}

Tabela 6 - Distribuição numérica $(\mathrm{N})$ e percentual $(\%)$ de 94 aves com afecções traumáticas, segundo as idades. HOVET-FMVZ-USP, 2000-2004

\begin{tabular}{ccc}
\hline Idade (anos) & $\mathbf{N}$ & $\mathbf{\%}$ \\
\hline$\leq 1$ & 29 & 30,85 \\
$2-3$ & 17 & 18,09 \\
$4-5$ & 8 & 8,51 \\
$6-7$ & 6 & 6,38 \\
$8-9$ & 1 & 1,06 \\
$\geq 10$ & 14 & 14,89 \\
Não consta & 19 & 20,21 \\
\hline Total & 94 & 100,00 \\
\hline
\end{tabular}

Tabela 7 - Distribuição numérica $(\mathrm{N})$ e percentual (\%) de 94 aves com afecções traumáticas, segundo o tipo de trauma. HOVET-FMVZ-USP, 2000-2004

\begin{tabular}{lcccc}
\hline \multirow{2}{*}{ Tipo de trauma } & \multicolumn{2}{c}{ Aves } & \multicolumn{2}{c}{ Ocorrências } \\
\cline { 2 - 5 } & $\mathbf{N}$ & $\mathbf{\%}$ & $\mathbf{N}$ & $\mathbf{\%}$ \\
\hline Fraturas & 70 & 74,47 & 86 & 68,80 \\
Luxações & 24 & 25,53 & 26 & 20,80 \\
Amputações ósseas & 10 & 10,64 & 13 & 10,40 \\
\hline Total & 94 & 100,00 & 125 & 100,00 \\
\hline
\end{tabular}

O trauma mais prevalente é a fratura, com 74,47\% das aves acometidas, proporção estatisticamente significativa. Lembramos que os percentuais foram calculados para o total de aves com afecções traumáticas, ou seja, 94. Assim, a soma dos percentuais passou de $100 \%$, pois uma ave pode ter mais do que um tipo de trauma. 
Tabela $8-$ Distribuição numérica $(\mathrm{N})$ e percentual $(\%)$ de 86 fraturas, segundo as localizações. HOVET-FMVZUSP, 2000-2004

\begin{tabular}{lcc}
\hline Localização & N & \% \\
\hline Tibiotarso & 32 & 37,21 \\
Úmero & 16 & 18,60 \\
Rádio & 9 & 10,47 \\
Ulna & 8 & 9,30 \\
Fêmur & 7 & 8,14 \\
Tarsometatarso & 5 & 5,81 \\
Escápula & 3 & 3,49 \\
Sinsacro & 2 & 2,33 \\
Coracóide & 1 & 1,16 \\
Dígito & 1 & 1,16 \\
Fíbula & 1 & 1,16 \\
Metacarpo & 1 & 1,16 \\
\hline Total & 86 & 100,00 \\
\hline
\end{tabular}

Tabela 9 - Distribuição numérica $(\mathrm{N})$ e percentual $(\%)$ de 86 fraturas, segundo as localizações. HOVETFMVZ-USP, 2000-2004

\begin{tabular}{lcc}
\hline Localização & N & \% \\
\hline Membros pélvicos & 45 & 52,33 \\
Membros torácicos & 35 & 40,70 \\
Cíngulo torácico & 4 & 4,65 \\
Coluna vertebral & 2 & 2,33 \\
\hline Total & 86 & 100,00 \\
\hline
\end{tabular}

Embora exista um maior percentual de fraturas localizadas nos membros pélvicos (n $=45,52,33 \%$ ), não houve diferença estatisticamente significativa quando comparada com o percentual de fraturas localizadas nos membros torácicos $(n=35,40,70 \%)$.

Fraturas de antebraço foram identificadas em 12 aves, sendo cinco $(41,67 \%)$ com fratura tanto de rádio quanto de ulna e sete $(58,33 \%)$ com fratura somente de um dos ossos, não havendo diferença estatisticamente significativa. 
Tabela 10 - Distribuição numérica (N) e percentual (\%) de 26 luxações, segundo as localizações. HOVETFMVZ-USP, 2000-2004

\begin{tabular}{lcc}
\hline Localização & N & \% \\
\hline Fêmorotibiotársica & 12 & 46,15 \\
Coxofemoral & 4 & 15,38 \\
Úmero-rádio-ulnar & 4 & 15,38 \\
Intertársica & 2 & 7,69 \\
Carporradial & 1 & 3,85 \\
Coracóideoesternal & 1 & 3,85 \\
Interfalangeana & 1 & 3,85 \\
Sacrococcígea & 1 & 3,85 \\
\hline Total & 26 & 100,00 \\
\hline
\end{tabular}

Tabela 11 - Distribuição numérica (N) e percentual (\%) de 13 amputações ósseas, segundo as localizações. HOVET-FMVZ-USP, 2000-2004

\begin{tabular}{lcc}
\hline Localização & N & \% \\
\hline Extremidades distais de membros & 10 & 76,92 \\
Bico & 2 & 15,38 \\
Osso longo & 1 & 7,69 \\
\hline Total & 13 & 100,00 \\
\hline
\end{tabular}




\subsection{DOENÇA ÓSSEO-METABÓLICA (DOM)}

As tabelas 12 a 15 elucidam os resultados encontrados para DOM.

Tabela 12 - Distribuição numérica $(\mathrm{N})$ e percentual (\%) de 48 aves com doença ósseo-metabólica, segundo as espécies. HOVET-FMVZ-USP, 2000-2004

\begin{tabular}{llcc}
\hline Ordem & Nome comum & $\mathbf{N}$ & $\mathbf{\%}$ \\
\hline ANSERIFORMES & Ganso & 1 & 2,08 \\
\hline \multirow{2}{*}{ COLUMBIFORMES } & Pombo-doméstico & 2 & 4,17 \\
\cline { 2 - 4 } & Rolinha & 1 & 2,08 \\
\hline GALLIFORMES & Galinha-doméstica & 3 & 6,25 \\
\hline \multirow{4}{*}{ PASSERIFORMES } & Bentevi & 1 & 2,08 \\
\cline { 2 - 4 } & Canário & 4 & 8,33 \\
\cline { 2 - 4 } & Canário-belga & 1 & 2,08 \\
\cline { 2 - 4 } & Canário-da-terra & 1 & 2,08 \\
\cline { 2 - 4 } & Pixarro & 1 & 2,08 \\
\cline { 2 - 4 } & Sanhaço & 1 & 2,08 \\
\hline \multirow{5}{*}{ PSITTACIFORMES } & Calopsita & 3 & 6,25 \\
\cline { 2 - 4 } & Moustache & 1 & 2,08 \\
\cline { 2 - 4 } & Papagaio & 4 & 8,33 \\
\cline { 2 - 4 } & Papagaio-africano & 1 & 2,08 \\
\cline { 2 - 4 } & Papagaio-verdadeiro & 13 & 27,08 \\
\cline { 2 - 4 } & Periquito & 1 & 2,08 \\
\cline { 2 - 4 } & Periquito-australiano & 6 & 12,50 \\
\cline { 2 - 4 } & Periquito-rico & 1 & 2,08 \\
\hline STRIGIFORMES & Coruja & 4,17 \\
\hline Total & & 100,00 \\
\hline
\end{tabular}

Tabela 13 - Distribuição numérica $(\mathrm{N})$ e percentual $(\%)$ de 48 aves com doença ósseometabólica, segundo as idades. HOVET-FMVZ-USP, 20002004

\begin{tabular}{ccc}
\hline Idade (anos) & $\mathbf{N}$ & $\mathbf{\%}$ \\
\hline$\leq 1$ & 30 & 62,50 \\
$2-3$ & 2 & 4,17 \\
$4-5$ & 4 & 8,33 \\
$6-7$ & 2 & 4,17 \\
$8-9$ & 2 & 4,17 \\
$\geq 10$ & 2 & 4,17 \\
Não consta & 6 & 12,50 \\
\hline Total & 48 & 100,00 \\
\hline
\end{tabular}


Tabela 14 - Distribuição numérica (N) e percentual (\%) de 48 aves com doença ósseo-metabólica, segundo as alterações radiográficas. HOVET-FMVZ-USP, 2000-2004

\begin{tabular}{lcc}
\hline Alteração radiográfica & $\mathbf{N}$ & $\mathbf{\%}$ \\
\hline Adelgaçamento de corticais ósseos & 45 & 93,75 \\
Osteopenia generalizada & 45 & 93,75 \\
Fraturas & 30 & 62,50 \\
Deformidades angulares de membros & 12 & 25,00 \\
Deformidades angulares de coluna vertebral & 6 & 12,50 \\
Deformidades angulares de costelas & 5 & 10,42 \\
Radiopacidade óssea generalizada normal & 3 & 6,25 \\
Deformidades angulares de cíngulo pélvico & 2 & 4,17 \\
Luxações & 2 & 4,17 \\
Alargamento dos discos epifisários e das extremidades articulares & 1 & 2,08 \\
\hline Total & 48 & 100,00 \\
\hline
\end{tabular}

\begin{tabular}{lcc} 
Tabela 15 & - & \multicolumn{2}{c}{ Distribuição } \\
numérica $(\mathrm{N})$ & e percentual $(\%)$ \\
de 71 fraturas & \multicolumn{2}{c}{ patológicas, } \\
segundo as & \multicolumn{2}{c}{ localizações. } \\
HOVET-FMVZ-USP, & $2000-$ \\
2004 & & \\
\hline Localização & N & \% \\
\hline Tibiotarso & 29 & 40,85 \\
Fêmur & 12 & 16,90 \\
Úmero & 12 & 16,90 \\
Fíbula & 5 & 7,04 \\
Ulna & 4 & 5,63 \\
Coracóide & 3 & 4,23 \\
Escápula & 2 & 2,82 \\
Clavícula & 1 & 1,41 \\
Rádio & 1 & 1,41 \\
Sinsacro & 1 & 1,41 \\
Tarsometatarso & 1 & 1,41 \\
\hline Total & 71 & 100,00 \\
\hline
\end{tabular}

As duas luxações identificadas foram observadas nas articulações intertársicas. 


\subsection{HIPEROSTOSE POLIOSTÓTICA}

Tabela 16 - Distribuição numérica (N) e percentual (\%) de 34 aves com hiperostose poliostótica, segundo as espécies. HOVET-FMVZ-USP, 2000-2004

\begin{tabular}{lllc}
\hline Ordem & Nome comum & $\mathbf{N}$ & $\mathbf{\%}$ \\
\hline COLUMBIFORMES & Pombo-doméstico & 3 & 8,82 \\
\hline \multirow{2}{*}{ GALLIFORMES } & Galinha-da-índia & 1 & 2,94 \\
\cline { 2 - 4 } & Galinha-doméstica & 1 & 2,94 \\
\hline \multirow{4}{*}{ PASSERIFORMES } & Canário & 7 & 20,59 \\
\cline { 2 - 4 } & Canário-belga & 1 & 2,94 \\
\cline { 2 - 4 } & Canário-do-reino & 1 & 2,94 \\
\cline { 2 - 4 } & Diamante-mandarim & 2 & 5,88 \\
\hline \multirow{4}{*}{ PSITTACIFORMES } & Agapornis & 1 & 2,94 \\
\cline { 2 - 4 } & Papagaio & 1 & 2,94 \\
\cline { 2 - 4 } & Papagaio-do-mangue & 3 & 8,82 \\
\cline { 2 - 4 } & Papagaio-verdadeiro & 3 & 8,82 \\
\cline { 2 - 4 } & Periquito-australiano & 9 & 26,47 \\
\cline { 2 - 4 } & Periquito-de-colar & 1 & 2,94 \\
\hline Total & & 34 & 100,00 \\
\hline
\end{tabular}

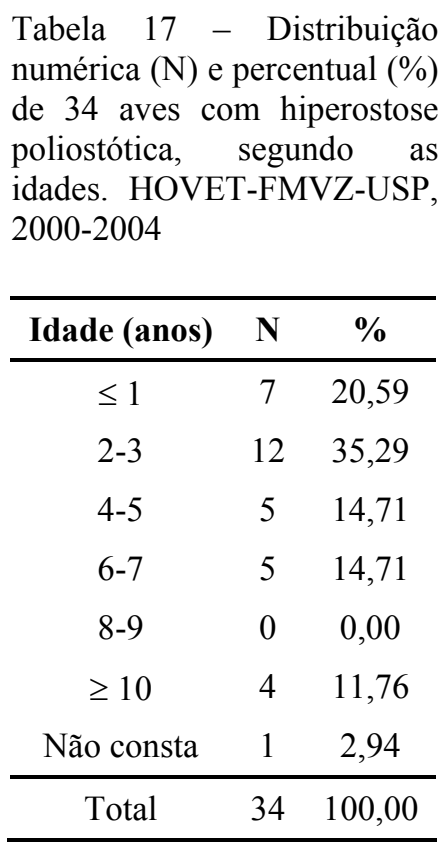

A faixa etária com maior prevalência dos dados é a de 2-3 anos (35,29\%), e, segundo o quadro de p-valores, somente não possui diferença estatisticamente significante em relação aos animais com idade menor ou igual a um ano $(20,59 \%)(p=0,177)$. 


\begin{tabular}{|c|c|c|c|c|c|c|c|c|c|c|c|c|c|c|c|c|c|}
\hline 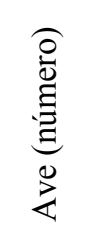 & 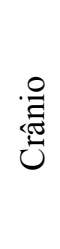 & 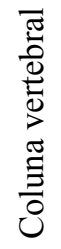 & $\frac{\tilde{a}}{\tilde{\theta}}$ & 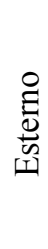 & 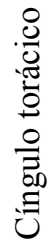 & 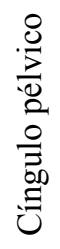 & 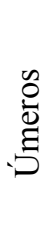 & 窇 & $\stackrel{\mathscr{E}}{\Xi}$ & 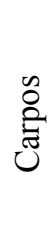 & 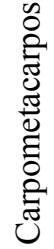 & $\frac{\mathscr{D}_{0}^{\circ}}{.00}$ & 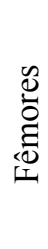 & 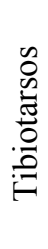 & 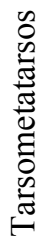 & $\begin{array}{l}\stackrel{0}{0} \\
.000 \\
\stackrel{0}{0}\end{array}$ & 坖 \\
\hline 1 & & +4 & 4 & & + & + & & & & & & & + & 4 & & & 6 \\
\hline 2 & & 4 & & & & & + & + & 4 & & & & 4 & 4 & & & 6 \\
\hline 3 & & & & & & & & 4 & 4 & & & & & & & & 2 \\
\hline 4 & & + & 4 & & 4 & + & 4 & 4 & 4 & & & & 4 & + & 4 & & 10 \\
\hline 5 & 4 & + & 4 & +4 & + & + & + & + & 4 & 4 & 4 & + & 4 & 4 & & & 14 \\
\hline 6 & & 4 & & & + & & + & + & 4 & & & & 4 & 4 & 4 & & 8 \\
\hline 7 & & & & & + & & + & + & 4 & & & & + & + & & & 6 \\
\hline 8 & & + & 4 & & + & + & + & + & 4 & & & & 4 & 4 & + & & 10 \\
\hline 9 & & & & & & & & + & + & & & & + & + & & & 4 \\
\hline 10 & & + & & & + & & 4 & & 4 & & + & & 4 & 4 & & & 7 \\
\hline 11 & & & & & & & & + & 4 & & & & & & & & 2 \\
\hline 12 & & & & & & & & & & & & & 4 & 4 & & & 2 \\
\hline 13 & + & + & 4 & + & + & & + & + & 4 & 4 & 4 & + & + & + & +4 & & 14 \\
\hline 14 & & + & & & + & & + & + & 4 & & & & 4 & + & & & 7 \\
\hline 15 & & + & & & + & & + & + & 4 & & & & 4 & 4 & & & 7 \\
\hline 16 & & + & & & & & & + & 4 & 4 & + & + & 4 & 4 & & & 8 \\
\hline 17 & & & & & & & & & & & & & + & & & & 1 \\
\hline 18 & & & & & & & & & & & & & + & 4 & + & & 3 \\
\hline 19 & & + & & & & + & & & & & & & + & + & + & + & 6 \\
\hline 20 & & + & & & + & & + & + & 4 & 4 & + & + & + & + & + & + & 12 \\
\hline 21 & 4 & + & & & + & + & + & + & 4 & + & + & + & + & + & + & 4 & 14 \\
\hline 22 & 4 & 4 & & & & & 4 & 4 & 4 & 4 & 4 & 4 & 4 & 4 & 4 & 4 & 12 \\
\hline 23 & & & & & & & & & + & & + & & + & 4 & & & 4 \\
\hline 24 & + & 4 & + & + & + & + & 4 & + & 4 & 4 & + & + & + & + & & & 14 \\
\hline 25 & & & & & & & & & & & & & & 4 & & & 1 \\
\hline 26 & + & + & 4 & + & +4 & + & + & + & 4 & 4 & + & + & + & + & & & 14 \\
\hline 27 & & & & & & & & & & & & & + & + & & & 2 \\
\hline 28 & & & & & & & + & + & 4 & & + & & + & + & & & 6 \\
\hline 29 & & +4 & & & + & & + & + & 4 & 4 & + & + & + & 4 & + & + & 12 \\
\hline 30 & + & + & & & + & & + & + & + & + & + & + & + & 4 & + & + & 13 \\
\hline 31 & 4 & 4 & 4 & & 4 & + & 4 & 4 & 4 & 4 & + & 4 & 4 & 4 & & & 13 \\
\hline 32 & & & & & & & & & & & & & 4 & 4 & & & 2 \\
\hline 33 & 4 & 4 & & & + & & + & + & 4 & & & & + & + & + & + & 10 \\
\hline 34 & + & + & 4 & & + & + & + & + & 4 & 4 & + & + & 4 & 4 & & & 13 \\
\hline Total & 10 & 22 & 9 & 4 & 19 & 10 & 21 & 24 & 26 & 12 & 15 & 12 & 31 & 31 & 12 & 7 & \\
\hline
\end{tabular}

Quadro 1 - Sítios de hiperostose poliostótica identificados em 34 aves. HOVET-FMVZ-USP, 2000-2004 
Tabela 18 - Distribuição numérica $(\mathrm{N})$ e percentual (\%) de 34 aves com hiperostose poliostótica, segundo as localizações. HOVETFMVZ-USP, 2000-2004

\begin{tabular}{lcc|lcc}
\hline Localização & $\mathbf{N}$ & $\mathbf{\%}$ & Localização & $\mathbf{N}$ & $\mathbf{\%}$ \\
\hline Fêmores & 31 & 91,18 & Carpos & 12 & 35,29 \\
Tibiotarsos & 31 & 91,18 & Falanges torácicas & 12 & 35,29 \\
lnas & 26 & 76,47 & Tarsometatarsos & 12 & 35,29 \\
Rádios & 24 & 70,59 & Cíngulo pélvico & 10 & 29,41 \\
Coluna vertebral & 22 & 64,71 & Crânio & 10 & 29,41 \\
Úmeros & 21 & 61,76 & Costelas & 9 & 26,47 \\
Cíngulo torácico & 19 & 55,88 & Falanges pélvicas & 7 & 20,59 \\
Carpometacarpos & 15 & 44,12 & Esterno & 4 & 11,76 \\
\hline Total & 34 & 100,00 & Total & 34 & 100,00 \\
\hline
\end{tabular}

Vinte aves (58,82\%) exibiram padrão heterogêneo de esclerose medular e 14 aves (41,18\%), padrão homogêneo. Embora exista um percentual maior de esclerose medular heterogênea em relação ao percentual de esclerose medular homogênea, essa diferença não foi estatisticamente significante $(\mathrm{p}=0,146)$. 


\subsection{AFECÇÕES INFLAMATÓRIO-INFECCIOSAS}

Os resultados referentes aos animais com afecções inflamatório-infecciosas encontram-se nas tabelas 19 a 25.

Tabela 19 - Distribuição numérica (N) e percentual (\%) de 20 aves com osteomielite, segundo as espécies. HOVET-FMVZUSP, 2000-2004

\begin{tabular}{llcc}
\hline Ordem & Nome comum & N & $\mathbf{\%}$ \\
\hline COLUMBIFORMES & Rolinha & 1 & 5 \\
\hline FALCONIFORMES & Caracará & 1 & 5 \\
\hline PASSERIFORMES & Canário & 1 & 5 \\
\hline PICIFORMES & Tucanuçu & 1 & 5 \\
\hline \multirow{4}{*}{ PSITTACIFORMES } & Agapornis & 2 & 10 \\
\cline { 2 - 4 } & Cacatua-de-crista-amarela & 1 & 5 \\
\cline { 2 - 4 } & Chauá & 1 & 5 \\
\cline { 2 - 4 } & Papagaio & 3 & 15 \\
\cline { 2 - 4 } & Papagaio-verdadeiro & 5 & 25 \\
\cline { 2 - 4 } & Papagaio-verdadeiro-do-sul & 2 & 10 \\
\cline { 2 - 4 } & Periquito & 1 & 5 \\
\cline { 2 - 4 } & Periquito-verde & 1 & 5 \\
\hline Total & & 20 & 100 \\
\hline
\end{tabular}

Tabela 20 - Distribuição numérica $(\mathrm{N})$ e percentual $(\%)$ de 20 aves com osteomielite, segundo as idades. HOVETFMVZ-USP, 2000-2004

\begin{tabular}{ccc}
\hline Idade (anos) & $\mathbf{N}$ & $\mathbf{\%}$ \\
\hline$\leq 1$ & 2 & 10,00 \\
$2-3$ & 1 & 5,00 \\
$4-5$ & 1 & 5,00 \\
$6-7$ & 2 & 10,00 \\
$8-9$ & 1 & 5,00 \\
$\geq 10$ & 6 & 30,00 \\
Não consta & 7 & 35,00 \\
\hline Total & 20 & 100,00 \\
\hline
\end{tabular}

A freqüência observada para os animais com idade maior ou igual a 10 anos, quando comparada com as demais faixas etárias, não mostrou diferença estatisticamente significante em relação aos animais com idade menor ou igual a um ano e entre seis e sete anos $(\mathrm{p}=$ $0,114)$.

Das 20 aves com osteomielite, três $(15,00 \%)$ apresentaram alterações ósseas em mais de uma localização. O úmero foi a localização mais afetada, com 35,00\% $(\mathrm{n}=7)$ do total de aves. Entretanto, averiguou-se que não existe diferença estatisticamente significante dos valores percentuais do úmero em relação ao tibiotarso $(p=0,288)$. Das sete aves com alterações ósseas no úmero, duas $(28,57 \%)$ exibiram alterações bilaterais.

A alteração óssea prevalente foi reação do periósteo, com 45,00\% $(\mathrm{n}=9)$ do total de aves com osteomielite. A freqüência observada, quando comparada com as demais alterações ósseas, não mostrou diferença estatisticamente significante para esclerose $(\mathrm{p}=0,749)$. 
Tabela 21 - Distribuição numérica (N) e percentual (\%) de 20 aves com osteomielite, segundo as localizações. HOVET-FMVZ-USP, 2000-2004

\begin{tabular}{lcccc}
\hline \multirow{2}{*}{ Localização } & \multicolumn{2}{c}{ Aves } & \multicolumn{2}{c}{ Ocorrências } \\
\cline { 2 - 5 } & $\mathbf{N}$ & $\mathbf{\%}$ & $\mathbf{N}$ & $\mathbf{\%}$ \\
\hline Úmero & 7 & 35,00 & 9 & 33,33 \\
Tibiotarso & 4 & 20,00 & 4 & 14,81 \\
Bula timpânica & 2 & 10,00 & 2 & 7,41 \\
Fêmur & 2 & 10,00 & 2 & 7,41 \\
Ulna & 2 & 10,00 & 2 & 7,41 \\
Bico & 1 & 5,00 & 1 & 3,70 \\
Coracóide & 1 & 5,00 & 1 & 3,70 \\
Escápula & 1 & 5,00 & 1 & 3,70 \\
Esterno & 1 & 5,00 & 1 & 3,70 \\
Falange & 1 & 5,00 & 2 & 7,41 \\
Osso frontal & 1 & 5,00 & 1 & 3,70 \\
Tarsometatarso & 1 & 5,00 & 1 & 3,70 \\
\hline Total & 20 & 100,00 & 27 & 100,00 \\
\hline
\end{tabular}

Tabela 22 - Distribuição numérica (N) e percentual (\%) de 20 aves com osteomielite, segundo as alterações radiográficas. HOVET-FMVZ-USP, 2000-2004

\begin{tabular}{lcccc}
\hline \multirow{2}{*}{ Alteração } & \multicolumn{3}{c}{ Aves } & \multicolumn{2}{c}{ Ocorrências } \\
\cline { 2 - 5 } & $\mathbf{N}$ & $\mathbf{\%}$ & $\mathbf{N}$ & $\mathbf{\%}$ \\
\hline Reação do periósteo & 9 & 45,00 & 13 & 32,50 \\
Esclerose & 8 & 40,00 & 11 & 27,50 \\
Osteólise de corticais & 4 & 20,00 & 4 & 10,00 \\
Esclerose puntiforme & 3 & 15,00 & 5 & 12,50 \\
Osteólise & 3 & 15,00 & 3 & 7,50 \\
Osteólise envolta por esclerose & 2 & 10,00 & 2 & 5,00 \\
Osteólise puntiforme & 1 & 5,00 & 1 & 2,50 \\
Seqüestro ósseo & 1 & 5,00 & 1 & 2,50 \\
\hline Total & 20 & 100,00 & 40 & 100,00 \\
\hline
\end{tabular}


Tabela 23 - Distribuição numérica $(\mathrm{N})$ e percentual (\%) de sete aves com artrite, segundo as espécies. HOVET-FMVZUSP, 2000-2004

\begin{tabular}{llcc}
\hline Ordem & Nome comum & N & \% \\
\hline COLUMBIFORMES & Pomba-goura & 1 & 14,29 \\
\hline PASSERIFORMES & Mainá & 3 & 42,86 \\
\hline \multirow{2}{*}{ PSITTACIFORMES } & Papagaio-verdadeiro & 2 & 28,57 \\
\cline { 2 - 4 } & Rosela-elegante & 1 & 14,29 \\
\hline Total & & 7 & 100,00 \\
\hline
\end{tabular}

Tabela 24 - Distribuição numérica $(\mathrm{N})$ e percentual (\%) de sete aves com artrite, segundo as idades. HOVETFMVZ-USP, 2000-2004

\begin{tabular}{ccc}
\hline Idade (anos) & $\mathbf{N}$ & $\mathbf{\%}$ \\
\hline$\leq 1$ & 4 & 57,14 \\
$2-3$ & 2 & 28,57 \\
$4-5$ & 0 & 0,00 \\
$6-7$ & 0 & 0,00 \\
$8-9$ & 0 & 0,00 \\
$\geq 10$ & 1 & 14,29 \\
\hline Total & 7 & 100,00 \\
\hline
\end{tabular}

Tabela 25 - Distribuição numérica $(\mathrm{N})$ e percentual $(\%)$ de sete aves com artrite, segundo as alterações radiográficas. HOVETFMVZ-USP, 2000-2004

\begin{tabular}{lcccc}
\hline \multirow{2}{*}{ Alteração } & \multicolumn{2}{c}{ Aves } & \multicolumn{2}{c}{ Ocorrências } \\
\cline { 2 - 6 } & N & \% & N & \% \\
\hline Osteólise subcondral & 6 & 85,71 & 9 & 37,50 \\
Esclerose subcondral & 4 & 57,14 & 7 & 29,17 \\
Mineralização de tecidos moles & 4 & 57,14 & 7 & 29,17 \\
Aumento de interlinha radiográfica & 1 & 14,29 & 1 & 4,17 \\
\hline Total & 7 & 100,00 & 24 & 100,00 \\
\hline
\end{tabular}

Não houve diferença estatisticamente significante entre as ordens $(p=0,237)$.

Temos que 57,14\% das aves com alterações radiográficas compatíveis com artrite, possuem idade menor ou igual a um ano. Segundo o quadro de p-valores, entretanto, este percentual não foi estatisticamente significante em relação a faixa etária de dois a três anos ( $p$ $=0,280)$.

Todas as alterações radiográficas localizaram-se na articulação intertársica, sendo bilateralmente simétricas em seis aves $(85,71 \%)$. A alteração óssea prevalente (osteólise subcondral), identificada em $85,71 \%$ das aves, somente foi estatisticamente significante em relação ao percentual de aumento de interlinha radiográfica $(14,29 \%)$. 


\subsection{AFECÇÕES DEGENERATIVAS}

Os resultados referentes às afecções degenerativas encontram-se nas tabelas 26 a 29.

Tabela 26 - Distribuição numérica (N) e percentual (\%) de 15 aves com afecções degenerativas, segundo as espécies. HOVET-FMVZUSP, 2000-2004

\begin{tabular}{llcc}
\hline \multirow{2}{*}{ Ordem } & Nome comum & N & $\mathbf{\%}$ \\
\hline ANSERIFORMES & Ganso-chinês & 1 & 6,67 \\
\hline COLUMBIFORMES & Pomba-goura & 1 & 6,67 \\
\hline \multirow{2}{*}{ GALLIFORMES } & Faisão & 1 & 6,67 \\
\cline { 2 - 4 } & Galinha-doméstica & 1 & 6,67 \\
\hline \multirow{2}{*}{ PASSERIFORMES } & Canário & 1 & 6,67 \\
\cline { 2 - 4 } & Mainá & 3 & 20,00 \\
\hline \multirow{3}{*}{ PSITTACIFORMES } & Papagaio-do-mangue & 1 & 6,67 \\
\cline { 2 - 4 } & Papagaio-verdadeiro & 3 & 20,00 \\
\cline { 2 - 4 } & Papagaio-verdadeiro-do-sul & 1 & 6,67 \\
\cline { 2 - 4 } & Periquito-australiano & 2 & 13,33 \\
\hline Total & & 15 & 100,00 \\
\hline
\end{tabular}

Tabela 27 - Distribuição numérica $(\mathrm{N})$ e percentual $(\%)$ de 15 aves com afecções degenerativas, segundo as idades. HOVET-FMVZ-USP, 2000-2004

\begin{tabular}{ccc}
\hline Idade (anos) & $\mathbf{N}$ & $\mathbf{\%}$ \\
\hline$\leq 1$ & 4 & 26,67 \\
$2-3$ & 2 & 13,33 \\
$4-5$ & 0 & 0,00 \\
$6-7$ & 2 & 13,33 \\
$8-9$ & 1 & 6,67 \\
$\geq 10$ & 5 & 33,33 \\
Não consta & 1 & 6,67 \\
\hline Total & 15 & 100,00 \\
\hline
\end{tabular}


Não houve diferença estatisticamente significante entre Psittaciformes (46,67\%) e Passeriformes $(26,67 \%)(\mathrm{p}=0,256)$.

A faixa etária com maior prevalência dos dados é a de idade maior ou igual a 10 anos $(33,33 \%)$, e, segundo o quadro de p-valores, somente possui diferença estatisticamente significante em relação aos animais com idade entre 8-9 anos (6,67\%).

Tabela 28 - Distribuição numérica $(\mathrm{N})$ e percentual (\%) de 15 aves com afecções degenerativas, segundo as localizações. HOVET-FMVZ-USP, 2000-2004

\begin{tabular}{lcccc}
\hline \multirow{2}{*}{ Articulação } & \multicolumn{2}{c}{ Aves } & \multicolumn{2}{c}{ Ocorrências } \\
\cline { 2 - 5 } & $\mathbf{N}$ & $\mathbf{\%}$ & $\mathbf{N}$ & $\mathbf{\%}$ \\
\hline Intertársica & 7 & 46,67 & 12 & 46,15 \\
Fêmorotibiotársica & 3 & 20,00 & 5 & 19,23 \\
Coxofemoral & 2 & 13,33 & 4 & 15,38 \\
Intervertebral & 2 & 13,33 & 2 & 7,69 \\
Escápuloumeral & 1 & 6,67 & 2 & 7,69 \\
Tarsometatarsofalangeana & 1 & 6,67 & 1 & 3,85 \\
\hline Total & 15 & 100,00 & 26 & 100,00 \\
\hline
\end{tabular}

Tabela 29 - Distribuição numérica (N) e percentual (\%) de 15 aves com afecções degenerativas, segundo as alterações radiográficas. HOVET-FMVZ-USP, 2000-2004

\begin{tabular}{lcccc}
\hline \multirow{2}{*}{ Alteração } & \multicolumn{2}{c}{ Aves } & \multicolumn{2}{c}{ Ocorrências } \\
\cline { 2 - 5 } & $\mathbf{N}$ & $\mathbf{\%}$ & $\mathbf{N}$ & $\mathbf{\%}$ \\
\hline Osteófitos periarticulares & 15 & 100,00 & 16 & 55,17 \\
Esclerose subcondral & 6 & 40,00 & 6 & 20,69 \\
Diminuição de interlinha radiográfica & 3 & 20,00 & 3 & 10,34 \\
Mineralização de tecidos moles & 3 & 20,00 & 3 & 10,34 \\
Anquilose & 1 & 6,67 & 1 & 3,45 \\
\hline Total & 15 & 100,00 & 29 & 100,00 \\
\hline
\end{tabular}


A articulação mais prevalente é a intertársica, com 46,67\% de aves acometidas. Segundo o quadro de p-valores, não houve diferença estatisticamente significante deste percentual para o da articulação fêmorotibiotársica $(20,00 \%)(p=0,121)$.

Nas duas aves com espondilose vertebral, os osteófitos eram ventrais e localizavamse no segmento torácico. Juntamente com os osteófitos, esclerose de faces articulares também foi perceptível.

Segundo a distribuição das alterações radiográficas, nove $(60,00 \%)$ aves exibiram alterações bilaterais e seis $(40,00 \%)$ unilaterais, não havendo diferença estatisticamente significante $(p=0,273)$. As articulações acometidas com alterações ósseas bilaterais foram coxofemoral, escápuloumeral, fêmorotibiotársica e intertársica. 


\subsection{OSTEOPENIA LOCALIZADA}

Adiante, estão apresentadas tabelas 30 a 32, ilustrando os resultados observados para osteopenia localizada.

Tabela 30 - Distribuição numérica (N) e percentual (\%) de 13 aves com osteopenia localizada, segundo as espécies. HOVET-FMVZ-USP, 2000-2004

\begin{tabular}{llcc}
\hline Ordem & Nome comum & N & $\mathbf{\%}$ \\
\hline COLUMBIFORMES & Pombo-doméstico & 1 & 7,69 \\
\hline \multirow{3}{*}{ PASSERIFORMES } & Canário-belga & 1 & 7,69 \\
\cline { 2 - 4 } & Corrupião & 1 & 7,69 \\
\cline { 2 - 4 } & Mainá & 2 & 15,38 \\
\hline PICIFORMES & Tucano & 1 & 7,69 \\
\hline \multirow{4}{*}{ PSITTACIFORMES } & Arara-canindé & 1 & 7,69 \\
\cline { 2 - 4 } & Calopsita & 1 & 7,69 \\
\cline { 2 - 4 } & Papagaio-verdadeiro & 2 & 15,38 \\
\cline { 2 - 4 } & Periquitão-maracanã & 1 & 7,69 \\
\cline { 2 - 4 } & Periquito-australiano & 1 & 7,69 \\
\cline { 2 - 4 } & Periquito-verde & 1 & 7,69 \\
\hline Total & & 13 & 100,00 \\
\hline
\end{tabular}

Não foi encontrada diferença estatisticamente significante entre Psittaciformes e Passeriformes $(\mathrm{p}=0,234)$.

Tabela 31 - Distribuição numérica $(\mathrm{N})$ e percentual (\%) de 13 aves com osteopenia localizada, segundo as idades. HOVET-FMVZ-USP, 20002004

\begin{tabular}{ccc}
\hline Idade (anos) & $\mathbf{N}$ & $\mathbf{\%}$ \\
\hline$\leq 1$ & 6 & 46,15 \\
$2-3$ & 2 & 15,38 \\
$4-5$ & 2 & 15,38 \\
$6-7$ & 0 & 0,00 \\
$8-9$ & 0 & 0,00 \\
$\geq 10$ & 1 & 7,69 \\
Não consta & 2 & 15,38 \\
\hline Total & 13 & 100,00 \\
\hline
\end{tabular}


Tabela 32 - Distribuição numérica $(\mathrm{N})$ e percentual (\%) de 13 aves com osteopenia localizada, segundo as localizações. HOVET-FMVZ-USP, 2000-2004

\begin{tabular}{lcccc}
\hline \multirow{2}{*}{ Localização } & \multicolumn{2}{c}{ Aves } & \multicolumn{2}{c}{ Ocorrências } \\
\cline { 2 - 5 } & $\mathbf{N}$ & $\mathbf{\%}$ & $\mathbf{N}$ & $\%$ \\
\hline Tarsometatarso e dígitos & 6 & 46,15 & 9 & 42,86 \\
Coluna vertebral & 4 & 30,77 & 4 & 19,05 \\
Crânio & 2 & 15,38 & 2 & 9,52 \\
Dígitos & 2 & 15,38 & 4 & 19,05 \\
Membro pélvico & 1 & 7,69 & 1 & 4,76 \\
Tibiotarso & 1 & 7,69 & 1 & 4,76 \\
\hline Total & 13 & 100,00 & 21 & 100,00 \\
\hline
\end{tabular}

O percentual de tarsometatarso e dígitos $(46,15 \%)$ foi estatisticamente significante em relação aos percentuais das demais localizações, a exceção da coluna vertebral $(30,77 \%)$ $(\mathrm{p}=0,420)$. 


\subsection{DEFORMIDADES ÓSSEAS}

Os resultados obtidos a partir do exame radiográfico para deformidades ósseas são apresentados nas tabelas 33 a 36.

Tabela 33 - Distribuição numérica $(\mathrm{N})$ e percentual (\%) de nove aves com deformidades ósseas, segundo as espécies. HOVET-FMVZ-USP, 2000-2004

\begin{tabular}{llll}
\hline Ordem & Nome comum & N & \multicolumn{1}{c}{$\%$} \\
\hline ANSERIFORMES & Ganso & 1 & 11,11 \\
\hline \multirow{2}{*}{ GALLIFORMES } & Galinha-doméstica & 1 & 11,11 \\
\cline { 2 - 4 } & Pavão-ombros-negros & 1 & 11,11 \\
\hline PASSERIFORMES & Mainá & 3 & 33,33 \\
\cline { 2 - 4 } & Arara-canindé & 1 & 11,11 \\
\cline { 2 - 4 } PSITTACIFORMES & Arara-vermelha & 1 & 11,11 \\
\cline { 2 - 4 } & Papagaio & 1 & 11,11 \\
\hline Total & & 9 & 100,00 \\
\hline
\end{tabular}

Tabela 34 - Distribuição numérica $(\mathrm{N})$ e percentual (\%) de nove aves com deformidades ósseas, segundo as idades. HOVETFMVZ-USP, 2000-2004

\begin{tabular}{ccc}
\hline Idade (anos) & $\mathbf{N}$ & $\mathbf{\%}$ \\
\hline$\leq 1$ & 6 & 66,67 \\
$2-3$ & 1 & 11,11 \\
$4-5$ & 0 & 0,00 \\
$6-7$ & 2 & 22,22 \\
$8-9$ & 0 & 0,00 \\
$\geq 10$ & 0 & 0,00 \\
\hline Total & 9 & 100,00 \\
\hline
\end{tabular}

Não houve diferença estatisticamente significante na comparação entre cada uma das ordens prevalentes com as demais ( $p=0,257$ e 0,599, para Anseriformes e Galliformes, respectivamente).

Tabela 35 - Distribuição numérica $(\mathrm{N})$ e percentual (\%) de nove aves com deformidades ósseas, segundo as localizações. HOVET-FMVZ-USP, 2000-2004

\begin{tabular}{lcccc}
\hline \multirow{2}{*}{ Localização } & \multicolumn{2}{c}{ Aves } & \multicolumn{2}{c}{ Ocorrências } \\
\cline { 2 - 5 } & $\mathbf{N}$ & $\mathbf{\%}$ & $\mathbf{N}$ & $\mathbf{\%}$ \\
\hline Coluna vertebral & 4 & 44,44 & 4 & 28,57 \\
Membros pélvicos & 4 & 44,44 & 7 & 50,00 \\
Membros torácicos & 2 & 22,22 & 3 & 21,43 \\
\hline Total & 9 & 100,00 & 14 & 100,00 \\
\hline
\end{tabular}


Tabela 36 - Distribuição numérica $(\mathrm{N})$ e percentual (\%) de nove aves com deformidades ósseas, segundo as alterações radiográficas. HOVET-FMVZ-USP, 20002004

\begin{tabular}{lcccc}
\hline \multirow{2}{*}{ Alteração } & \multicolumn{2}{c}{ Aves } & \multicolumn{2}{c}{ Ocorrências } \\
\cline { 2 - 5 } & $\mathbf{N}$ & $\mathbf{\%}$ & $\mathbf{N}$ & $\mathbf{\%}$ \\
\hline Deformidades angulares & 8 & 88,89 & 13 & 92,86 \\
Anquilose & 1 & 11,11 & 1 & 7,14 \\
\hline Total & 9 & 100,00 & 14 & 100,00 \\
\hline
\end{tabular}

Não houve diferença estatisticamente significante entre os percentuais de coluna vertebral e membros pélvicos com relação ao percentual de membros torácicos $(\mathrm{p}=0,317)$.

A análise das radiografias permitiu constatar a presença de deformidades ósseas em nove animais $(9 / 201,4,48 \%)$. Destes, oito $(8 / 9,88,89 \%)$ apresentavam alterações angulares dos eixos ósseos da coluna vertebral e/ou dos membros e um $(1 / 9,11,11 \%)$, anquilose das articulações vertebrais da cauda. 


\subsection{ALTERAÇÕES ÓSSEAS AGRESSIVAS}

Em estudo de 201 aves, foram identificadas quatro aves (1,99\%) com alterações ósseas agressivas, cujos diagnósticos não foram estabelecidos. Constatou-se a realização de exame citológico somente em duas das aves afetadas, obtendo-se, em ambos os pacientes, resultados inconclusivos.

Um agapornis (Agapornis sp), de seis anos de idade, e um papagaio (espécie indeterminada), de 15 anos, exibiram reação osteolítica localizada no úmero distal e no bico superior, respectivamente.

Dois agapornis (Agapornis sp), de um e quatro anos de idade, exibiram reação proliferativa localizada em múltiplos ossos. Os ossos acometidos foram úmeros, costelas, segmento vertebral cervical e metacarpiano maior no primeiro; tibiotarso, esterno e segmentos vertebrais torácico e sinsacral no segundo. 


\subsection{ALTERAÇÕES INESPECÍFICAS}

Um ganso, de espécie indeterminada, de dois meses de idade, e um tucanuçu (Ramphastos toco), de idade indeterminada, exibiram alterações radiográficas inespecíficas.

A primeira ave revelou mineralização no tarsometatarso proximal e região medial adjacente, imediatamente abaixo da fileira distal dos ossos társicos (animal jovem). O mesmo, apresentava luxação traumática da articulação intertársica no membro contralateral.

Diminuição de interlinha radiográfica foi demonstrada nos exames radiográficos do segundo animal, e localizava-se nas articulações intertársica e tarsometatarsofalangeana dos dígitos I e IV. Este, também demonstrava mais um afecção esquelética, osteomielite no tarsometatarso do referido membro. 


\subsection{ALTERAÇÕES INESPECÍFICAS}

Um ganso, de espécie indeterminada, de dois meses de idade, e um tucanuçu (Ramphastos toco), de idade indeterminada, exibiram alterações radiográficas inespecíficas.

A primeira ave revelou mineralização no tarsometatarso proximal e região medial adjacente, imediatamente abaixo da fileira distal dos ossos társicos (animal jovem). O mesmo, apresentava luxação traumática da articulação intertársica no membro contralateral.

Diminuição de interlinha radiográfica foi demonstrada nos exames radiográficos do segundo animal, e localizava-se nas articulações intertársica e tarsometatarsofalangeana dos dígitos I e IV. Este, também demonstrava mais um afecção esquelética, osteomielite no tarsometatarso do referido membro. 


\subsection{ILUSTRAÇÕES}

As figuras a seguir, ilustram alguns dos achados observados nos exames radiográficos.

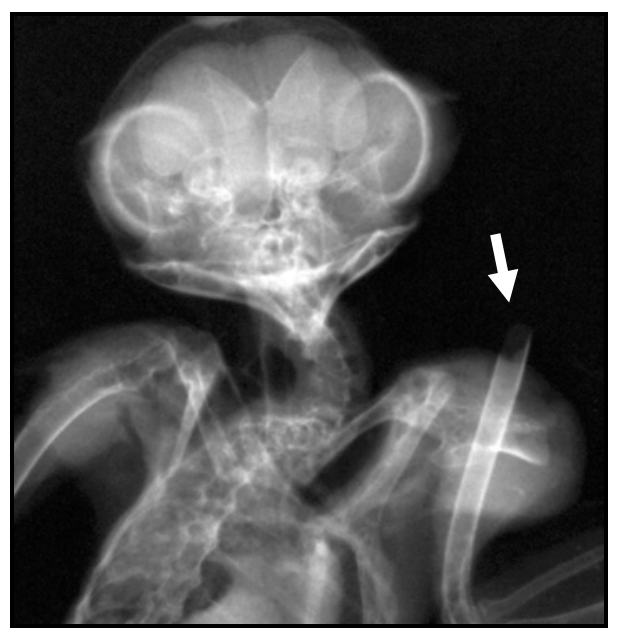

Figura 7 - Projeção ventrodorsal, de uma coruja, de espécie e idade indeterminadas. Presença de fratura exposta de segmento proximal do úmero esquerdo (seta).

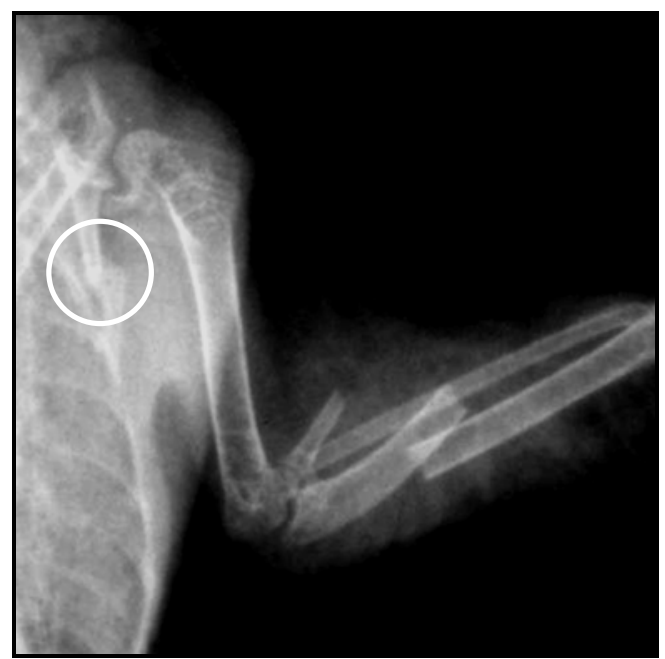

Figura 8 - Projeção ventrodorsal, de um periquito-verde (Brotogeris viridissimus), de idade indeterminada. Observar a presença de fraturas na escápula (círculo), rádio e ulna esquerdos. 


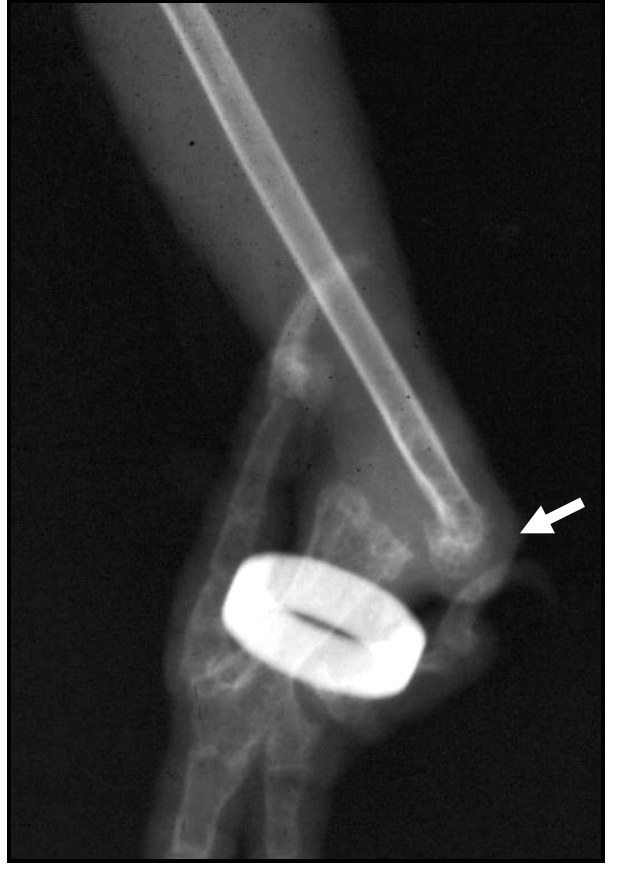

Figura 9 - Projeção mediolateral, do membro pélvico direito de um papagaioverdadeiro (Amazona aestiva), de nove anos de idade. Articulação intertársica luxada (seta).

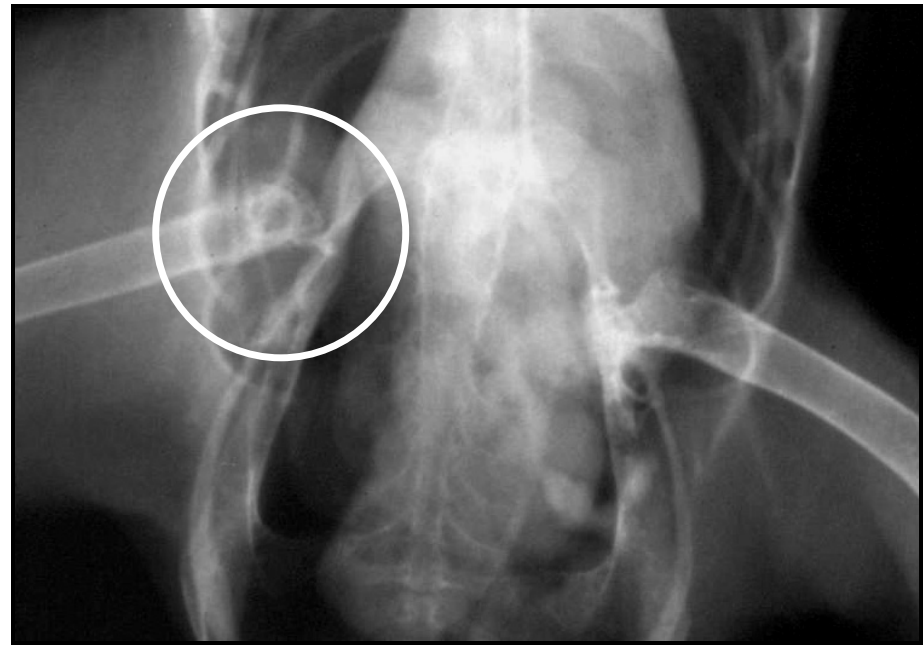

Figura 10 - Projeção ventrodorsal, de um papagaio-verdadeiro (Amazona aestiva), de um mês de idade. Notar a luxação coxofemoral direita (ćrculo) com concomitante aumento de volume de tecidos moles em região adjacente.

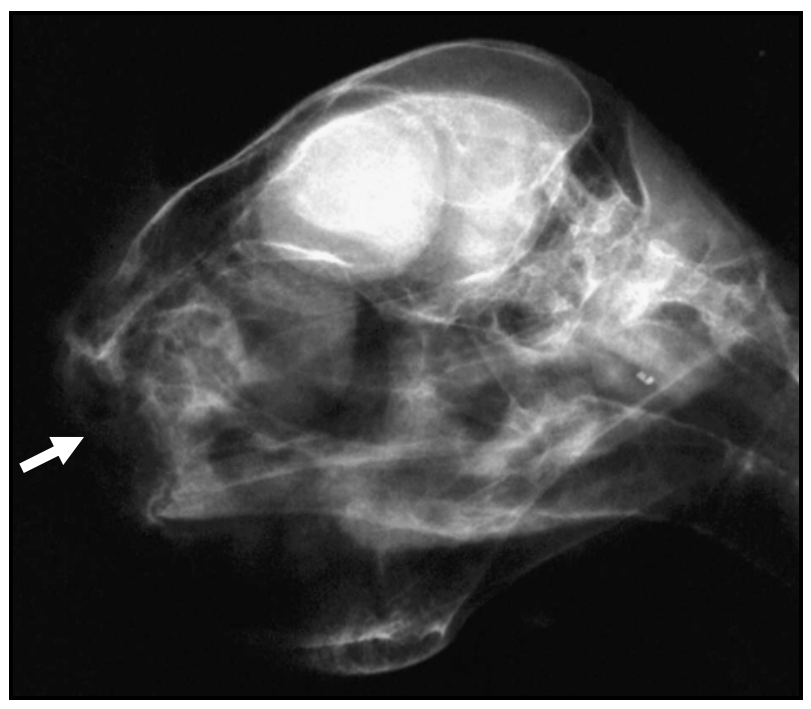

Figura 11 - Projeção laterolateral, do crânio de uma cacatua-branca (Cacatua alba), de 10 anos de idade. Amputação do bico superior (seta). Causa: briga com outra ave. 


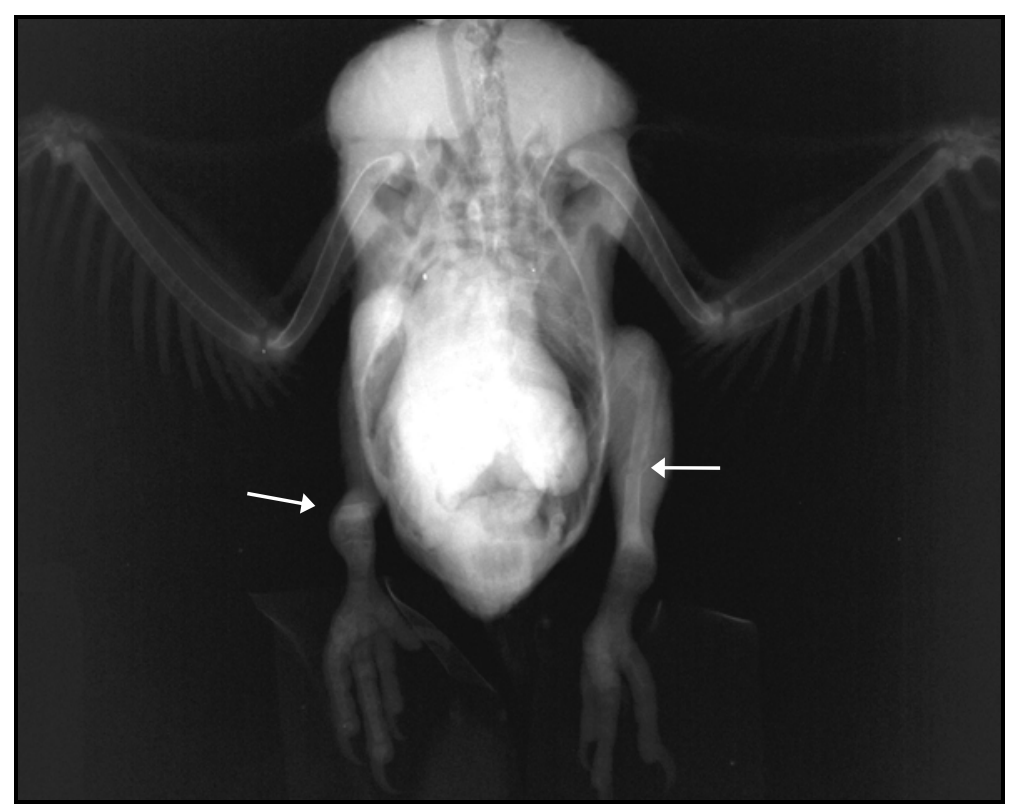

Figura 12 - Projeção ventrodorsal, de um papagaio-verdadeiro (Amazona aestiva), de 35 dias de idade. Observar a acentuada osteopenia generalizada, adelgaçamento do osso cortical e fraturas patológicas localizadas nos tibiotarsos (setas). Observação: a alimentação desse paciente consistia apenas de fubá e milharina, misturados com água.

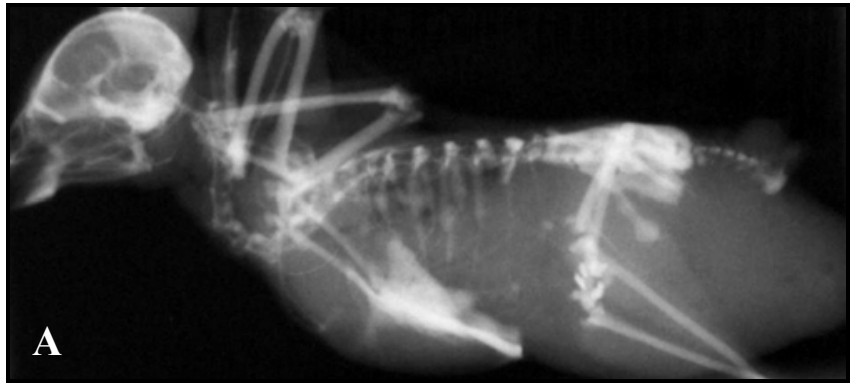

Figura 13 - Projeções laterolateral (A) e ventrodorsal (B), de um canário (de espécie indeterminada), de três anos de idade. Presença de acentuada esclerose medular homogênea generalizada e cavidade celomática caudal distendida e homogênea.

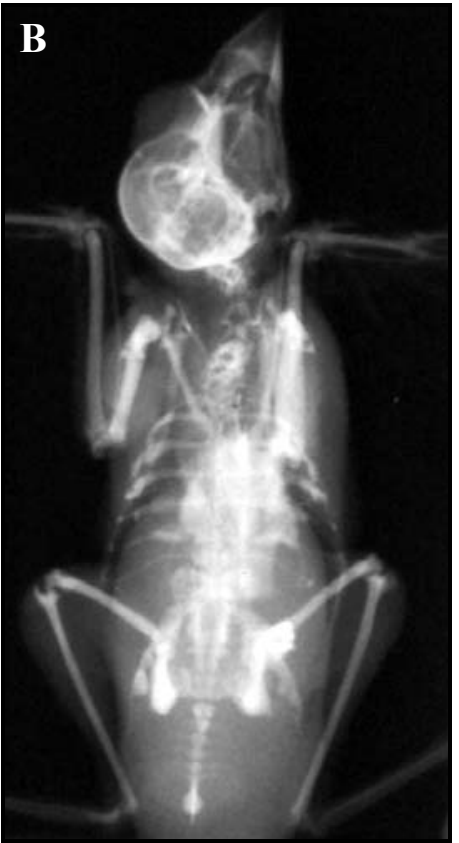




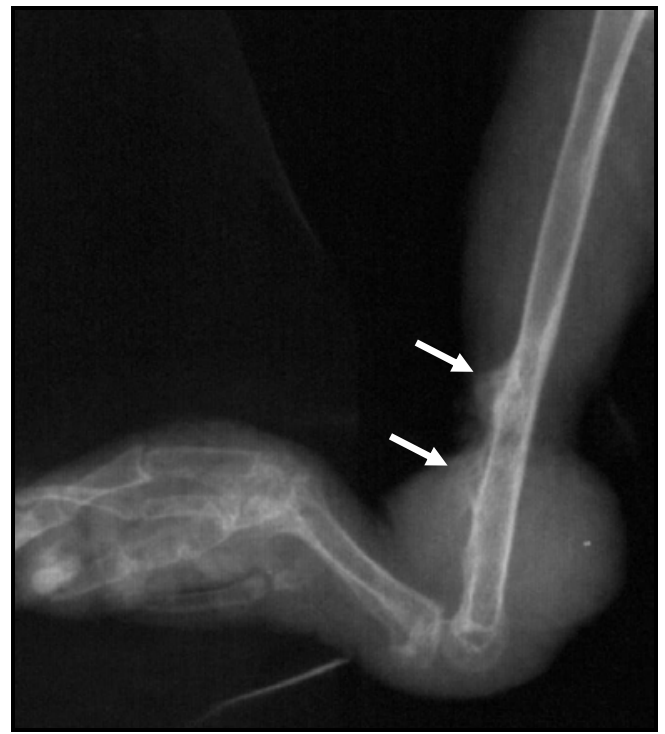

Figura 14 - Projeção mediolateral do membro pélvico direito de um papagaio (espécie indeterminada), de três meses de idade. Reação do periósteo (setas) e aumento de volume de tecidos moles no segmento distal do tibiotarso. Causa: compressão local por objeto linear.

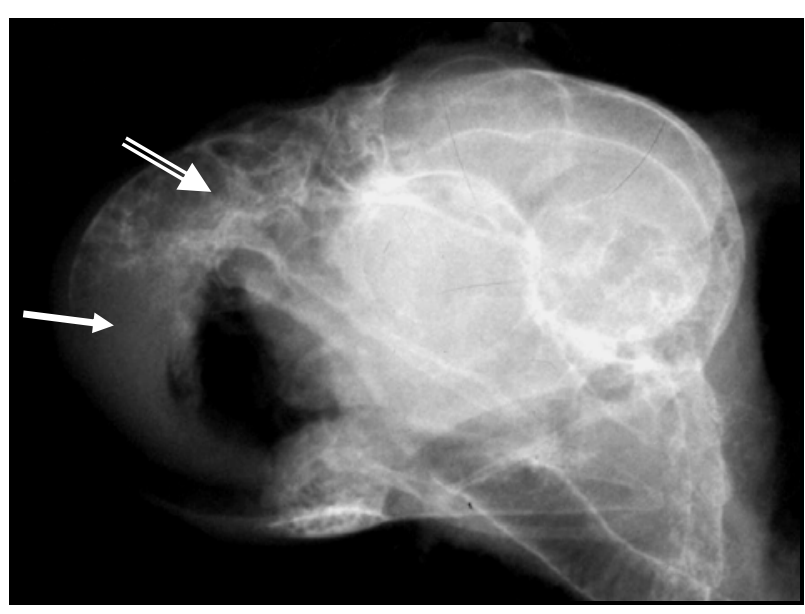

Figura 15 - Projeção laterolateral do crânio de um papagaio-verdadeiro (Amazona aestiva), de oito anos de idade. Osteólise de premaxila cranial (seta sólida) e opacificação de seios infraorbitários (seta vazia). Causa: sinusite crônica causada por Streptococcus sp.

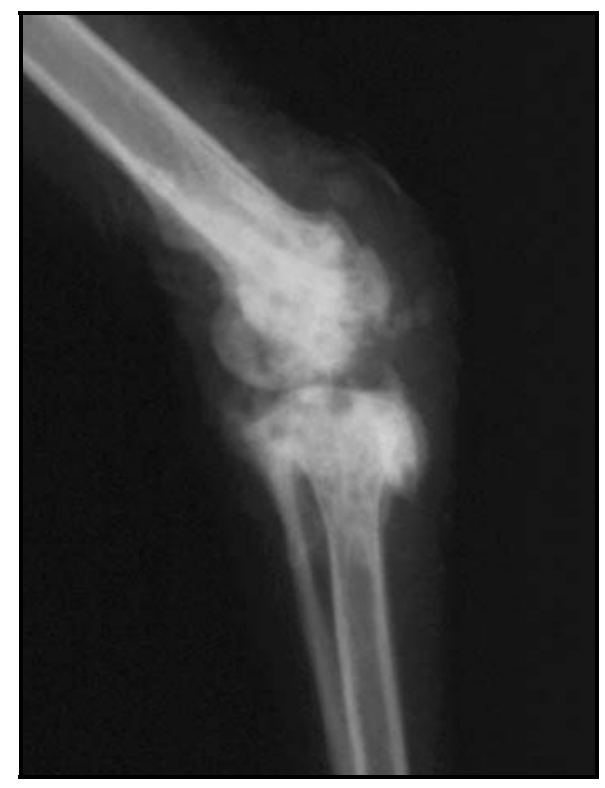

Figura 16 - Projeção mediolateral, da articulação intertársica direita de uma pomba-goura (Goura cristata), de 10 anos de idade. Observar a presença de múltiplas alterações ósseas como osteólise e esclerose subcondrais, mineralização de tecidos moles e aumento de volume de tecidos moles. 


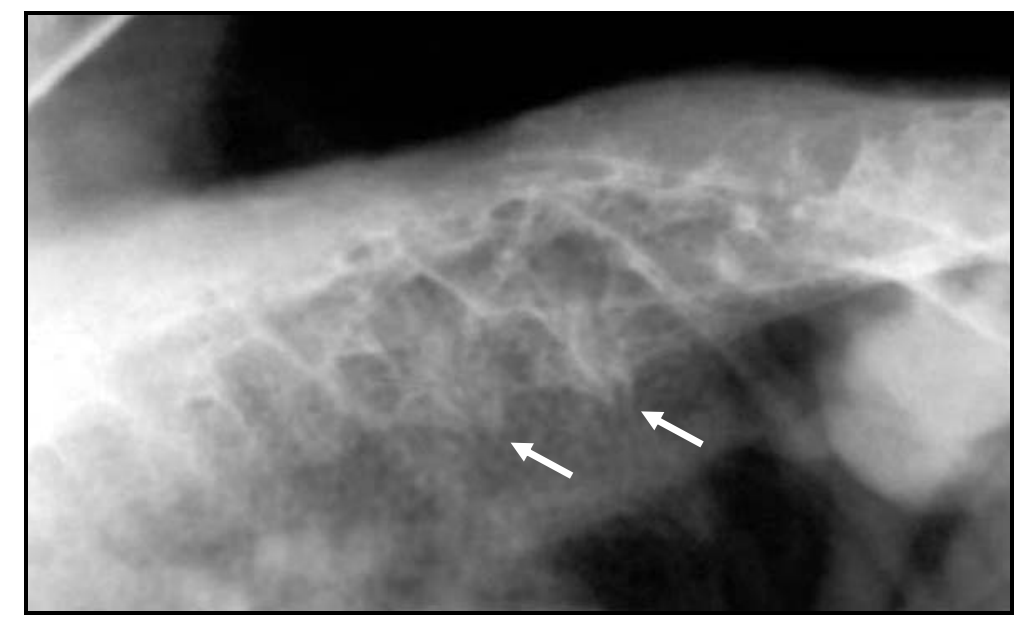

Figura 17 - Projeção laterolateral, de um papagaio-verdadeiro-do-sul (Amazona aestiva xanthopteryx), de oito anos de idade. Notar a presença de osteófitos ventrais localizados nas epífises das vértebras torácicas caudais (setas).

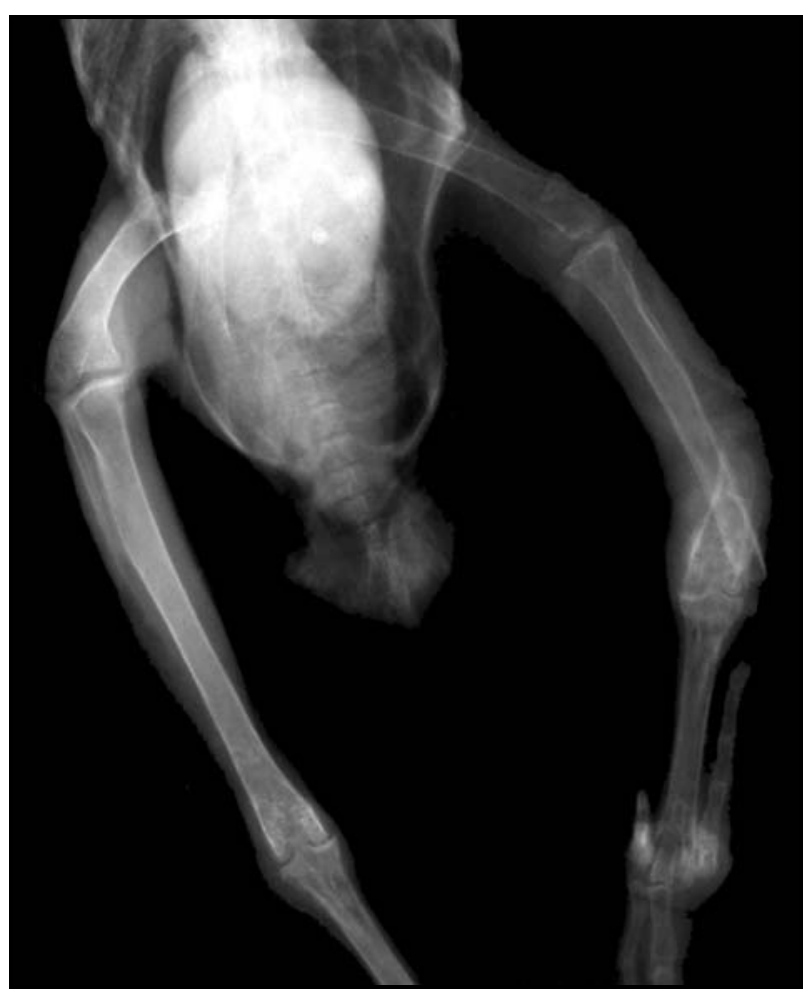

Figura 18 - Projeção ventrodorsal, de um tucano (de espécie indeterminada), de dois anos de idade. Notar a osteopenia localizada no membro pélvico esquerdo. Causa: impotência funcional em razão da presença de luxação coxofemoral e fratura de tibiotarso. 


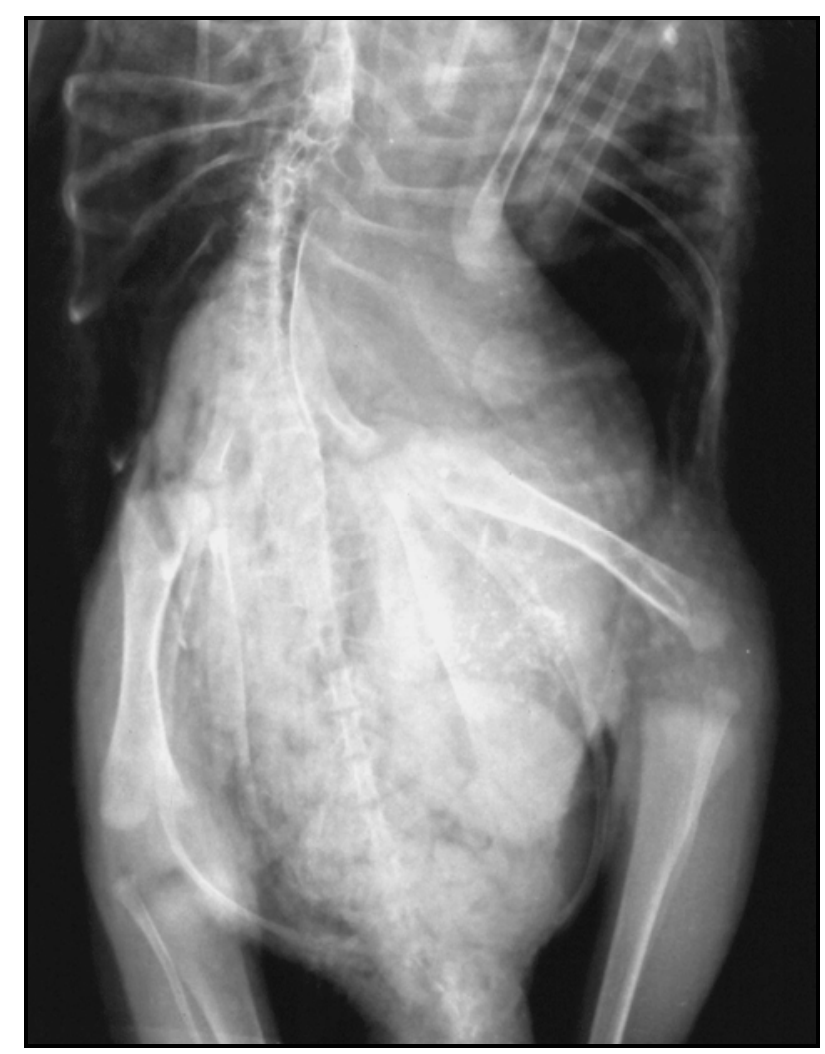

Figura 19 - Projeção ventrodorsal, de um ganso (de espécie indeterminada), de um mês de idade. Observar a curvatura anormal do segmento vertebral toracolombar (escoliose). 


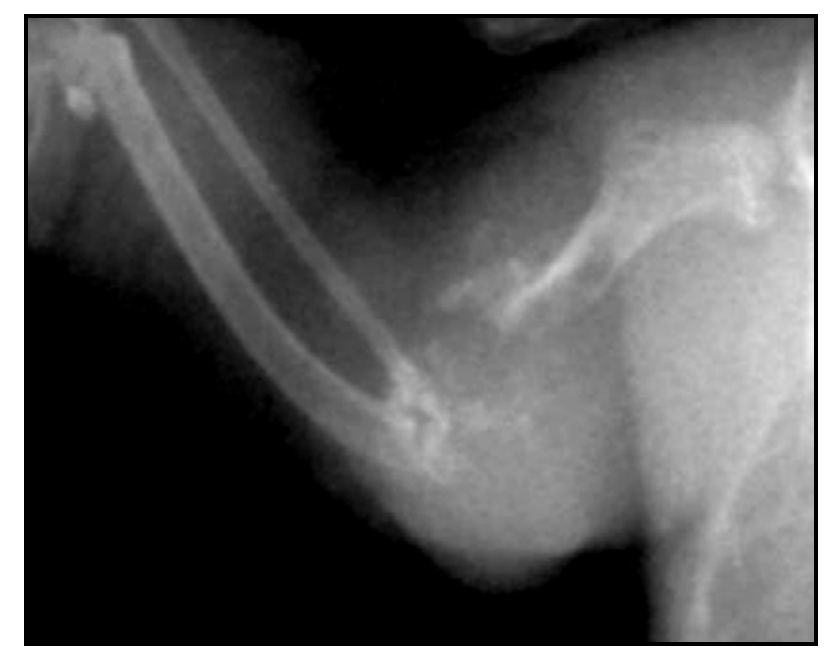

Figura 20 - Projeção mediolateral, da asa direita de um Agapornis sp, de seis anos de idade. Observar a presença de uma extensa reação osteolítica acometendo o segmento distal do úmero.

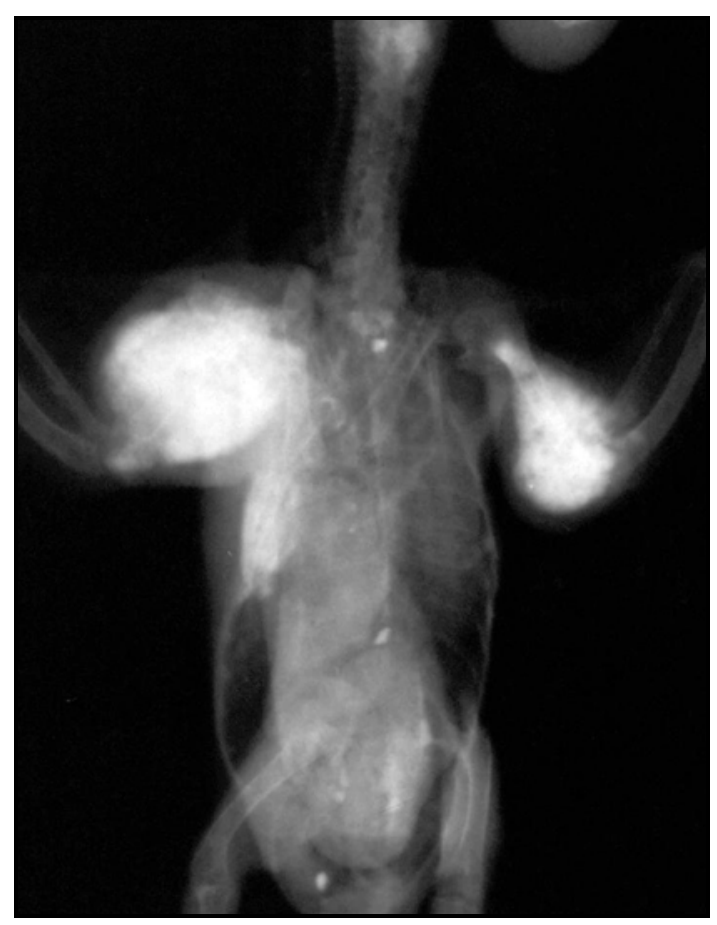

Figura 21 - Projeção ventrodorsal, de um Agapornis sp, de um ano de idade. Observar a presença de uma extensa reação proliferativa acometendo segmento vertebral cervical, úmeros e costelas. 
Existem diferenças anatômicas entre o sistema esquelético de aves e mamíferos. Portanto, julga-se imprescindível para o reconhecimento e a interpretação das alterações radiográficas, a literatura que abrange as características anatômicas do sistema esquelético em aves (BAUMEL; WITMER, 1993; CRACKNELL, 2004b; DYCE et al., 1997; EVANS, 1996; FEDUCCIA, 1986; GHETIE et al., 1981; KING; MCLELLAND,1984; KOCH, 1973; MCKIBBEN; HARRISON, 1986; MCLELLAND, 1991; NICKEL et al., 1977; O'MALLEY, 2005; OROSZ, 1997b; PAUL-MURPHY et al., 1990; SMITH; SMITH, 1992, 1997; SMITH et al., 1990).

A seleção adequada dos fatores de exposição e o correto posicionamento radiográfico tornam-se necessários para a produção de radiografias diagnósticas de alta qualidade.

No período de 2000 a 2004, exames radiográficos de 201 aves, portadoras de alterações radiográficas no sistema esquelético, foram analisados. A maioria das aves registradas neste estudo pertenceu a duas ordens: Psittaciformes e Passeriformes $(64,68 \%$ e $16,42 \%$, respectivamente). De acordo com a literatura, estas são as aves mais populares, mantidas como animais de estimação (FORBES; LAWTON, 1996; PETRAK; GILMORE, 1969; WALLACH; BOEVER, 1983). Os Psittaciformes, em particular, constituíram um contingente bastante numeroso (130/201, 64,68\%), sendo o papagaio-verdadeiro (Amazona aestiva) a espécie mais comum (45/130, 34,62\%). Os psitacídeos são muito inteligentes e capazes de pronunciar palavras, o que lhes conferem a posição de companheiros favoritos do homem (FORBES; LAWTON, 1996).

Em função da escassez de características sexuais externas em muitas espécies de aves, particularmente nos Psittaciformes, técnicas para a determinação do sexo são requeridas (HALVERSON, 1997). Por essa razão, a variável sexo não foi considerada nesse estudo.

A análise dos resultados alcançados será abordada adiante para cada uma das afecções do sistema esquelético. 


\subsection{AFECÇÕES TRAUMÁTICAS}

As afecções de origem traumática foram as mais freqüentes identificadas no sistema esquelético das espécies aviárias, tendo sido observadas em 94 aves (46,77\%). Os resultados, ora apresentados, estão de acordo com a opinião dos autores que consideram as injúrias traumáticas como as mais freqüentemente encontradas em aves (QUESENBERRY, 1997; ROUSH, 1984). Não existe uma predisposição etária para a ocorrência de traumas. Neste estudo, todavia, a faixa etária com maior índice percentual de afecções traumáticas foi a de idade menor ou igual a um ano (29/94, 30,85\%), seguida pela de dois a três anos (17/94, 18,09\%). Um fato que poderia explicar a maior incidência de injúrias traumáticas em aves nestas duas faixas etárias seria o maior nível de atividade física em cativeiro após a aquisição das mesmas.

As alterações traumáticas foram classificadas em três categorias: fraturas, luxações e amputações ósseas.

A avaliação de 70 aves mostrou um total de 86 fraturas. Destas, 45 (52,33\%) foram encontradas nos membros pélvicos e 35 (40,70\%) nos torácicos, sugerindo que as mesmas foram provocadas tanto durante o vôo como em solo. Estes resultados contradizem a opinião dos autores Benett (1997) e Mccartney (1994), que relatam ser os membros torácicos os mais fraturados. Já o oposto foi observado por Blass (1987), conferindo, assim, com os resultados ora expostos.

O tibiotarso é considerado por Harcourt-Brown (1996) como o osso mais fraturado, fato constatado também no presente estudo (32/86, 37,21\%). Fraturas localizadas no úmero são freqüentes (MACCOY, 1996) e este foi o segundo osso mais fraturado (16/86, 18,60\%).

De uma amostragem de 12 aves com fraturas de antebraço, sete $(58,33 \%)$ possuíam fraturas de apenas um dos ossos e cinco (41,67\%), tanto de rádio quanto de ulna. Estes resultados coincidiram com a citação de Redig (1986), referindo que a maioria das fraturas de antebraço envolve apenas o rádio ou a ulna.

Ocupando a segunda posição entre as afecções traumáticas, deslocamentos articulares, sejam eles parciais ou totais, foram observados em 24 aves (24/94, 25,53\%). Os resultados obtidos demonstraram que as luxações traumáticas não são afecções tão infreqüentes em aves como referidas na literatura (ALTMAN, 1969; BLASS, 1987; 
MARTIN; RITCHIE, 1994; MCMILLAN, 1994). Constatou-se 26 luxações. Como já observado por Mcmillan (1994), a articulação fêmorotibiotársica foi a mais acometida, representando 46,15\% $(n=12)$. Estes resultados, entretanto, estão em desacordo com Roush (1984), que refere ser fraturas mais freqüentes que luxações no joelho traumatizado. $\mathrm{Na}$ coluna vertebral, a única luxação identificada localizava-se entre o sinsacro e as vértebras caudais, contrariando, mais uma vez, os achados da literatura (HARCOURT-BROWN, 1996; KOSTKA; KRAUTWALD-JUNGHANNS，1991; KRAUTWALD-JUNGHANNS，1996; RUPLEY, 1999; WILLIAMS, 2002).

Denominaram-se amputações ósseas, os casos com separação traumática do osso, ou parte dele, em relação ao restante do esqueleto (MANUILA et al., 2003). Baseando-se nesta definição, identificou-se 13 casos de amputações ósseas, sendo 10 (76,92\%) localizados nos ossos distais dos membros, dois $(15,38 \%)$ no bico e um $(7,69 \%)$ no úmero. No que diz respeito às amputações ósseas acidentais, a literatura foi bastante escassa. É provável que os autores consideram fraturas e amputações traumáticas como uma coisa só.

\subsection{DOENÇA ÓSSEO-METABÓLICA (DOM)}

Em termos de freqüência, aves com alterações ósseas compatíveis com DOM ocuparam o segundo lugar na presente pesquisa, perfazendo 48 casos ou 23,88\% do total de casos analisados. O resultado, ora apresentado, contraria a opinião de Mcmillan (1994), que menciona serem as alterações ósseas decorrentes de DOM predominantes às alterações traumáticas.

Essa enfermidade está comumente associada a animais alimentados com dietas desbalanceadas em cálcio, fósforo e vitamina $D_{3}$ (RUPLEY, 1999). Embora ocorra em animais adultos, os animais jovens e recém-nascidos são os mais comumente afetados (KOSTKA; KRAUTWALD-JUNGHANNS, 1991). Ao analisar a distribuição etária das aves afetadas, evidenciou-se 30 casos $(62,50 \%)$ com idade inferior ou igual a um ano.

Osteopenia generalizada foi observada em 45 aves (93,75\%). Nos três casos restantes $(6,25 \%)$, com radiopacidade óssea generalizada normal, a definição do diagnóstico foi auxiliada pela combinação de outras alterações radiográficas, incluindo fraturas patológicas e 
deformidades ósseas de membros, coluna vertebral e costelas, além da análise dos sinais clínicos apresentados e da dieta oferecida. Das 45 aves com osteopenia generalizada, uma ave (2,22\%), espécie Gallus gallus domesticus, idade indeterminada, exibiu alterações radiográficas compatíveis com raquitismo, coincidindo com as alterações reportadas na literatura (BIESTER; SCHWARTE ${ }^{1}, 1965$ apud WALLACH; FLIEG, 1969, p. 1048). Ainda que o disco epifisário das aves seja radiograficamente indefinido (KRAUTWALDJUNGHANNS, 1996), casos avançados de hiperparatireoidismo nutricional secundário, em combinação com uma hipovitaminose $\mathrm{D}$, são manifestados radiograficamente por um alargamento dos discos epifisários e das extremidades articulares (BIESTER; SCHWARTE ${ }^{1}$, 1965 apud WALLACH; FLIEG, 1969, p. 1048).

Das 201 aves avaliadas, 30 (14,93\%) revelaram 71 fraturas decorrentes de DOM e 70 (34,83\%), 86 fraturas traumáticas. Certamente, estes resultados contrariam Mcmillan (1994). Segundo o autor, fraturas decorrentes de DOM são mais comuns do que as decorrentes de traumas.

No que diz respeito aos fatores de exposição que afetam a qualidade dos raios-X, cabe lembrar que uma superexposição radiográfica não permitirá uma visibilização precisa do sistema esquelético e da cavidade celomática. A importância disso reside no fato de que essa superexposição poderá mimetizar radiograficamente uma "falsa" osteopenia generalizada do sistema esquelético e, portanto, um "falso" diagnóstico de DOM.

\subsection{HIPEROSTOSE POLIOSTÓTICA (HP)}

Imagens radiográficas de HP foram observadas em 34 aves $(34 / 201,16,92 \%)$. A literatura reporta que esta condição é comumente encontrada no periquito-australiano (Melopsittacus undulatus) (BAUMGARTNER et al., 1995; COLES, 1985; KOSTKA et al., 1988; KRAUTWALD-JUNGHANNS, 1996). No presente estudo, entretanto, temos que o periquito-australiano e o canário foram as duas espécies que mais representaram a amostra, perfazendo nove casos cada $(9 / 34,26,47 \%)$. Não há uma predisposição etária. Neste estudo, a faixa etária de maior representação foi de dois a três anos de idade, em que se registraram 12 casos $(35,29 \%)$, seguidos por sete casos $(20,59 \%)$ com idade menor ou igual a um ano. A HP

1 BIESTER, H. E.; SCHWARTE, L. H. Diseases of poultry. 5. ed. Ames: Iowa State University Press, 1965. p. 49, 159-163, 194. 
normalmente consiste em um achado ao se radiografar a ave por outra razão ou suspeita (COLES, 1985; RUPLEY, 1999), fato este devidamente presenciado no transcorrer do levantamento radiográfico, e isoladamente não tem significado clínico (RUPLEY, 1999). Portanto, é provável que esta faixa etária não signifique a verdadeira idade de início da condição.

Os quatro sítios mais prevalentes com esclerose medular foram, em ordem decrescente de freqüência: fêmores $(31 / 34,91,18 \%)$, tibiotarsos $(31 / 34,91,18 \%)$, ulnas $(26 / 34,76,47 \%)$ e rádios $(24 / 34,70,59 \%)$, resultados estes que coincidem com as informações de Quesenberry (1997).

A única alteração radiográfica demonstrável é o aumento da radiopacidade óssea na cavidade medular dos ossos. O osso medular pode ou não obliterar completamente a cavidade medular, tornando-se evidente, respectivamente, um aspecto homogêneo ou heterogêneo de esclerose medular. Assim sendo, a HP deve ser diferenciada de outras afecções ósseas que possuam alterações radiográficas semelhantes (LATIMER, 1994; QUESENBERRY, 1997). Para Latimer (1994), a doença ósseo-metabólica deve fazer parte do diagnóstico diferencial. Todavia, discordamos do autor, já que uma das alterações radiográficas mais clássicas encontrada em animais com doença ósseo-metabólica, trata-se da osteopenia generalizada, caracterizada pela diminuição da radiopacidade óssea.

\subsection{AFECÇÕES INFLAMATÓRIO-INFECCIOSAS}

\subsubsection{Artrite}

Diversos microrganismos podem alcançar a articulação e implicar na inflamação das estruturas intra-articulares (GERLACH, 1994; GYLSTORFF; GRIMM, 1987). As fontes de contaminação são diversas (MCMILLAN, 1994). Aliado ao exame radiográfico, o diagnóstico é elaborado pela identificação do agente etiológico no líqüido sinovial e no material de biopsia (QUESENBERRY, 1997).

Quanto à faixa etária dos animais, temos que aves com idade menor ou igual a um ano foram as mais freqüentemente acometidas (4/7; 57,14\%). Janovski (1966), afirma que as 
artrites, em especial as do tipo supurativas, atingem predominantemente aves entre seis e 12 meses de idade. Apontamento este que corrobora com os dados encontrados. Conforme visto na literatura, o autor relata uma artrite em um passeriforme de apenas seis meses de idade, que se manteve exposto a um ambiente de alta contaminação fecal. Como medida profilática, o proprietário deve ser orientado a inspecionar a gaiola diariamente e limpar se estiver suja por excrementos, incluindo o piso, bebedouros, comedouros, poleiros e a gaiola propriamente dita, a fim de evitar uma exposição contínua ao material fecal. Embora não constituindo um objetivo deste trabalho, pode-se sugerir que esta seja uma das principais fontes de infecção em aves jovens e em desenvolvimento com alterações radiográficas compatíveis com artrite nas articulações distais.

O desenvolvimento de artrites é mais comum nas articulações distais dos membros pélvicos (ALTMAN, 1969; KOSTKA et al., 1988; MCMILLAN, 1994; QUESENBERRY, 1997; WALSH, 1986). No presente estudo, somente a articulação intertársica foi afetada (7/7; 100,00\%), observação que confere com os autores que já discutiram o assunto (MCMILLAN, 1994; QUESENBERRY, 1997; WALSH, 1986).

As alterações radiográficas observadas, isolada ou conjuntamente, foram: osteólise subcondral $(6 / 7 ; 85,71 \%)$, esclerose subcondral $(4 / 7 ; 57,14 \%)$, mineralização de tecidos moles $(4 / 7 ; 57,14 \%)$ e aumento de interlinha radiográfica $(1 / 7 ; 14,29 \%)$. A espessura da interlinha radiográfica torna-se diminuída por ocasião do detrimento da cartilagem articular (MCMILLAN, 1994). Todavia, das sete aves com alterações radiográficas compatíveis com artrite, uma (14,29\%) revelou exuberante aumento de interlinha radiográfica, tamanho era o grau de lise do osso subcondral adjacente. Quanto à distribuição das alterações radiográficas, seis aves exibiram alterações tanto no membro esquerdo como no direito, representando $85,71 \%$ dos casos. Este dado difere da literatura consultada (ALTMAN, 1969), sendo praticamente o oposto.

\subsubsection{Osteomielite}

A análise dos exames radiográficos de 201 aves registradas no presente estudo, permitiu a identificação de 20 aves $(9,95 \%)$ com alterações ósseas compatíveis com osteomielite. Lembramos, todavia, que o diagnóstico definitivo somente é alcançado após o 
isolamento do agente etiológico. Os dados de literatura sobre a ocorrência das espécies mais acometidas são escassos, e em relação às idades também o são. A distribuição percentual das ordens identificadas foi de $80,00 \%$ para Psittaciformes e 5,00\% para cada uma das seguintes ordens: Columbiformes, Falconiformes, Passeriformes e Piciformes. No relativo à idade, observou-se que $30,00 \%$ (6/20) dos animais tinham idade maior ou igual a 10 anos, e 35,00\% (7/20), idade desconhecida. Contudo, o elevado número de casos encontrados com idade desconhecida, não nos permite dizer se realmente há alguma prevalência para os animais com idade maior ou igual a 10 anos.

A osteomielite vertebral é considerada uma enfermidade rara em aves (MCMILLAN, 1994), mas relatos têm sido encontrados (GERLACH, 1986; VEEN et al., 1999). Caso algum foi aqui observado. Entretanto, lembramos que anormalidades de postura, como cifose, podem se desenvolver como resultado de uma osteomielite vertebral, conforme observado por Veen et al. (1999). Aves com anormalidades posturais foram visibilizadas no presente estudo e estão discutidas adiante.

Como pôde ser visto nos resultados deste estudo, aves com osteomielite exibiram manifestações diversas de osteólise e esclerose (Tabela 22). Uniformizando os dados, temos: 11 aves $(11 / 20,55,00 \%)$ com esclerose, nove $(9 / 20,45,00 \%)$ com osteólise, nove (9/20, $45,00 \%)$ com reação do periósteo e uma $(1 / 20,5,00 \%)$ com seqüestro ósseo. Perceba que são nove e não 10 aves com osteólise, porque uma só ave revelou duas manifestações diferentes de osteólise. Embora a esclerose revelou ser a alteração radiográfica prevalente, osteólise e reação do periósteo também se destacaram. De acordo com Mcmillan (1994), a visibilização radiográfica de esclerose, osteólise e/ou reação do periósteo, dependerá do tempo de duração da afecção óssea. Assim sendo, osteólise tem sido predominante na fase aguda. Esclerose e reação do periósteo comumente aparecem na fase crônica da doença ou, eventualmente, na fase inicial de uma infecção causada por fungos ou Mycobacterium sp.

Embora considerado mais freqüente em aves que nos mamíferos (EVANS, 1986), foi visibilizado seqüestro ósseo em apenas uma ave (5,00\%), localizado em região adjacente a uma fratura antiga de tarsometatarso. A formação de seqüestração ocorre quando, nos locais de uma fratura composta, fragmentos ósseos são contaminados e isolados de seu suprimento sangüíneo (DOIGE; WEISBRODE, 1998). 
O exame radiográfico mostrou envolvimento de múltiplos ossos, sendo o úmero o osso mais afetado $(7 / 20,35,00 \%)$, seguido pelo tibiotarso $(4 / 20,20,00 \%)$. Conforme descrito na literatura (MCMILLAN, 1994), a infecção costuma manifestar-se nos ossos das asas e dos membros pélvicos, em especial nas extremidades. Neste momento um aspecto merece ser enfatizado. $\mathrm{O}$ úmero constitui o osso pneumático mais importante do sistema esquelético (KRAUTWALD-JUNGHANNS, 1996) e tal importância reflete-se na capacidade de disseminação da infecção óssea para o sistema de sacos aéreos e vice-versa (MCKIBBEN; HARRISON, 1986; MCMILLAN, 1994; SMITH; SMITH, 1992).

\subsection{AFECÇÕES DEGENERATIVAS}

A doença articular degenerativa (DAD) caracteriza-se pelo desgaste da cartilagem articular e por alterações articulares, entre elas os osteófitos periarticulares (DOIGE; WEISBRODE, 1998). Pode ser dividida em sem causa conhecida, dita primária, ou com causa conhecida, dita secundária (ALTMAN², 1982 apud PENCE, 1996a, p. 459; DEGERNES, 1994; KEALY; MCALLISTER, 2000; MACCOY, 1996; SMITH; SMITH, 1997; WILLIAMS, 2002).

No período estudado, afecções degenerativas representaram um total de 15 aves (7,46\%), sendo $13(86,67 \%)$ com alterações radiográficas compatíveis com DAD e duas $(13,33 \%)$ com espondilose vertebral. A literatura refere ser a DAD uma condição raramente encontrada em aves (ALTMAN², 1982 apud PENCE, 1996a, p. 459). Decerto, não é possível afirmar o mesmo.

Das 15 aves, cinco apresentavam idade maior ou igual a 10 anos $(33,33 \%)$ e quatro idade menor ou igual a um ano (26,67\%). Contudo, o pequeno número de casos encontrados não nos permite dizer se realmente há alguma predisposição para aves mais velhas.

De acordo com a localização das alterações radiográficas, duas aves (13,33\%) exibiram osteófitos periarticulares ventrais nas epífises vertebrais, condição similar àquela vista nos mamíferos, chamada espondilose vertebral. Osteófitos dorsais e/ou dorsolaterais não

2 ALTMAN, R. B. Disorders of the skeletal system. In: PETRAK, M . L. (Ed.). Diseases of cage and aviary birds. 2. ed. Philadelphia: Lea \& Febiger, 1982. p. 386. 
foram identificados. As demais articulações acometidas por afecções degenerativas foram: intertársica (46,67\%), fêmorotibiotársica $(20,00 \%)$, coxofemoral $(13,33 \%)$, escápuloumeral $(6,67 \%)$ e tarsometatarsofalangeana $(6,67 \%)$.

Dentre as alterações radiográficas, osteófitos periarticulares são freqüentemente encontrados nas articulações osteoartríticas (JOHNSTON, 2001; WILLIAMS, 2002). Neste estudo, osteófitos periarticulares estiveram presentes em $100 \%$ das aves com DAD. Nas espécies pequenas, osteófitos e efusão articular podem passar despercebidos em razão do tamanho reduzido da articulação (WILLIAMS, 2002). Nestes casos, acredita-se que técnicas para magnificação da imagem radiográfica (MCMILLAN, 1994; WILLIAMS, 2002), seriam auxiliadoras. Efusão articular (MCMILLAN, 1994; WILLIAMS, 2002) não foi visibilizada em nenhuma ave, mesmo com a magnificação da imagem.

\subsection{OSTEOPENIA LOCALIZADA}

O desuso, ou a atividade física reduzida, tem efeitos deletérios no esqueleto, e é caracterizado por uma redução localizada da radiopacidade óssea normal, além de atrofia da musculatura, conforme relatado por Freeman et al. (1999). O desuso de um membro aumenta a desmineralização óssea e, por conseguinte, o risco de fraturas patológicas. Nos resultados apresentados, osteopenia localizada foi visibilizada em 13 aves $(6,47 \%)$. Deste total, 11 $(84,62 \%)$ tinham história de traumas e/ou afecções inflamatório-infecciosas.

\subsection{DEFORMIDADES ÓSSEAS}

As más-formações ósseas podem ser causadas por anomalias congênitas, alterações traumáticas, deficiências nutricionais, substrato de material inadequado e mau posicionamento embrionário (RUPLEY, 1999).

$\mathrm{Na}$ maioria dos casos identificados, as más-formações ósseas constituíram-se tão somente em achados radiográficos, inexistindo suspeita diagnóstica para tal. A análise das radiografias permitiu constatar a presença de deformidades ósseas em nove animais (9/201, $4,48 \%)$. Destes, oito $(8 / 9,88,89 \%)$ apresentavam alterações angulares dos eixos ósseos da 
coluna vertebral e/ou dos membros e um $(1 / 9,11,11 \%)$, anquilose das articulações vertebrais da cauda. Lembramos que, os animais aqui mencionados não possuíam qualquer evidência radiográfica de afecções traumáticas ou doença óssea metabólica. Aves com deformidades ósseas como conseqüência de afecções traumáticas não foram consideradas neste estudo. A idade prevalente encontrou-se na faixa etária menor ou igual a um ano (6/9, 66,67\%). A manifestação precoce de deformidades ósseas no sistema esquelético das aves pode ser explicada pelo fato de ser esta faixa etária a ideal para a detecção de afecções ósseas de origem congênita e/ou nutricional.

De acordo com as idéias apresentadas por Altman (1969) e Rupley (1999), deformidades ósseas são especialmente prevalentes nos membros pélvicos. $\mathrm{Na}$ amostra registrada, a coluna vertebral e os membros pélvicos foram as duas localizações mais comprometidas, perfazendo quatro casos cada $(4 / 9,44,44 \%)$, e dois animais $(2 / 9,22,22 \%)$ apresentavam comprometimento de membros torácicos. Os resultados ora obtidos contrariam, portanto, as idéias sustentadas pelos autores acima citados. Como se pode observar, a soma dos percentuais ultrapassou $100 \%$, o que demonstra ter ocorrido, em um mesmo animal, deformidades ósseas em mais de uma localização no sistema esquelético.

Independente do tipo, as deformidades ósseas, assim como quaisquer outras doenças ósseas, devem ser reconhecidas e tratadas adequadamente, pois com o passar do tempo, se deixadas ao acaso, as mesmas poderão se agravar, dificultando o sucesso da correção e o prognóstico geral do paciente.

\subsection{ALTERAÇÕES ÓSSEAS AGRESSIVAS}

Não foi possível chegar a um diagnóstico definitivo em quatro casos $(1,99 \%)$, pois os animais exibiram alterações ósseas comuns a osteomielite e a neoplasia, além dos resultados inconclusivos ao exame citológico. As radiografias das quatro aves acometidas, três agapornis (Agapornis sp) e um papagaio (de espécie indeterminada), revelaram uma característica em comum: a agressividade das lesões, seja lise ou neoformação óssea. De acordo com Evans (1986), alterações radiográficas agressivas têm sido associadas a neoplasias ósseas. Outros autores, contudo, têm destacado e confirmado a dificuldade em definir o diagnóstico radiográfico de neoplasia óssea, visto que osteomielite e neoplasia óssea possuem achados 
radiográficos similares (MCMILLAN, 1994; SMITH; SMITH, 1997; WALSH, 1986). Julgase que o exame radiográfico é uma ferramenta valiosa na identificação das alterações ósseas, porém, a biopsia é o procedimento mais adequado para a acurácia do diagnóstico (MCMILLAN, 1994). A biopsia não é um procedimento rotineiramente adotado e algumas possíveis explicações para isto seriam, segundo a literatura, a inexperiência do profissional para a execução da técnica e o tamanho reduzido da ave (COLES, 1996). Acrescentaríamos, ainda, o custo do exame e os riscos da anestesia, com conseqüente relutância do proprietário.

Os dois aspectos radiográficos exibidos pelas aves com alterações ósseas agressivas foram: lesão puramente lítica, caracterizada por lise ou destruição óssea, em duas aves (2/4, $50,00 \%$ ), e lesão puramente esclerótica, caracterizada por neoformação óssea, também em duas aves $(2 / 4,50,00 \%)$. O aspecto radiográfico mais comumente observado nos casos de neoplasia óssea é o primeiro (tipo lítico), com pouca ou nenhuma neoformação óssea (KOSTKA et al., 1988; RUPLEY, 1999). Neoplasias ósseas com acentuada reação do periósteo, entretanto, também podem estar presentes (MCMILLAN, 1994). A idade variou de um a 15 anos. Segundo os achados de literatura, a idade de aparecimento das neoplasias ósseas e/ou articulares tem variado de um a 13 anos de idade (HORST et al., 1996; LIU et al., 1982; PETRAK; GILMORE, 1969). Em relação à localização anatômica acometida, as aves com lesão esclerótica possuíam um envolvimento poliostótico, o que se faz pensar, primariamente, na presença de uma afecção inflamatório-infecciosa, com disseminação hematogênica, que neoplásica, embora haja relatos de neoplasias ósseas metástaticas com envolvimento poliostótico (HORST et al., 1996; LIU et al., 1982).

\subsection{ALTERAÇÕES INESPECÍFICAS}

Duas aves (1,01\%) exibiram alterações radiográficas inespecíficas.

Um tucanuçu (Ramphastos toco), de idade indeterminada, exibiu diminuição de interlinha radiográfica, de envolvimento poliarticular em um único membro. Diminuição de interlinha radiográfica é uma alteração radiográfica que condiz com a fase inicial da doença articular degenerativa (MCMILLAN, 1994). Entretanto, osteófitos periarticulares, indicando as alterações radiográficas mais evidentes da doença (JOHNSTON, 2001; WILLIAMS, 2002), não foram identificados em combinação. Considera-se que a interlinha radiográfica é 
difícil de ser definida com precisão, pelo hábito de se fazerem radiografias aplicando uma determinada tração no membro. Portanto, é arriscado diagnosticar o caso mencionado como doença articular degenerativa, baseando-se apenas na interlinha radiográfica diminuída.

O segundo caso refere-se a um ganso (espécie indeterminada), de dois meses de idade, apresentando mineralização parcial do segmento proximal do tarsometatarso esquerdo, imediatamente abaixo da fileira distal dos ossos do tarso. Em razão da presença de uma subluxação na articulação intertársica do referido membro, suspeitou-se, inicialmente, de uma fratura compressiva. Entretanto, alguns fatores nos desencorajaram a acreditar nisso, incluindo: histórico de trauma e impactação da linha epifisária com conseqüente aparência esclerótica, ambos ausentes. Por se tratar de um osso imaturo, com deformidades angulares no membro e mais subluxação intertársica, uma segunda suspeita diagnóstica foi levantada, a de fechamento precoce da linha epifisária. A força de um trauma, mesmo não relatado pelo proprietário, seria o responsável pelo surgimento das alterações acima descritas. A literatura, no entanto, mostrou-se escassa ou inexistente sobre o assunto em aves. 
Baseada na metodologia empregada e nos resultados obtidos, foi possível concluir que:

1 O exame radiográfico em aves se mostrou um método de diagnóstico por imagem prático, eficiente e de baixo custo para a identificação de afecções localizadas no sistema esquelético.

2 O objetivo do protocolo radiográfico de aves deve ser produzir radiografias de elevado contraste, livres de artefato de movimento e com uma variação mínima no posicionamento.

3 Dissimilaridades anatômicas entre aves e mamíferos são consideráveis e devem ser adequadamente conhecidas a fim de estabelecer uma avaliação radiográfica precisa.

4 As aves mais acometidas por afecções do sistema esquelético pertenceram às ordens Psittaciformes, principalmente, e Passeriformes.

5 Afecções traumáticas foram as mais freqüentes identificadas no sistema esquelético de aves. As fraturas ocuparam a primeira posição, destacando o tibiotarso como o osso mais fraturado. A localização mais freqüente das luxações foi a articulação fêmorotibiotársica.

6 Dentre as aves com doença ósseo-metabólica, pelo menos uma exibiu alterações radiográficas compatíveis com raquitismo.

7 A hiperostose poliostótica normalmente consistiu em um achado ao se radiografar a ave por outra razão ou suspeita. Foi comumente encontrada em canários e periquitosaustralianos, e os ossos mais acometidos foram rádios, ulnas, fêmores e tibiotarsos.

8 Quanto às afecções inflamatório-infecciosas, a osteomielite foi predominante no úmero. A articulação intertársica foi a única localização acometida pelas artrites. 
9 Osteopenia localizada, como resultado do desuso prolongado de um membro em decorrência de afecções ortopédicas, foi observada com relativa freqüência em aves.

10 Osteófitos periarticulares estiveram presentes em todas as aves com afecções degenerativas. A formação de osteófitos ventrais nas epífises vertebrais, como é vista em cães e gatos, também é ocorrente em aves e encontrou-se presente no segmento vertebral torácico.

11 Embora algumas imagens possam sugerir neoplasia óssea, o exame radiográfico não deve ser avaliado isoladamente.

$12 \mathrm{O}$ estudo da ocorrência por meio de arquivos radiográficos talvez subestime a real ocorrência das afecções do sistema esquelético em aves. É provável que outros casos tenham ocorrido na população, no período estudado, e que não foram diagnosticados por não terem sido realizados os exames radiográficos.

13 A radiografia não substitui o exame clínico cuidadoso e requer dados obtidos a partir dele para nos fornecer todas as informações potencialmente relevantes. As alterações radiográficas devem ser correlacionadas com a história clínica, exame físico e exames laboratoriais, a fim de estabelecer um diagnóstico preciso. 


\section{REFERÊNCIAS ${ }^{1}$}

ALTMAN, I. E. Disorders of the skeletal system. In: PETRAK, M. L. (Ed.). Diseases of cage and aviary birds. Philadelphia: Lea \& Febiger, 1969. p. 255-262.

ALTMAN, R. B. Radiography. Veterinary Clinics of North America, v. 3, n. 2, p. 165-173, 1973.

BARREIRO, A.; TROCÓNIZ, P. F.; VILA, M.; LÓPEZ-BECEIRO, A. M.; PEREIRA, J. L. Congenital skeletal abnormalities in a tawny owl chick (Strix aluco). Avian Diseases, v. 47, n. 3, p. 774-776, 2003.

BAUCK, L. Neoplasms. In: ROSSKOPF JÚNIOR, W. J.; WOERPEL, R. W. Diseases of cage and aviary birds. 3. ed. Baltimore: Williams \& Wilkins, 1996. p. 480-489.

BAUMEL, J. J.; WITMER, L. M. Osteologia. In: BAUMEL, J. J.; KING, A. S.; BREAZILE, J. E.; EVANS, H. E.; VANDEN BERGE, J. C. Handbook of avian anatomy: nomina anatomica avium. 2. ed. Cambridge: Nuttall Ornithological Club, 1993. p. 45-132.

BAUMGARTNER, R.; HATT, J.-M.; DOBELI, M.; HAUSER, B. Endocrinologic and pathologic findings in birds with polyostotic hyperostosis. Journal of Avian Medicine and Surgery, v. 9, n. 4, p. 251-254, 1995.

BENEZ, S. M. Aves. 4. ed. Ribeirão Preto: Tecmedd, 2004. p. 21-24, 347-352.

BENNETT, R. A. Orthopedic surgery. In: ALTMAN, R. B.; CLUBB, S. L.; DORRESTEIN, G. M.; QUESENBERRY, K. Avian medicine and surgery. Philadelphia: W. B. Saunders Company, 1997. p. 733-766.

BEREGI, A.; MOLNÁR, V.; FELKAI, F.; BÍRÓ, F.; SZENTGÁLI, Z. Diagnostic radiology of pet and wild birds: a review. Acta Veterinaria Hungarica, v. 47, n. 4, p. 395-408, 1999.

BERRY, C. R.; LOVE, N. E.; THRALL, D. E. Interpretation paradigms for the appendicular skeleton. In: THRALL, D. E. Textbook of veterinary diagnostic radiology. 4. ed. Philadelphia: W. B. Saunders Company, 2002. p. 135-145.

1 Conforme as diretrizes para apresentação de dissertações e teses na Faculdade de Medicina Veterinária e Zootecnia da Universidade de São Paulo. 4. ed. São Paulo: FMVZ-USP, 2003. 84 p. 
BLACKMORE, D. K. Diseases of the endocrine system. In: PETRAK, M. L. (Ed.). Diseases of cage and aviary birds. Philadelphia: Lea \& Febiger, 1969. p. 339-350.

BLASS, C. E. Orthopedics. In: BURR, E. W. (Ed.). Companion bird medicine. Ames: Iowa State University Press, 1987. p. 155-165.

BUBENIK, L. J. Infections of the skeletal system. The Veterinary Clinics of North America: Small Animal Practice, v. 35, n. 5, p. 1093-1109, 2005.

CAMPBELL, T. W. Neoplasia. In: HARRISON, G. J.; HARRISON, L. R. Clinical avian medicine and surgery. Philadelphia: W. B. Saunders Company, 1986. p. 500-508.

CARCIOFI, A. C. Alimentação de psitacídeos em cativeiro. Clínica Veterinária, v. 1, n. 4, p. 6-10, 1996.

CBRO. COMITÊ BRASILEIRO DE REGISTROS ORNITOLÓGICOS. Listas das aves do Brasil. Versão 15/07/2006. Disponível em: <http://www.cbro.org.br>. Acesso em: 10 ago. 2006.

COLES, B. H. Avian medicine and surgery. Oxford: Blackwell Scientific Publications, 1985. p. 45-58, 123-164.

COLES, B. H. Wing problems. In: BEYNON, P. H.; FORBES, N. A.; LAWTON, M. P. C. (Ed.). Manual of psittacine birds. Cheltenham: BSAVA, 1996. p. 134-145.

CRACKNELL, J. Avian radiography and radiology in practice. Veterinary Times, v. 34, n. 4, p. 6-7, 2004a.

CRACKNELL, J. Avian radiography and radiology in practice. Veterinary Times, v. 34, n. 5, p. 6-7, 2004b.

DEGERNES, L. A. Trauma medicine. In: RITCHIE, B. W.; HARRISON, G. J.; HARRISON, L. R. Avian medicine: principles and application. Lake Worth: Wingers, 1994. p. 417-433.

DOIGE, C. E.; WEISBRODE, S. E. Doenças dos ossos e das articulações. In: CARLTON, W. W.; MCGAVIN, M. D. Patologia veterinária especial de Thomson. 2. ed. Porto Alegre: Artmed, 1998. p. 448-485. 
DYCE, K. M.; SACK, W. O.; WENSING, C. J. G. Tratado de anatomia veterinária. 2. ed. Rio de Janeiro: Guanabara Koogan, 1997. p. 631-650.

EVANS, H. E. Anatomy of the budgerigar and other birds. In: ROSSKOPF JÚNIOR, W. J.; WOERPEL, R. W. Diseases of cage and aviary birds. 3. ed. Baltimore: Williams \& Wilkins, 1996. p. 79-162.

EVANS, S. Avian radiography. In: THRALL, D. E. Texbook of veterinary diagnostic radiology. Philadelphia: W. B. Saunders Company, 1986. p. 522-532.

FEDUCCIA, A. Osteologia das aves. In: GETTY, R. Anatomia dos animais domésticos. 5. ed. Rio de Janeiro: Guanabara Koogan, 1986. p. 1680-1690.

FERREIRA, A. B. H. Novo dicionário Aurélio da língua portuguesa. 3. ed. Curitiba: Positivo, 2004. 2120 p.

FORBES, N. A. Avian nutrition. The Veterinary Quarterly, v. 20, n. 1, p. 64-65, 1998.

FORBES, N. A.; LAWTON, M. P. C. Introduction. In: BEYNON, P. H.; FORBES, N. A.; LAWTON, M. P. C. (Ed.). Manual of psittacine birds. Cheltenham: BSAVA, 1996. p. 7-10.

FOWLER, M. E. Metabolic bone disease. In: FOWLER, M. E. (Ed.). Zoo \& wild animal medicine. 2. ed. Philadelphia: W. B. Saunders Company, 1986. p. 70-90.

FREEMAN, K. P.; HAHN, K. A.; JONES, M. P.; TOAL, R. L. Right leg muscle atrophy and osteopenia caused by renal adenocarcinoma in a cockatiel (Nymphicus hollandicus).

Veterinary Radiology \& Ultrasound, v. 40, n. 2, p. 144-147, 1999.

FROST, C. Experiences with pet budgerigars. The Veterinary Record, v. 73, n. 25, p. 621626, 1961.

GERLACH, H. Bacteria. In: RITCHIE, B. W.; HARRISON, G. J.; HARRISON, L. R. Avian medicine: principles and application. Lake Worth: Wingers, 1994. p. 949-983.

GERLACH, H. Bacterial diseases. In: HARRISON, G. J.; HARRISON, L. R. Clinical avian medicine and surgery. Philadelphia: W. B. Saunders Company, 1986. p. 434-453. 
GHETIE, V.; CHITESCU, S. T.; COTOFAN, V.; HILLEBRAND, A. Atlas de anatomía de las aves domesticas. Zaragoza: Acribia, 1981. p. 17-86.

GILL, F. B. Ornithology. 2. ed. New York: W. H. Freeman and Company, 1995. p. 93-113, 617-691.

GOODMAN, G. J. Metabolic disorders. In: ROSSKOPF JÚNIOR, W. J.; WOERPEL, R. W. Diseases of cage and aviary birds. 3. ed. Baltimore: Williams \& Wilkins, 1996. p. 470-479.

GREENWELL, M.; ROBERTSON, J. J.; CONSTANTINESCU, G. M. Próteses de bico de aves. Cães e Gatos, v. 6, n. 32, p. 22-26, 1990.

GYLSTORFF, I.; GRIMM, F. Vogelkrankheiten. Stuttgart: Verlag Eugen Ulmer, 1987. p. 484-489.

HAHN, K. A.; JONES, M. P.; PETERSEN, M. G.; PATTERSON, M. M. Clinical and pathological characterization of an osteoma in a barred owl. Avian Pathology, v. 27, n. 3, p. 306-308, 1998.

HALVERSON, J. Nonsurgical methods of avian sex identification. In: ALTMAN, R. B.; CLUBB, S. L.; DORRESTEIN, G. M.; QUESENBERRY, K. Avian medicine and surgery. Philadelphia: W. B. Saunders Company, 1997. p. 117-121.

HARCOURT-BROWN, N. H. Pelvic limb problems. In: BEYNON, P. H.; FORBES, N. A.; LAWTON, M. P. C. (Ed.). Manual of psittacine birds. Cheltenham: BSAVA, 1996. p. 123133.

HARRISON, G. J. Reproductive medicine. In: HARRISON, G. J.; HARRISON, L. R.

Clinical avian medicine and surgery. Philadelphia: W. B. Saunders Company, 1986. p. 620633.

HARTUP, B. K.; STEINBERG, H. Osteosarcoma in an American Robin (Turdus migratorius). Avian Diseases, v. 40, n. 4, p. 938-940, 1996.

HOLZ, P. H. Coracoid fractures in wild birds: repair and outcomes. Australian Veterinary Journal, v. 81, n. 8, p. 469-471, 2003. 
HORST, H. V. D.; HAGE, M. V. D.; WOLVEKAMP, P.; LUMEJ, J. T. Synovial cell sarcoma in a sulphur-crested cockatoo (Cacatua galerita). Avian Pathology, v. 25, n. 1, p. 179-186, 1996.

JANOVSKI, N. A. Arthropathy associated with Escherichia coli septicemia in caged birds. Journal of the American Veterinary Medical Association, v. 148, n. 12, p. 1517-1522, 1966.

JOHNSTON, S. A. Osteoartrite: fisiopatologia e expectativas relacionadas ao tratamento. Topics em Medicina Veterinária para Animais de Companhia, v. 3, n. 2, p. 16-25, 2001.

KEALY, J. K.; MCALLISTER, H. Diagnostic radiology and ultrasonography of the dog and cat. 3. ed. Philadelphia: W. B. Saunders Company, 2000. p. 253-338, 339-411.

KING, A. S. Introdução às aves. In: GETTY, R. Anatomia dos animais domésticos. 5. ed. Rio de Janeiro: Guanabara Koogan, 1986. p. 1677-1679.

KING, A. S.; MCLELLAND, J. Birds: their structure and function. 2. ed. London: Ballière Tindall, 1984. p. 43-78, 200-213.

$\mathrm{KOCH}, \mathrm{T}$. Anatomy of the chicken and domestic birds. Ames: Iowa State University Press, 1973. p. 6-65.

KOSTKA, V.; KRAUTWALD-JUNGHANNS, M.-E. Zur röntgendiagnostik bei erkrankungen des skelettsystems des vogelpatienten. Der Praktische Tierarzt, v. 72, p. 9799, 1991. sondernummer.

KOSTKA, V.; KRAUTWALD-JUNGHANNS, M.-E.; TELLHELM, B.; SCHILDGER, B. A contribution to radiologic examination of bone alterations in psittacines, birds of prey and pigeons. Proceedings of Association of Avian Veterinarians, p. 37-60, 1988.

KRAUTWALD-JUNGHANNS, M. Avian radiology. In: ROSSKOPF JÚNIOR, W. J.; WOERPEL, R. W. Diseases of cage and aviary birds. 3. ed. Baltimore: Williams \& Wilkins, 1996. p. 630-663.

KRAUTWALD-JUNGHANNS, M.-E.; HENDRICH-SCHUSTER, S. Radiography. In: BEYNON, P. H.; FORBES, N. A.; LAWTON, M. P. C. (Ed.). Manual of psittacine birds. Cheltenham: BSAVA, 1996. p. 60-68. 
KYES, P.; POTTER, T. S. Physiological marrow ossification in female pigeons. The Anatomical Record, v. 60, n. 4, p. 377-379, 1934.

LAFEBER, T. J. Radiography in the caged bird clinic. Journal of the American Veterinary Medical Association, v. 4, n. 1, p. 41-48, 1968.

LATIMER, K. S. Oncology. In: RITCHIE, B. W.; HARRISON, G. J.; HARRISON, L. R. Avian medicine: principles and application. Lake Worth: Wingers Publishing, 1994. p. 640672.

LAVIN, L. M. Radiography in veterinary technology. Philadelphia: W. B. Saunders Company, 1994. p. 279-296.

LINDLEY, D. M.; HATHCOCK, J. T.; MILLER, W. W.; NINA DIPINTO, M. Fractured scleral ossicles in a red tail hawk. Veterinary Radiology, v. 29, n. 3, p. 209-212, 1988.

LIU, S.; DOLENSEK, E. P.; TAPPE, J. P. Osteosarcoma with multiple metastases in a Panama boat-billed heron. Journal of the American Veterinary Medical Association, v. 181, n. 11, p. 1396-1398, 1982.

LOTHROP, C.; HARRISON, G. J.; SCHULTZ, D.; UTTERIDGE, T. Miscellaneous diseases. In: HARRISON, G. J.; HARRISON, L. R. Clinical avian medicine and surgery. Philadelphia: W. B. Saunders Company, 1986. p. 525-536.

LOTHROP JUNIOR, C. D. Diseases of the endocrine system. In: ROSSKOPF JÚNIOR, W. J.; WOERPEL, R. W. (Ed.). Diseases of cage and aviary birds. 3. ed. Baltimore: Williams \& Wilkins, 1996. p. 368-379.

LUMEIJ, J. T. Endocrinology. In: RITCHIE, B. W.; HARRISON, G. J.; HARRISON, L. R. Avian medicine: principles and application. Lake Worth: Wingers Publishing, 1994. p. 582606.

MACCOY, D. M. Orthopedic surgery. In: ROSSKOPF JÚNIOR, W. J.; WOERPEL, R. W. Diseases of cage and aviary birds. 3. ed. Baltimore: Williams \& Wilkins, 1996. p. 722-738.

MACCOY, D. M. Treatment of fractures in avian species. The Veterinary Clinics of North America: Small Animal Practice, v. 22, n. 1, p. 225-238, 1992. 
MACWHIRTER, P. Malnutrition. In: RITCHIE, B. W.; HARRISON, G. J.; HARRISON, L. R. Avian medicine: principles and application. Lake Worth: Wingers, 1994. p. 842-861.

MANUILA, L.; MANUILA, A.; LEWALLE, P.; NICOULIN, M. Manuila dicionário médico. 9. ed. Rio de Janeiro: MEDSI, 2003. p. 13-14.

MARTIN, H.; RITCHIE, B. W. Orthopedic surgical techniques. In: RITCHIE, B. W.; HARRISON, G. J.; HARRISON, L. R. Avian medicine: principles and application. Lake Worth: Wingers, 1994. p. 1137-1169.

MAZZUCO, H. Osteoporose em poedeiras comerciais: uso da densitometria óssea e outras técnicas. Avicultura Industrial, v. 96, n. 1136, p. 16-34, 2005.

MCCARTNEY, W. T. Orthopaedic injuries in pigeons. Veterinary Record, v. 134, n. 19, p. 305-307, 1994.

MCKIBBEN, J. S.; HARRISON, G. J. Clinical anatomy with emphasis on the Amazon parrot. In: HARRISON, G. J.; HARRISON, L. R. Clinical avian medicine and surgery. Philadelphia: W. B. Saunders Company, 1986. p. 31-66.

MCLELLAND, J. A color atlas of avian anatomy. Philadelphia: W. B. Saunders Company, 1991. p. 33-46.

MCMILLAN, M. C. Imaging techniques. In: RITCHIE, B. W.; HARRISON, G. J.;

HARRISON, L. R. Avian medicine: principles and application. Lake Worth: Wingers, 1994. p. 246-326.

NEWTON, C. D.; ZEITLIN, S. Avian fracture healing. Journal of the American Veterinary Medical Association, v. 170, n. 6, p. 620-625, 1977.

NICKEL, R.; SCHUMMER, A.; SEIFERLE, E. Anatomy of the domestic birds. Berlin: Verlag Paul Parey, 1977. p. 1-25.

O'MALLEY, B. Clinical anatomy and physiology of exotic species. Edinburgh: Elsevier Saunders, 2005. p. 95-161.

ORLOWSKI, G.; SIEMBIEDA, J. Skeletal injuries of passerines caused by road traffic. Acta Ornithologica, v. 40, n. 1, p. 15-19, 2005. 
OROSZ, S. Anatomy of the endocrine system. In: ALTMAN, R. B.; CLUBB, S. L.; DORRESTEIN, G. M.; QUESENBERRY, K. Avian medicine and surgery. W. B. Saunders Company: Philadelphia, 1997a. p. 475-488.

OROSZ, S. Anatomy of the musculoskeletal system. In: ALTMAN, R. B.; CLUBB, S. L.; DORRESTEIN, G. M.; QUESENBERRY, K. Avian medicine and surgery. W. B. Saunders Company: Philadelphia, 1997b. p. 517-522.

PAUL-MURPHY, J. R.; KOBLIK, P. D.; STEIN, G.; PENNINCK, D. G. Psittacine skull radiography. Veterinary Radiology, v. 31, n. 3, p. 125-131, 1990.

PENCE, P. A. Degenerative diseases. In: ROSSKOPF JÚNIOR, W. J.; WOERPEL, R. W.

Diseases of cage and aviary birds. 3. ed. Baltimore: Williams \& Wilkins, 1996a. p. 458-463.

PENCE, P. A. Developmental anomalies. In: ROSSKOPF JÚNIOR, W. J.; WOERPEL, R. W. Diseases of cage and aviary birds. 3. ed. Baltimore: Williams \& Wilkins, 1996b. p. 464-469.

PETRAK, M. L.; GILMORE, C. E. Neoplasms. In: PETRAK, M. L. (Ed.). Diseases of cage and aviary birds. Philadelphia: Lea \& Febiger, 1969. p. 459-489.

PIERMATTEI, D. L.; FLO, G. L. Manual de ortopedia e tratamento das fraturas dos pequenos animais. São Paulo: Manole, 1999. p. 24-138.

QUESENBERRY, K. Disorders of the musculoskeletal system. In: ALTMAN, R. B.; CLUBB, S. L.; DORRESTEIN, G. M.; QUESENBERRY, K. Avian medicine and surgery. Philadelphia: W. B. Saunders Company, 1997. p. 523-539.

RANDELL, M. G. Nutritionally induced hypocalcemic tetany in an Amazon parrot. Journal of the American Veterinary Medical Association, v. 179, n. 11, p. 1277-1278, 1981.

REAVILL, D. R. Tumors of pet birds. Veterinary Clinics of North America: Exotic Animal Practice, v. 7, n. 3, p. 537-560, 2004.

REDIG, P. T. Evaluation and nonsurgical management of fractures. In: HARRISON, G. J.; HARRISON, L. R. Clinical avian medicine and surgery. Philadelphia: W. B. Saunders Company, 1986. p. 380-394.

RICH, G. A. Basic history taking and the avian physical examination. The Veterinary Clinics of North America: Small Animal Practice, v. 21, n. 6, p. 1135-1145, 1991. 
RICH, G. A. Traumatic disorders. In: ROSSKOPF JÚNIOR, W. J.; WOERPEL, R. W. Diseases of cage and aviary birds. 3. ed. Baltimore: Williams \& Wilkins, 1996. p. 523-534.

ROSSKOPF JUNIOR, W. J.; WOERPEL, R. W. Pet avian conditions and syndromes of the most frequently presented species seen in practice. The Veterinary Clinics of North America: Small Animal Practice, v. 21, n. 6, p. 1189-1211, 1991.

ROUDYBUSH, T. Nutritional disorders. In: ROSSKOPF JÚNIOR, W. J.; WOERPEL, R. W. (Ed.). Diseases of cage and aviary birds. 3. ed. Baltimore: Williams \& Wilkins, 1996. p. 490-500.

ROUSH, J. C. Ortopedia aviária. In: KIRK, R. W. Atualização terapêutica veterinária. São Paulo: Manole, 1984. p. 733-746.

RUPLEY, A. E. Manual de clínica aviária. São Paulo: Roca, 1999. p. 213-242, 283-332, 431-458.

SCHALLER, O. (Ed.). Nomenclatura anatômica veterinária ilustrada. São Paulo: Manole Ltda, 1999. p. 10-75.

SCHLUMBERGER, M. D. Polyostotic hyperostosis in the female parakeet. The American Journal of Pathology, v. 35, n. 1, p. 1-13, 1959.

SCHMIDT, R. E. Neoplastic diseases. In: ALTMAN, R. B.; CLUBB, S. L.; DORRESTEIN, G. M.; QUESENBERRY, K. Avian medicine and surgery. W. B. Saunders Company: Philadelphia, 1997. p. 590-600, 602-603.

SICK, H. Ornitologia brasileira. Rio de Janeiro: Nova Fronteira, 2001. p. 17-19, 351-382, 467-471, 519-816.

SILVERMAN, S. Técnica radiográfica para aves. In: TICER, J. W. Técnicas radiológicas na prática veterinária. 2. ed. São Paulo: Roca, 1987. p. 412-420.

SIMPSON, G. N. Trauma. In: BEYNON, P. H.; FORBES, N. A.; LAWTON, M. P. C. (Ed.). Manual of psittacine birds. Cheltenham: BSAVA, 1996. p. 186-189.

SMITH, B. J.; SMITH, S. A. Radiology. In: ALTMAN, R. B.; CLUBB, S. L.; DORRESTEIN, G. M.; QUESENBERRY, K. Avian medicine and surgery. Philadelphia: W. B. Saunders Company, 1997. p. 170-199. 
SMITH, B. J.; SMITH, S. A.; FLAMMER, K.; SPAULDING, K. A.; SMALLWOOD, J. E. The normal xeroradiographic and radiographic anatomy of the orange-winged amazon parrot (Amazona amazonica amazonica). Veterinary Radiology, v. 31, n. 3, p. 114-124, 1990.

SMITH, J. M.; ROUDYBUSH, T. E. Nutritional disorders. In: ALTMAN, R. B.; CLUBB, S. L.; DORRESTEIN, G. M.; QUESENBERRY, K. Avian medicine and surgery.

Philadelphia: W. B. Saunders Company, 1997. p. 501-516.

SMITH, S. A.; SMITH, B. J. Atlas of avian radiographic anatomy. Philadelphia: W. B. Saunders Company, 1992. p. 5-18.

STAUBER, E.; PAPAGEORGES, M.; SANDE, R.; WARD, L. Polyostotic hyperostosis associated with oviductal tumor in a cockatiel. Journal of the American Veterinary Medical Association, v. 196, n. 6, p. 939-940, 1990.

STORER, T. I.; USINGER, R. L.; STEBBINS, R. C.; NYBAKKEN, J. W. Zoologia geral. 6. ed. São Paulo: Companhia Editora Nacional, 1998. p. 668-696.

TICER, J. W. Técnicas radiológicas na prática veterinária. 2. ed. São Paulo: Roca, 1987. p. 3-12, 13-37.

THORP, B. H. Skeletal disorders in the fowl: a review. Avian Pathology, v. 23, n. 2, p. $203-$ 236, 1994.

TOAL, R. L. Fracture healing and complications. In: THRALL, D. E. Texbook of veterinary diagnostic radiology. Philadelphia: W. B. Saunders Company, 1986. p. 96-114.

TULLY JUNIOR, T. N. Basic avian bone growth and healing. The Veterinary Clinics of North America: Exotic Animal Practice, v. 5, n. 1, p. 23-30, 2002.

VEEN, L. V.; DWARS, R. M.; FABRI, T. H. F. Mycotic spondylitis in broilers caused by Aspergillus fumigatus resulting in partial anterior and posterior paralysis. Avian Pathology, v. 28, n. 5, p. 487-490, 1999.

WALLACH, J. D.; BOEVER, W. J. Diseases of exotic animals: medical and surgical management. Philadelphia: W. B. Saunders Company, 1983. p. 925-975. 
WALLACH, J. D.; FLIEG, G. M. Nutritional secondary hyperparathyroidism in captive birds. Journal of the American Veterinary Medical Association, v. 155, n. 7, p. 1046-1051, 1969.

WALLACH, J. D.; FLIEG, G. M. Nutritional secondary hyperparathyroidism in captive psittacine birds. Journal of the American Veterinary Medical Association, v. 151, n. 7, p. 880-883, 1967.

WALSH, M. T. Radiology. In: HARRISON, G. J.; HARRISON, L. R. Clinical avian medicine and surgery. Philadelphia: W. B. Saunders Company, 1986. p. 201-233.

WILLIAMS, J. Orthopedic radiography in exotic animal practice. The Veterinary Clinics of North America: Exotic Animal Practice, v. 5, n. 1, p. 1-22, 2002. 


\section{ANEXOS}

\section{ANEXO A - EXEMPLO DE CONTENÇÃO FÍSICA}

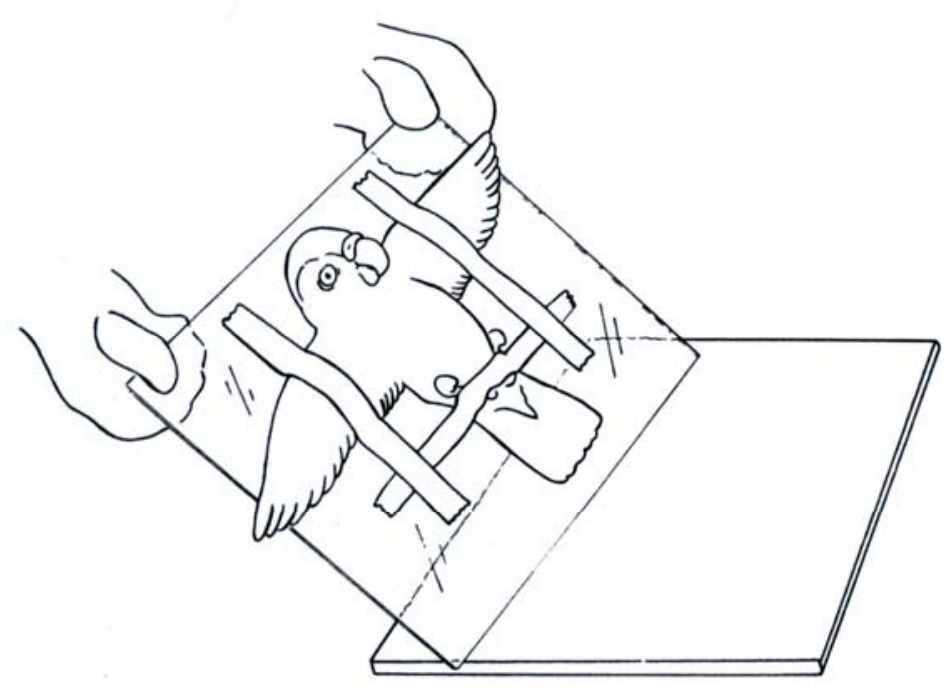

Fonte: Lavin (1994)

Figura 1 - Exemplo de contenção física. A ave é primeiramente posicionada e segura com fita adesiva sobre uma superfície intermediária radiolucente. Posteriormente, esta superfície intermediária é posicionada sobre o chassi. 


\section{ANEXO B - PROJEÇÕES RADIOGRÁFICAS}
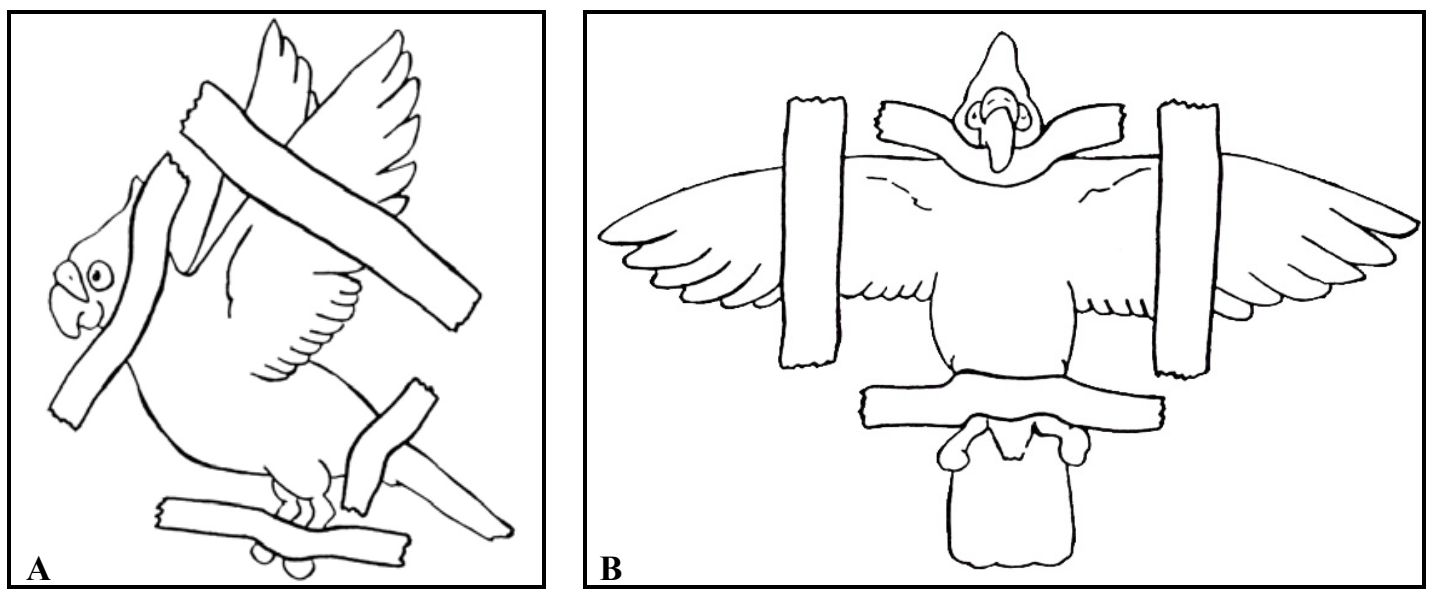

Fonte: Lavin (1994)

Figura 2 - Exemplo de contenção física e posicionamento radiográfico para as projeções laterolateral (A) e ventrodorsal (B).
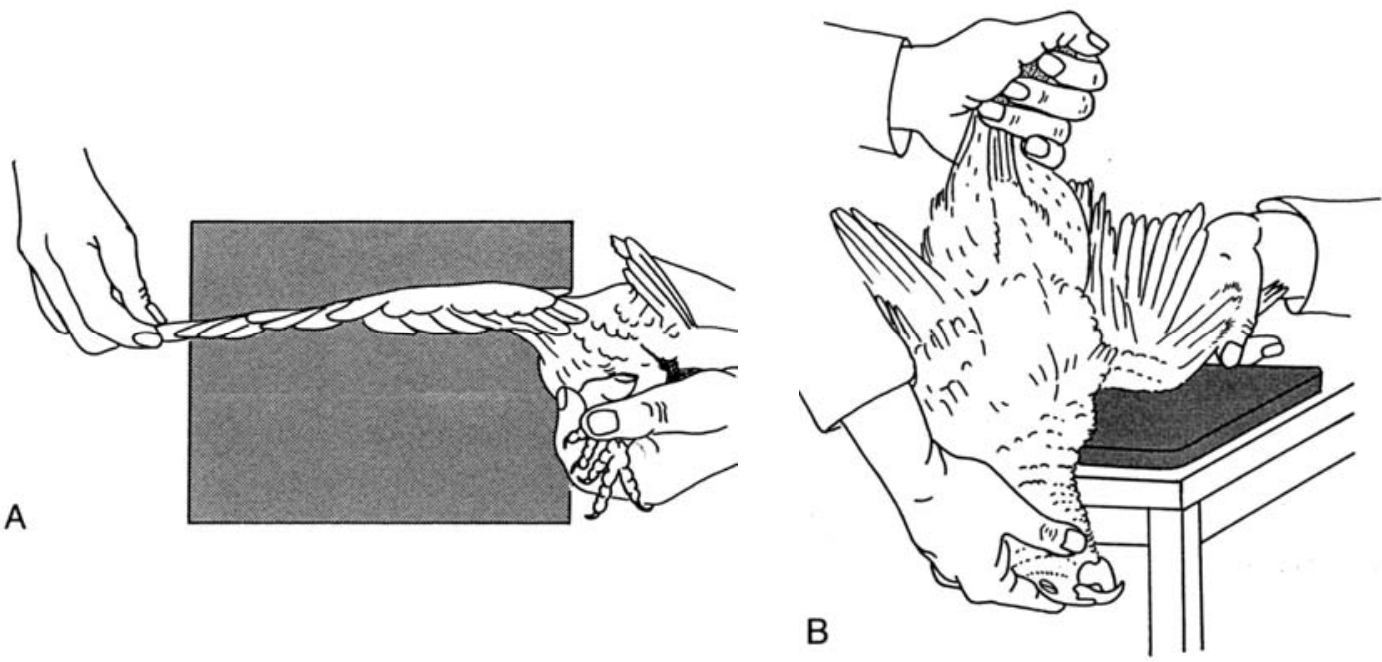

Fonte: Krautwald-Junghanns (1996)

Figura 3 - Exemplo de contenção manual para o posicionamento radiográfico da asa em projeção caudocranial. Vista por cima (A) e vista lateral (B). 


\section{ANEXO C - TÉCNICA DE MAGNIFICAÇÃO DA IMAGEM RADIOGRÁFICA}
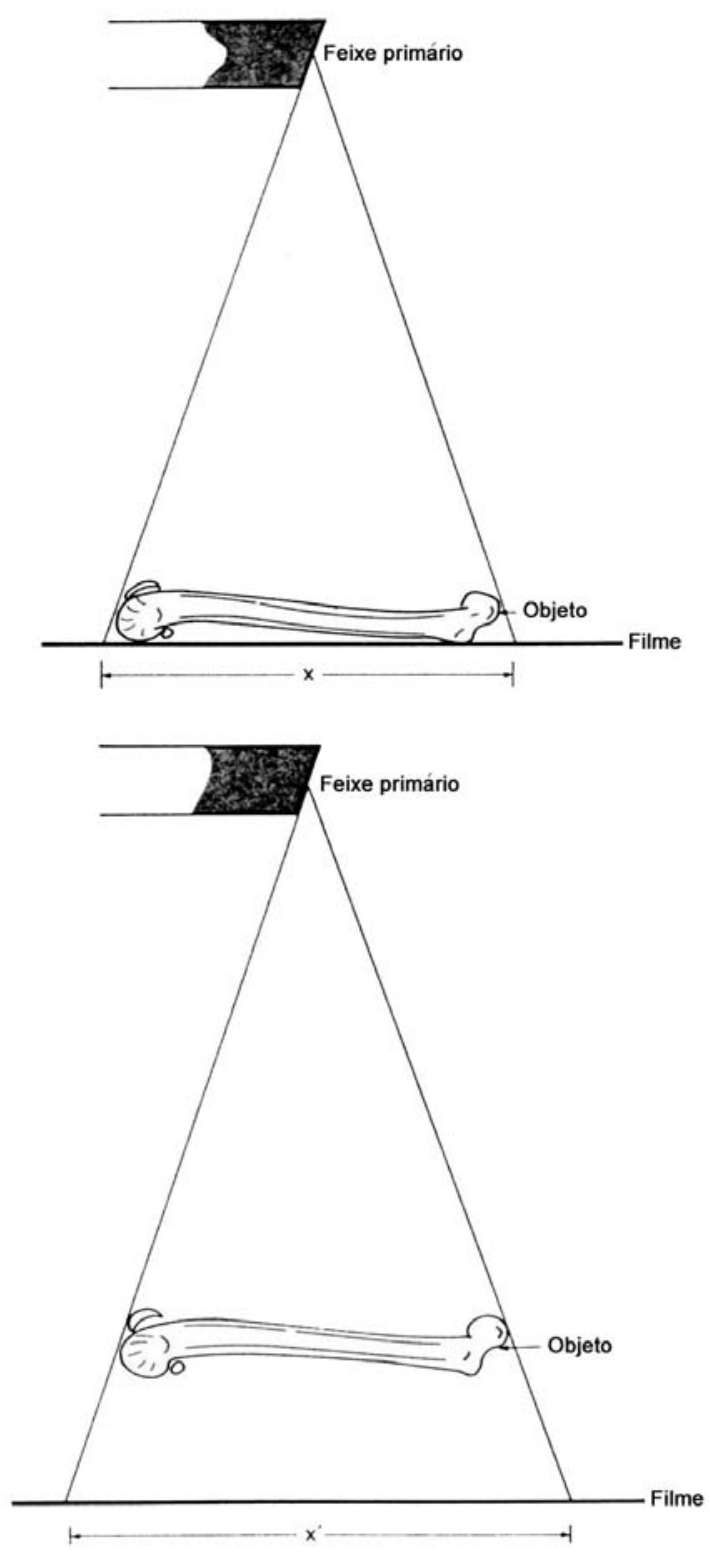

Fonte: Ticer (1987)

Figura 4 - Ilustração do efeito de magnificação da imagem registrada, aumentando-se a distância entre o paciente e o chassi. 


\section{ANEXO D - SISTEMA ESQUELÉTICO DA AVE}

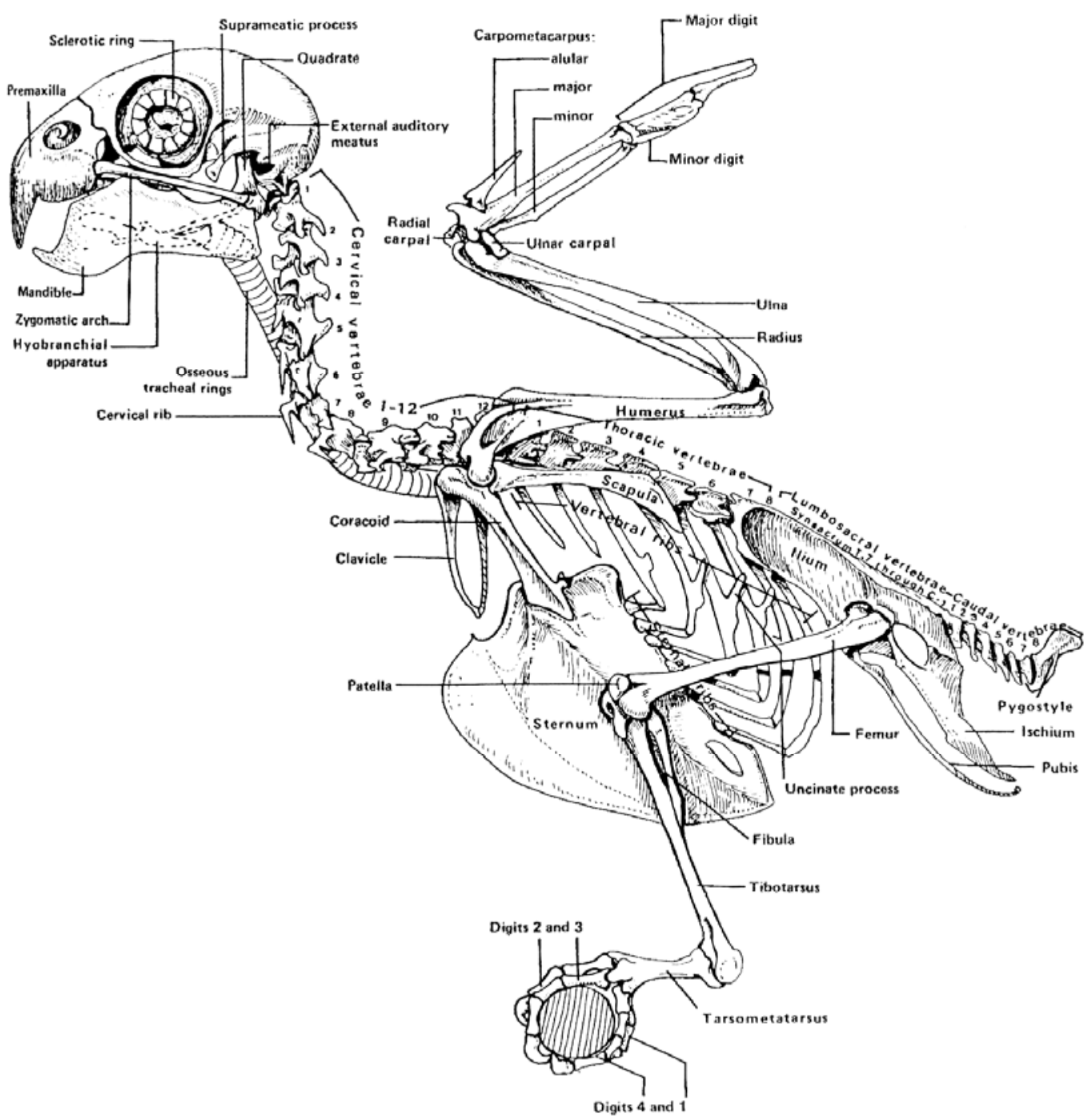

Fonte: Mckibben e Harrison (1986)

Figura 5 - Sistema esquelético de um papagaio (Amazona sp). 


\section{ANEXO E - OSSO MEDULAR}

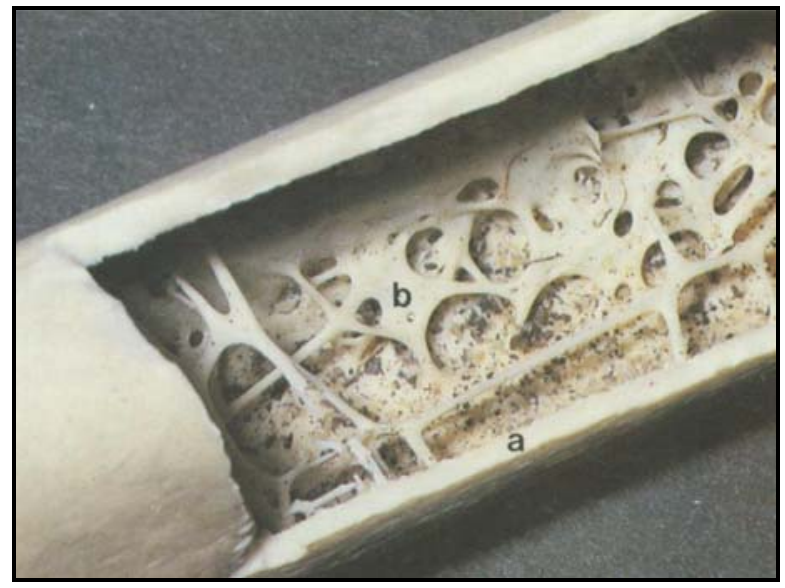

Fonte: Mclelland (1991)

Figura 6 - Anatomia macroscópica do úmero de uma ave aquática. Córtex delgado (a) e cavidade medular (b) com uma rede de espículas ósseas. 